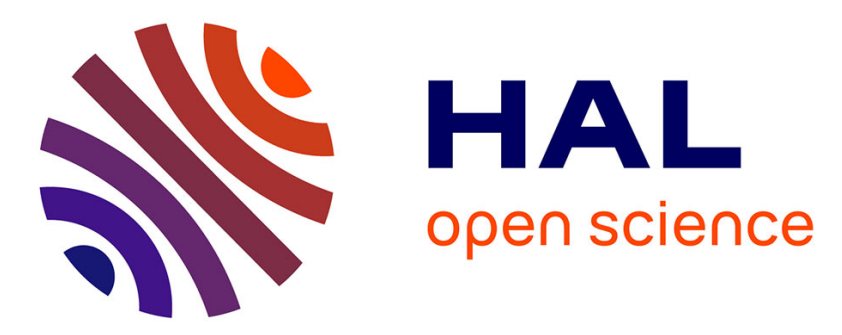

\title{
Does Tax-Benefit Linkage Matter for the Incidence of Social Security Contributions?
}

\author{
Antoine Bozio, Thomas Breda, Julien Grenet
}

\section{To cite this version:}

Antoine Bozio, Thomas Breda, Julien Grenet. Does Tax-Benefit Linkage Matter for the Incidence of Social Security Contributions?. 2020. halshs-02191315v3

\section{HAL Id: halshs-02191315}

\section{https://shs.hal.science/halshs-02191315v3}

Preprint submitted on 18 Aug 2020 (v3), last revised 23 Mar 2023 (v4)

HAL is a multi-disciplinary open access archive for the deposit and dissemination of scientific research documents, whether they are published or not. The documents may come from teaching and research institutions in France or abroad, or from public or private research centers.
L'archive ouverte pluridisciplinaire $\mathbf{H A L}$, est destinée au dépôt et à la diffusion de documents scientifiques de niveau recherche, publiés ou non, émanant des établissements d'enseignement et de recherche français ou étrangers, des laboratoires publics ou privés. 


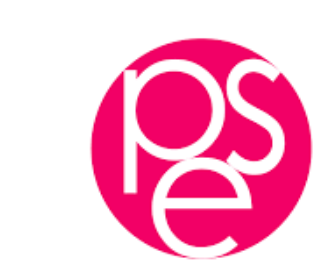

PARIS SCHOOL OF ECONOMICS
ECOLE D'ECONOMIE DE PARIS

WORKING PAPER N ${ }^{\circ} 2019$ - 43

Does Tax-Benefit Linkage Matter for the Incidence of Social Security Contributions?

Antoine Bozio

Thomas Breda

Julien Grenet

JEL Codes: H22, H55

Keywords: Tax Incidence, Payroll Tax, Social Security Contributions, TaxBenefit Linkage

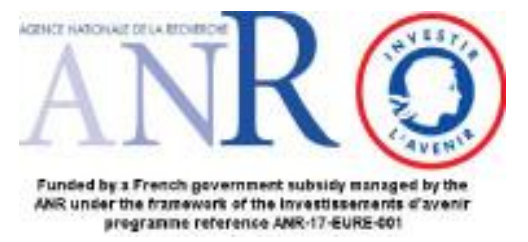




\title{
Does Tax-Benefit Linkage Matter for the Incidence of Social Security Contributions? *
}

\author{
Antoine Bozio \\ Thomas Breda \\ Julien Grenet
}

July 2020

\begin{abstract}
We study the earnings responses to three large increases in employer Social Security contributions (SSCs) in France. We find evidence of full pass-through to workers in the case of a strong and salient relationship between contributions and expected benefits. By contrast, we find a limited pass-through of employer SSCs to wages for reforms that increased SSCs with no tax-benefit linkage. Together with a metaanalysis of the literature, we interpret these results as evidence that tax-benefit linkage and its salience matter for incidence, a claim long made by the literature but not backed by empirical evidence to date.
\end{abstract}

JEL CODES: H22, H55

Keywords: Tax Incidence, Payroll Tax, Social Security Contributions, Tax-Benefit Linkage

*Bozio: École des Hautes Études en Sciences Sociales (EHESS) and Paris School of Economics (PSE), 48 boulevard Jourdan, 75014 Paris, France (e-mail: antoine.bozio@ipp.eu). Breda: CNRS and PSE (e-mail: thomas.breda@ens.fr). Grenet: CNRS and PSE (e-mail: julien.grenet@psemail.eu). We thank Stuart Adam, Youssef Benzarti, Richard Blundell, Pierre Boyer, Pierre Cahuc, Guillaume Chapelle, Clemens Fuest, Peter Haan, Xavier Jaravel, Camille Landais, Etienne Lehmann, Jeffrey Liebman, Emmanuel Saez, Andreas Peichl, Thomas Piketty, Daniel Reck, Jean-Marc Robin, Johannes Spinnewijn, Albert Solé Ollé, Toshiaki Tachibanaki, Alain Trannoy, Andrea Weber, Danny Yagan, Gabriel Zucman, and seminar/conference participants at Aix-Marseille, American University of Beirut, U.C. Berkeley, Banca d'Italia, BETA-Université de Strasbourg, Bologna University, Collegio Carlo Alberto, CAPWELCARE France-Japan workshop in Kyoto, CES Munich, Centraal Plan Bureau, Conseil d'Orientation des Retraites, CRED Université Paris 2, CREST/Polytechnique, DIW Berlin, EIEF, Séminaire Fourgeaud, Hitotsubashi University, IEB Barcelona, Institute for Fiscal Studies, Mannheim University, NBER Summer Institute, OFCE, Paris-London Public Economics Conference, and ZEW for constructive comments. We also express our gratitude to Sophie Cottet, Malka Guillot, and Marianne Tenand for their assistance in developing the microsimulation model TAXIPP. We acknowledge financial support from the Agence nationale de la recherche (ANR) under grant number ANR-12-ORAR-0004 under the ORA call. Data access through the Centre d'accès sécurisé aux données (CASD) has been supported by ANR grant ANR-10-EQPX-17. 


\section{Introduction}

According to the OECD definition, Social Security contributions (SSCs) or payroll taxes are "compulsory payments paid to general government that confer entitlement to receive a future social benefit." ${ }^{1}$ SSCs represent an important part of total tax revenues in OECD countries (on average 26 percent of total tax revenues, or 9 percent of GDP), and an even larger share in countries with extended social insurance systems (37 percent of total tax revenues in France, or 17 percent of GDP).

Tax-benefit linkage is the key element that distinguishes Social Security contributions from other forms of labor income taxation. There are, however, many different institutional settings that can lead to various degrees of tax-benefit linkage. ${ }^{2}$ In its purest form, a payroll tax can be described as a quid pro quo tax providing actuarially fair benefits. ${ }^{3}$ In practice, there are wide disparities in institutional designs, from U.K. National insurance contributions, which have very little linkage to individual benefits, to the Swedish Notional Defined Contributions system, which offers actuarially fair pensions.

A longstanding question in public economics is whether the payroll tax is a lower form of taxation compared to the income tax, or rather an efficient tax to fund Social Security or any social insurance scheme (Musgrave, 1968). This debate has revolved around the effective role of the tax-benefit linkage. The argument in favor of payroll taxation highlights that if wage earners incorporate in their labor supply decisions not only the net wage but also the expected benefits, behavioral responses should be mitigated, and with them the deadweight loss induced by SSCs (Summers, 1989; Gruber, 1997). The consequence is that SSCs with strong tax-benefit linkage are expected to be fully shifted to workers. On the other hand, it has been stressed that, with full information, changes in the degree of tax-benefit linkage can only come about with changes in the redistributive profile of the scheme, implying that stronger tax-benefit linkage is merely a change in

\footnotetext{
${ }^{1}$ In this paper, payroll tax has the meaning given to this term in the U.S. context, i.e., we use the terms Social Security contributions and payroll tax interchangeably. In a number of OECD countries, including France and Sweden, payroll taxes exist alongside SSCs but, contrary to SSCs, they confer no entitlement to benefits and usually fund general government expenditures.

${ }^{2}$ Note that the usual OECD classification relies mostly on institutional arrangements (e.g., earmarking to Social Security), and not systematically on the effective degree of tax-benefit linkage.

${ }^{3}$ See for instance the definition provided by Musgrave (1968): "'Social Security' in our sense means mandatory provision for economic contingencies, financed out of contributions on a quid pro quo basis. Thus, all those subject to certain contingencies must contribute and the actuarial value of each person's benefits must match the cost of his contribution."
} 
the equity-efficiency trade-off (Kaplow, 2008). Notwithstanding that remark, for a given level of redistribution, the salience of the tax-benefit linkage is likely to modify labor supply responses and hence the efficiency of the taxation that is used to fund the benefit in question (Chetty, Looney and Kroft, 2009). If workers do not understand that their contributions give the right to future benefits, they will perceive them as no different from general income taxation.

Compared to its share of tax revenue, payroll taxation has been the subject of a relatively limited number of studies, and empirical evidence on the role of tax-benefit linkage is even scarcer. The literature has long assessed the incidence of payroll taxes from a theoretical perspective, with the two main hypotheses being that the tax could be shifted backward, to workers, or forward, to consumers (Atkinson and Stiglitz, 1980; Kotlikoff and Summers, 1987; Fullerton and Metcalf, 2002). While early empirical studies did not reach a consensus, ${ }^{4}$ a series of papers using micro data and more robust identification strategies has led to the general finding of full pass-through of SSCs to employees (Gruber and Krueger, 1991; Gruber, 1994, 1997; Anderson and Meyer, 1997, 2000). This "received wisdom" has, however, been recently challenged by two recent studies (Saez, Matsaganis and Tsakloglou, 2012; Saez, Schoefer and Seim, 2019) that provide compelling evidence of zero pass-through of employer SSCs to wages using well-identified changes in payroll taxes in Greece and Sweden.

If one takes a closer look at the most prominent SSC incidence studies, which find opposite incidence effects, it seems clear that their institutional design differs markedly. Gruber (1997) exploits the decrease in pension SSCs in Chile during the privatization of the public pension scheme to assess the incidence of these taxes and finds convincing evidence that the decrease in SSCs led to an equivalent increase in wages, which is consistent with full pass-through of SSCs to wages. In this setting, the tax-benefit linkage was strong and extremely salient - employees needed to fund an increase in private pension contributions to compensate for the removal of publicly funded pension benefits. On the other hand, Saez et al. (2012) consider a payroll tax reform in Greece whereby adjacent cohorts of workers permanently faced different employer and employee SSC rates, while their

\footnotetext{
${ }^{4}$ The literature from the 1970s has found relatively mixed results (Brittain, 1972; Feldstein, 1972; Hamermesh, 1979; Holmlund, 1983), while studies exploiting cross-country variations in SSCs to assess their ultimate incidence have concluded to a variety of possible outcomes depending on the structure of wage bargaining (OECD, 1990; Tyrväinen, 1995; Alesina and Perotti, 1997; Daveri, Tabellini, Bentolila and Huizinga, 2000; Ooghe, Schokkaert and Flechet, 2003).
} 
entitlements to benefits remained unchanged. In this setting, full incidence on employees would have required firms to pay equally productive workers differently on the sole basis of their date of entry into the labor market. As suggested by the authors, this differential treatment might have raised serious fairness issues, thereby precluding full-shifting at the individual level. In the case of Sweden, Saez et al. (2019) exploit a reduction in payroll tax targeted at workers aged 19-25, which did not change benefit entitlements. They show that the reform did not affect the relative posted wages of younger vs. older workers. While differences in tax-benefit linkage could explain these contrasting results, it is difficult to draw firm conclusions from these relatively disparate natural experiments. What is missing in the literature is convincing evidence from standard SSC reforms with varying degrees of tax-benefit linkage, which could be compared within the same institutional context.

This paper provides evidence on the role played by tax-benefit linkage by estimating the pass-through of employer SSCs using large SSC reforms in France over a period of thirty years, based on a long panel of administrative data. We exploit three reforms that led to large increases in marginal SSC rates above the Social Security threshold (SST) (plafond de la sécurité sociale or PSS, in French), which is the main earnings' ceiling. Two of these reforms concern SSCs with little tax-benefit linkage, whereas the most recent reform relates to complementary pension schemes with a strong link between contributions paid and expected benefits. Importantly, the three reforms impacted workers at a similar position in the earnings distribution (around the 70th percentile). We implement a difference-indifferences analysis by comparing wage earners just below and just above the SST, before and after each of the three reforms. This approach allows us to compare changes in labor costs to changes in gross earnings, in order to assess how much of the initial increase in employer SSCs has been shifted to treated workers with earnings above the SST. By carrying out separate estimations for every year after the reforms, we can identify effects up to eight years after the changes in SSC rates were first implemented, and hence provide evidence of incidence in the medium to long term.

Our first contribution is to show that perceived tax-benefit linkage is likely to matter for payroll tax incidence, a claim long made by the literature but not backed by empirical evidence to date. We find marked differences in the pass-through of employer SSCs across the three French reforms we analyze. Increases in employer SSCs are found to be 
fully passed through to wages in the case of a strong and salient relationship between contributions and expected benefits - our estimates are close to 100 percent. By contrast, we find limited pass-through of employer SSCs to wages within five to six years after reforms that increased SSCs with little or no tax-benefit linkage - our estimates are respectively of 6 percent and 21 percent for these two reforms and are not significantly different from zero. These results are robust to a wide range of sensitivity checks.

A limitation of this analysis is that it relies on only three reforms that took place in different time periods. The ideal research setting would require a large number of payroll tax reforms, involving both substantial changes in SSC rates and contemporaneous quasi-experimental variation in tax-benefit linkage - a very unlikely institutional setting. To address this limitation and to strengthen the interpretation of our results, we proceed in two ways. First, we carefully discuss macroeconomic and labor market conditions at the time of the three reforms and show that they are unlikely to explain the differences in pass-through. Second, and more importantly, we extend the analysis beyond the case of France by conducting a meta-analysis of existing studies of payroll tax incidence to investigate whether tax-benefit linkage can reconcile the seemingly conflicting results in this literature. Comparing twenty-one estimates of pass-through rates of employer SSCs to wages, we find that seven concern SSCs with clear and salient tax-benefit linkage while eleven relate to SSCs with no linkage. We find an average pass-through rate of 103 percent for SSCs with strong tax-benefit linkage, compared to an average pass-through of 15 percent for SSCs with no tax-benefit linkage. This difference is statistically significant and robust to controlling for potential confounders such as macroeconomic and labor market conditions. Although this evidence does not rely on a very large number of exogenous variations - by nature limited to the relatively few SSC reforms that have been analyzed in the literature - perceived tax benefit linkage appears as an empirically relevant explanation for the heterogeneity in estimated payroll tax incidence across existing studies.

We discuss how alternative models of the labor market can help to explain our empirical findings. We compare the theoretical predictions of models with competitive labor markets and of wage bargaining models to analyze how tax-benefit linkage affects the incidence of SSCs depending on the specific parameters of each model. All models predict full passthrough of employer SSCs to workers in the case of strong tax-benefit linkage, irrespective of the values of other parameters such as labor supply and demand elasticities. Our 
empirical estimates are therefore consistent with a wide range of labor market models. The intuition is straightforward: if workers fully perceive the expected benefits of SSCs, they do not consider them as taxes.

A second contribution of the paper is to provide additional evidence of limited shifting of employer SSCs to workers in the absence of tax-benefit linkage, thus confirming the two recent studies by Saez et al. (2012) and Saez et al. (2019). Such findings cannot be easily rationalized within standard models of competitive labor markets. This is because our pass-through estimates for the SSC reforms with no tax-benefit linkage would imply an implausibly low elasticity of substitution between treated and control workers with earnings above and below the Social Security threshold. By contrast, we show how inequality aversion in collective wage bargaining can help to rationalize both the modest pass-through of SSC increases to the wages of workers who were directly affected by the reforms, and the possible shifting of these SSCs at the firm level, as evidenced by Saez et al. (2019) in the Swedish context. ${ }^{5}$

Related literature. This paper is related to five strands of the literature. First, it provides an explanation to the seemingly contradictory results reported in the literature on payroll tax incidence. To the best of our knowledge, the role of tax-benefit linkage has not been empirically investigated in this body of research, despite being the distinctive feature of payroll taxation. While several recent papers have found less than full pass-through of employer SSCs to workers, the proposed explanation has generally been that, depending on labor supply or demand elasticities, one could expect a wide range of pass-through estimates (Komamura and Yamada, 2004; Baicker and Chandra, 2006; Murphy, 2007; Kugler and Kugler, 2009; Korkeamäki and Uusitalo, 2009; Bennmarker et al., 2009; Cruces et al., 2010; Lehmann et al., 2013; Bozio et al., 2017; Adam et al., 2019). We show that our empirical results are difficult to rationalize using this line of argument, whereas taking into account tax-benefit linkage can explain the disparities in the pass-through estimates not only in France but also in other countries. Second, our paper is directly related to the literature on tax salience (Chetty et al., 2009, 2011; Chetty, 2012). The evidence we present is consistent with the notion that wage earners' valuation of Social Security benefits depends not only on their actuarial fairness but also on the salience of the tax-benefit linkage. Third, our paper complements the literature on tax remittance (e.g., Slemrod,

\footnotetext{
${ }^{5}$ The authors show that firms that were affected the most by the payroll tax reduction raised the wages of all their workers - young as well as old.
} 
2008; Kopczuk et al., 2016) by providing another example in which the statutory incidence is likely to matter, contrary to the tax-collection invariance prediction of the standard competitive framework. Fourth, we contribute to the literature on the distributional effects of taxation. The policy analysis of tax reforms often assumes full shifting of employer SSCs to workers without taking into account tax-benefit linkage. Our results suggest that absent tax-benefit linkage, this assumption can be challenged and might lead to erroneous conclusions regarding the redistributive effects of SSCs. Finally, our paper is related to a broader issue in the literature on cross-country differences in labor supply (e.g., Prescott, 2004; Alesina et al., 2005; Rogerson, 2007; Ohanian et al., 2008; Blundell et al., 2011; Keane and Rogerson, 2012; Kleven, 2014). Most of this literature pays limited attention to the specific design of SSCs and, in particular, to the fact that the actual and perceived relationship between pension contributions and expected pension benefits varies considerably across countries. Without accounting for differences in tax-benefit linkage, estimates of labor supply elasticities to changes in total taxation could be misleading.

Organization. The remainder of the paper is organized as follows. Section 1 presents the standard conceptual framework for analyzing the incidence of employer SSCs with or without tax-benefit linkage. Section 2 discusses the institutional design of SSCs in France as well as the main reforms being studied. Section 3 describes the administrative data and the microsimulation model that we use to compute SSCs. Section 4 presents the empirical framework and the results are reported in Section 5. Section 6 discusses the findings and their interpretation. Section 7 concludes.

\section{Conceptual Framework}

The conceptual framework underlying our analysis is fairly standard. In this section, we describe the different earnings concepts used in our study, define tax-benefit linkage, and specify how we measure the pass-through of employer SSCs to wages. Using an equilibrium model of competitive labor markets with two types of workers, we then discuss how tax-benefit linkage affects the pass-through rate of employer SSCs to workers.

General setup and wage concepts. Our framework is the standard equilibrium model of tax incidence with competitive markets (Feldstein, 1974). We consider a one-sector model in which a representative firms' output is produced using two labor inputs: treated 
workers $\left(L_{T}\right)$, for whom employer SSCs change as the result of the reform under study, and control workers $\left(L_{C}\right)$, for whom employer SSCs are unchanged. The firm's production function $F\left(L_{T}, L_{C}\right)$ is assumed to be homogeneous of degree one and to exhibit positive and diminishing marginal products. One key parameter of this general production function is the elasticity of substitution between the two types of workers, which we denote by $\sigma$.

For simplicity, we assume that all SSCs are nominally paid by the firm and we denote by $w_{k}$ the posted, or gross wage, of each worker of type $k$, where $k \in\{T, C\} .{ }^{6}$ The corresponding labor cost to the firm is denoted by $z_{k} \equiv w_{k}\left(1+\tau_{k}\right)$, where $\tau_{k}$ is the rate of SSCs that are nominally paid by the firm for a worker with a posted wage $w_{k}{ }^{7}$

Labor supply with tax-benefit linkage. On the supply side, we denote by $\tilde{w}_{k}$ the perceived wage of workers of type $k \in\{T, C\}$, with $\tilde{w}_{k} \equiv w_{k}\left(1+q \tau_{k}\right)$, i.e., their posted/gross wage augmented by the perceived benefits from employer SSCs. Following Gruber (1997), tax-benefit linkage is modeled as a reduced-form parameter $q$ whose value lies in the interval $[0,1]$. This parameter, which is assumed to be constant across worker types, measures the extent to which workers value employer SSCs relative to cash income. It subsumes two dimensions of tax-benefit linkage that we do not model separately: (i) the actuarial fairness of SSCs, which determines the extent of linkage between SSCs and future benefit entitlements at the individual level, and (ii) the salience of this linkage to workers. The case with $q=1$ corresponds to fully salient linkage, i.e., a situation akin to the quid pro quo tax described in the classic public finance literature (Musgrave, 1968). In the opposite polar case with $q=0$, the tax-benefit linkage is either non-existent or not salient to workers.

We model the extensive margin of labor supply by assuming that workers of type $k$ have an indirect utility function $V\left(\tilde{w}_{k}, R_{k}\right)=V\left(w_{k}\left(1+q \tau_{k}\right), R_{k}\right)$, which is increasing in their perceived wage, $\tilde{w}_{k}$, and non-labor income, $R_{k}$. The labor supply of a worker of type $k$ can be expressed as

$$
L_{k}^{S}=L_{k}^{S}\left(\tilde{w}_{k}, R_{k}\right)=L_{k}^{S}\left(w_{k}\left(1+q \tau_{k}\right), R_{k}\right), \quad k=C, T
$$

\footnotetext{
${ }^{6}$ The term gross is in a sense a misnomer as it does not include SSCs nominally paid by employers, but it is the term most commonly used in Europe to describe posted earnings, e.g., gross earnings in the U.K., salaire brut in France, and Bruttoverdienst in Germany.

${ }^{7}$ The concept of labor cost is close to total compensation, which includes various fringe benefits provided by employers (e.g., health insurance, forms of leave, pension plans) but differs in the sense that non-legally binding compensation is generally not included (in the U.S. context, see, e.g., Pierce, 2001).
} 
We further denote by $\eta_{k}^{S} \equiv \frac{\mathrm{d} \ln L_{k}^{S}}{\mathrm{~d} \ln w_{k}}$ the labor supply elasticity of workers of type $k$ with respect to the posted wage.

Pass-through of employer SSCs to wages. We denote by $\rho$ the pass-through rate of employer SSCs to the wage of treated workers relative to control workers, i.e., the proportional change in the relative wage of treated workers that results from a one percent change in the rate of employer SSCs levied on these workers. This measure can be understood as pass-through at the individual level in the sense that treated workers are those directly affected by the change in SSCs. Within our framework, we can derive a general closed-form formula for the pass-through (see Appendix A for details). Assuming that treated and control workers have similar labor supply elasticities (i.e., $\eta_{T}^{S} \approx \eta_{C}^{S} \equiv \eta^{S}$ ), the formula simplifies to

$$
\rho=-\frac{\mathrm{d} \ln \left(\frac{w_{T}}{w_{C}}\right)}{\mathrm{d} \ln \left(1+\tau_{T}\right)} \approx \frac{\sigma+\eta^{S} \cdot q}{\sigma+\eta^{S}} .
$$

Equation (1) clarifies the theoretical interpretation of our empirical estimates when a competitive labor market equilibrium is assumed. ${ }^{8}$ This expression generalizes the wellknown partial equilibrium incidence formula (Kotlikoff and Summers, 1987; Gruber, 1997) to a general equilibrium with two types of workers. ${ }^{9}$

Three polar cases. In this model, the pass-through of employer SSCs depends on the elasticity of labor supply, $\eta^{S}$, the elasticity of substitution between both types of workers, $\sigma$, and the (perceived) tax-benefit linkage, $q$. Three polar cases can be highlighted:

(i) If workers value the benefits as much as the SSCs paid $(q=1)$, then irrespective of the values of labor supply and substitution elasticities, SSCs are entirely shifted to treated workers $(\rho \approx 1)$. In that case, employer SSCs are not perceived as a tax as they fund benefits that are fully valued by workers. ${ }^{10}$

(ii) If there is no perceived tax-benefit linkage $(q=0)$ and if the elasticity of substitution

\footnotetext{
${ }^{8}$ The formulas for the elasticities of $w_{T}$ and $w_{C}$ to the employer SSC rate of treated workers can be found in Appendix A. Here, we focus on the elasticity of relative wages as it is the only parameter that can be credibly identified within a difference-in-differences framework.

${ }^{9}$ The partial equilibrium formula for the pass-through rate of SSCs with tax-benefit linkage can be found in Section A.2 of Appendix A.

${ }^{10}$ In the case where $q<1$, one can show that the pass-through parameter $\rho$ is bounded between $q$ and 1 , hence $\rho$ tends to 1 as $q$ approaches 1 .
} 
between worker types is much larger than the labor supply elasticity $\left(\sigma \gg \eta^{S}\right)$, then employer SSCs are fully shifted to employees $(\rho \approx 1)$. This is the usual assumption made in the labor supply/taxation literature, which commonly assumes that $\sigma$ is large while $\eta^{S}$ is small.

(iii) If there is no perceived tax-benefit linkage $(q=0)$ and if the labor supply elasticity is much larger than the elasticity of substitution $\left(\eta^{S} \gg \sigma\right)$, there is no pass-through to relative wages $(\rho \approx 0)$, i.e., the relative labor cost of both types of workers increases in the same proportion as the additional employer SSCs that are levied on treated workers.

In Appendix A, we discuss other possible theoretical foundations for our results, such as individual or collective bargaining. We show that the first polar case (i) holds for a wide range of alternative models of the labor market. A key intuition is that the relationship between tax-benefit linkage and pass-through to wages, which is illustrated in the framework above, will hold in virtually all models where workers fully value the future benefits brought about by higher employer SSCs. Indeed, setting $q=1$ simply corresponds to ignoring taxes and their potential effects in the considered model. The polar cases (ii) and (iii) are more model-dependent. We discuss in Section 6 how our empirical results align with the alternative models of the labor market that we review in Appendix A.

The dynamics of wage adjustments to changes in employer SSCs are not described in this simple framework, which implicitly assumes complete wage flexibility. In the very short term (the day after the reform), however, one expects the economic incidence of an increase in employer SSCs to be close to the nominal incidence, i.e., the labor cost should increase by the amount of additional employer SSCs. Depending on the extent of labor market rigidities, wages might take time to adjust, for instance through an adjustment in nominal wage growth, or turnover. Hence, the key empirical measure of interest for incidence is the long-run change in labor cost resulting from a change in SSCs.

\section{Social Security Contribution Reforms}

In this section, we describe the main features of three SSC reforms that we exploit in the paper. Before doing so, we provide a brief overview of the architecture of SSCs in France. 


\subsection{Social Security Contributions in France}

Social Security contributions are a major part of taxation in France, as they represent 37.1 percent of total tax revenues and 17.0 percent of GDP, which is the highest share among OECD countries. Among the total SSCs levied nominally on employers and employees, the share of employer SSCs is also more important in France than in other countries, representing 11.3 percent of GDP - more than twice the OECD average of 5.2 percent.

In France, SSCs fund several aspects of the welfare system, notably health care spending, pensions, unemployment benefits, but also child benefits. The different schemes differ according to the type of governance and the nature of the tax-benefit linkage (see Appendix B for details). Some SSCs are not related to the amount of benefits they fund (e.g., child care benefits, health care), others have an imperfect relationship with future benefits (e.g., main pension scheme, unemployment insurance), while some specific SSCs have very strong linkage (e.g., complementary pension schemes).

Although French SSCs vary widely in terms of the benefits they fund, their schedule follows the same structure. The tax base is gross (posted) wage $w$. Different marginal employer and employee SSC rates $\tau$ are applied to different wage brackets expressed as fractions of the reference threshold $\bar{w}$-referred to as the Social Security threshold (SST). Importantly for our empirical strategy, the SSC schedule is expressed in terms of hourly wage, i.e., the total amount of SST is multiplied by contractual hours of work $h$ over the duration of the job spell. This means that unlike income taxation, marginal SSC rates are unaffected by changes in contractual hours of work.

The SSC schedule is composed of different thresholds (expressed as multiples of the SST) depending on the population considered - the main distinction being between executives and non executives in the private sector. For non-executive workers, on which we focus in our empirical analysis, SSC rates apply to four wage brackets: (i) below the SST; (ii) between the SST and 3 times the SST; (iii) between 3 and 4 times the SST; and (iv) above 4 times the SST. Formally, employer SSCs for non-executive workers are 
computed as follows:

$$
\begin{aligned}
\operatorname{SSC}_{\text {employer }} & =h \times\left(\tau_{1} \cdot \min (w, \bar{w})+\mathbb{1}_{w>\bar{w}} \cdot \tau_{2} \cdot[\min (w, 3 \bar{w})-\bar{w}]\right. \\
& \left.+\mathbb{1}_{w>3 \bar{w}} \cdot \tau_{3} \cdot[\min (w, 4 \bar{w})-3 \bar{w}]+\mathbb{1}_{w>4 \bar{w}} \cdot \tau_{4} \cdot[w-4 \bar{w}]\right),
\end{aligned}
$$

where $\tau_{k}$ denotes the marginal employer SSC rate that applies to the wage bracket $k$ and $\mathbb{1}(\cdot)$ denotes the indicator function.

Figure 2 illustrates graphically this SSC schedule for non-executive workers for the years surrounding each of the three reforms we describe in the next section, focusing on the change above the SST. A distinctive feature of French SSCs is that the main threshold (the SST) is lower than in most other countries, around the 70th percentile of the earnings distribution, while there are SSCs for very high levels of earnings - the highest threshold being close to the 99.95 th percentile.

\section{$2.2 \quad$ Three SSC Reforms}

During the period covered by our study, from 1976 to 2010, several SSC reforms have been carried out in France. The most well known and studied of these reforms are the reductions in employer SSCs around the minimum wage that were put in place in the 1990s (Kramarz and Philippon, 2001; Lehmann, Marical and Rioux, 2013). In this paper, we focus on another set of reforms, which have attracted far less attention in the literature - we are not aware of any previous analysis. These reforms involved large increases in employer SSC rates above the SST, affecting the top three deciles of the earnings distribution. Figure 1 shows the evolution of marginal employer SSC rates for non-executive workers, separately for the different earnings brackets. ${ }^{11}$ While the rates of employer SSCs applying to the fraction of earnings below the SST only increased modestly between 1976 and 2001, from 36 percent to 38 percent in 2001, the rates applying to the fraction of earnings above the SST increased dramatically over the same period, from 7 percent to 38 percent.

Reform 1-Complementary pensions. The first reform we consider is the increase in pension SSCs that took place in the early 2000s for the complementary pension schemes

\footnotetext{
${ }^{11}$ Since the most recent of the three reforms (Reform 1) concerns only non executives, we focus our analysis on this group of workers. Employer SSC rates are slightly different for executives because these workers are affiliated with a different complementary pension scheme.
} 
ARRCO. Complementary pensions in France are private pension schemes that cover non-executive private sector workers. They are managed by employer and employee unions without oversight from the government or Parliament - the government's only role is to make these SSCs mandatory. Rates and benefits are determined by unions' representatives. These schemes used to be voluntary, employer-sponsored pension funds, before they were made mandatory in the early 1970s at the request of employer and employee unions. Since then, they function as unfunded defined contribution point-based systems. Wage earners pay contributions (both employer and employee SSCs) that are converted from euros to points using a shadow price $p_{t}^{b}$ (the value in euros to buy a point), which is indexed by the year $(t)$ in which the contribution was paid. Points are accumulated during the entire career, starting in $t_{0}$, and are converted into annuity pensions at retirement, using a separate shadow price $p_{R}^{s}$, which is indexed by the retirement year, $R$. Hence, the amount of pension at retirement, denoted by $B_{R}$, can be expressed as the following function of past SSC contributions, $\tau_{t} \cdot w_{t}$ (for a detailed presentation, see Legros, 2006):

$$
B_{R}=\sum_{t=t_{0}}^{R-1} \frac{\tau_{t} \cdot w_{t}}{p_{t}^{b}} \times p_{R}^{s}
$$

The complementary scheme ARRCO offers both a complementary pension below the SST and a supplementary pension for the fraction of earnings between the SST and three times the SST. In 1996, a major reform was decided by the employer and employee unions managing the ARRCO scheme. ${ }^{12}$ It stated that ARRCO's implicit rate of return would progressively decline in order to balance the scheme in light of increased life expectancy. Additionally, the agreement planned a steep increase in pension contribution rates above the SST, from 4.5 percent in 1999 to 12 percent in 2005 for employer SSCs, and from 3 percent to 8 percent for employee SSCs (see Figure 2, Panel A and Table 1, Panel A). ${ }^{13}$ For firms created from 1997 onwards, the increase in SSC rates was planned to be phased in more rapidly, reaching the target of 12 percent as soon as $2000 .{ }^{14}$

\footnotetext{
${ }^{12}$ The reform is formalized by the ARRCO Agreement of April 24, 1996.

${ }^{13}$ We also present in Table 1 and Figure 1 the total change in the employer SSC rate, which differs slightly from that induced by the ARRCO reform ( +7.7 percentage points compared to +7.5 percentage points), as other minor changes in SSC rates have occurred at the same time.

${ }^{14}$ In 1998, the French government passed a law reducing the workweek to 35 hours in all firms. The reform was gradually implemented between 1998 and 2000, with financial incentives for early adopters of the new regulation. Importantly for our empirical strategy, all non executive employees, control or treated, were affected similarly by this reform - even if the timing of its adoption could vary across firms.
} 
With the formula for pension benefits in Equation (2), the increase in pension contribution rates above the threshold led, for the affected workers, to an increase in the expected pension level directly proportional to the reform-induced change in rates, $\Delta \tau$ :

$$
\Delta B_{R}=\left(\sum_{t=t_{0}}^{R-1} \frac{w_{t}}{p_{t}^{b}} \times p_{R}^{s}\right) \Delta \tau .
$$

Equation (3) highlights the strong tax-benefit linkage underlying Reform 1: individuals directly affected by the increase in pension SSCs could expect a proportional increase in their individual pension benefits. As discussed in Appendix B.3, this strong linkage does not preclude some form of implicit taxation, as the market interest rate was slightly higher than the internal rate of return of these pay-as-you-go pension schemes. Nonetheless, the perception of the reform (see Appendix C) was that it led to increased pension benefits. This aspect was clearly put forward by the unions that had bargained over the details of the reform, e.g., by claiming that "this measure will allow non executives to multiply by 2.66 their amount of pension benefits above the threshold." 15

Reform 2-Family benefits. The second reform we consider is the uncapping of family SSCs in the late 1980s. These SSCs do not fund a specific social insurance scheme but rather universal child benefits. All families with children are entitled to such benefits irrespective of their employment status and the amount received is completely unrelated to the amount of contributions paid. This lack of tax-benefit linkage is fully perceived by individuals ( $q \approx 0$ in our framework) and is reinforced by the fact that family SSCs have only taken the form of employer SSCs. Over a two-year period between 1989 and 1990, these SSCs were "uncapped", i.e., became applicable to the full earnings instead of the fraction of earnings below the SST, the marginal rate below the SST dropping from 9 percent to 7 percent and the rate above the SST increasing from 0 percent to 7 percent (see Figure 2, Panel B and Table 1, Panel B). ${ }^{16}$ Unlike Reform 1, the uncapping of family SSCs was decided by the French government with no involvement of employer and employee unions.

\footnotetext{
${ }^{15}$ Bulletin du Retraité CFDT, No. 140, July-August-September 1996.

${ }^{16}$ Legal references are the Decree 90-5 of February 1, 1990 and the Decree 89-48 of January 27, 1989.
} 
Reform 3-Health care. Our third reform of interest is the uncapping of health care SSCs, which was implemented in the early 1980s. Health care SSCs are a set of contributions funding access to the French health care system. The corresponding contributions fund public health insurance (Assurance maladie), which reimburses individuals covered for the health expenses they incur from either public or private health care providers. Health care SSCs can be characterized as non-contributory in the sense that the level of insurance does not depend on the amount of contributions paid. There was originally a contributory link insofar as eligibility to health insurance was conditional on being covered (hence on having paid contributions in the past), but a change in the rate of SSCs would not change the amount of benefits received. At the onset of the scheme, health care SSCs took the form of large employer SSCs for the fraction of earnings up to the SST, and of much smaller employee SSCs. In the early 1980s, employer health SSCs were uncapped in two stages. In November 1981, the marginal rate of employer SSCs on full earnings rose from 4.5 percent to 8 percent ( +3.5 percentage points), while remaining at 13.45 percent for the fraction of earnings below the SST. In January 1984, the marginal employer SSC rate on full earnings was further increased to 12.6 percent ( +4.5 percentage points), while the SSC rate applying to the fraction of earnings below the SST was decreased to the same level $\left(-0.85\right.$ percentage point). ${ }^{17}$

Panel $\mathrm{C}$ of Figure 2 and Panel $\mathrm{C}$ in Table 1 present the total changes in employer SSC rates that were brought about by the uncapping of health care SSCs between the last pre-reform year and the first post-reform year. Similarly to Reform 2, the reform was decided unilaterally by the French government-without the support of employer or employee unions - and was part of a larger package of health care reforms aimed at balancing the budget of the public insurance scheme. ${ }^{18}$

In summary, the three SSC reforms described in this section all resulted in increased SSCs for the fraction of earnings above the SST, but differ in their respective timing and their perceived tax-benefit linkage. Reform 1, the most recent one, affected both employer and employee SSCs and raised the level of expected pension benefits for the workers concerned. By contrast, the two earlier reforms (Reforms 2 and 3) affected only

\footnotetext{
${ }^{17}$ Legal references are the Decree $81-1013$ of November 13, 1981, and the Decree 83-1198 of December 30, 1983.

${ }^{18}$ The uncapping of health care SSCs was partly motivated by employment concerns for low-wage earners. In the French daily newspaper Le Monde, dated November 12, 1981, the French Minister of Health N. Questiaux is quoted as saying: "The decision to increase SSCs only above the threshold has been motivated by our desire to spare firms with a large number of employees."
} 
employer SSCs and did not lead to proportional changes in benefits.

\section{Data}

\subsection{The DADS Panel Dataset}

Our primary source of data comes from the matched employer-employee DADS (Déclaration Annuelle de Données Sociales) Panel, which is constructed by the French Statistical Office, the Institut National de la Statistique et des Études Économiques (INSEE), from the compulsory declarations made annually by all employers for each of their employees. The main purpose of these declarations is to provide the different Social Security schemes with the earnings information necessary to determine workers' eligibility to benefits and to compute their levels, notably for pension schemes. INSEE transforms the raw DADS data into user files available to researchers under restricted access. ${ }^{19}$ The panel version of the DADS consists of a $1 / 25$ th sample of private sector employees, born in October of even-numbered years, from 1976 onwards. In 2002, the sample size was doubled to represent $1 / 12$ th of all private sector workers. The data include roughly 1.1 million workers each year between 1976 and 2001, and 2.2 million workers from 2002 onwards. Unfortunately, some years of the original data sources are unavailable (1981, 1983 and 1990) and are therefore missing in the panel data.

The DADS Panel provides information about the firm (identifier, sector, size) and each job spell (start and end date, earnings, occupation, whether part-time or full-time). Importantly for our study, the raw data for earnings come in the form of "net taxable earnings", i.e., earnings reported for income tax. This definition of earnings is net of SSCs, but not net of flat-rate contributions not deductible for the income tax, namely the Contribution sociale généralisée (CSG) and the Contribution au remboursement de la dette sociale (CRDS). From 1993 onwards, additional variables are available in the panel: number of hours of work, CSG tax base, and net earnings. ${ }^{20}$

\footnotetext{
${ }^{19}$ We were granted access to the DADS data by the decisions of the Comité du Secret Statistique ME27 of October 2, 2013, ME56 of June 2, 2014, and ME91 of June 6, 2015.

${ }^{20}$ For further details on the data sources and earnings concepts, see Appendix D.1.
} 


\subsection{Microsimulation of SSCs}

Microsimulation techniques are required to compute the labor cost using the information available in the DADS Panel data. The present work relies on the use of the TAXIPP model which is developed at the Institut des Politiques Publiques (IPP), and in particular on the Social Security contribution module. The model takes as input the SSC schedule, as collected in the IPP Tax and Benefit Tables (Institut des Politiques Publiques, 2018), and computes employer and employee SSCs, reductions in employer SSCs, flat-rate income tax (CSG and CRDS) as well as other payroll taxes. The model simulates the complexity of French SSCs in great detail, including local Social Security schemes such as the one in place in the Alsace-Moselle region.

The main challenge in computing SSCs from the DADS Panel comes from the missing information in the raw data. Two main issues must be noted. First, because net taxable earnings are the only earnings measure available throughout the period under study, we need to compute gross earnings and labor cost using the microsimulation model. Second, SSCs are defined as a function of the hourly wage for part-time workers (the SST is defined for each period of work and adjusted for the number of hours worked). Since we do not observe hours of work in the DADS data before 1993, the SSCs for part-time workers cannot be computed precisely before $1993 .^{21}$

\section{Empirical Approach}

We take advantage of the three SSC reforms described in Section 2 to identify the earnings responses to changes in SSC rates. For each reform, the year-to-year shifts in the total amount of SSCs vary with base year earnings according to a well-defined schedule: they are null below the SST and increase linearly above it.

The most straightforward way of estimating earnings responses to changes in SSC rates is to compare, before and after each of the reforms, workers with earnings above the SST in the last pre-reform year (treatment group) to workers with earnings below the SST (control group) in the same year. The validity of this difference-in-differences (DiD) approach relies on the assumption that the average earnings of workers in the treatment and control groups would have followed parallel trends, absent the reform.

\footnotetext{
${ }^{21}$ More details on the microsimulation of SSCs are provided in Appendix D.2.
} 


\subsection{Sample Restrictions}

We construct separate unbalanced panels of workers for each of the three reforms under study. Each sample includes all workers who are observed in employment in the reference year (i.e., in last available pre-reform year) and follows these workers throughout a period which starts four years before the reform was implemented and ends eight to nine years after. These time windows were chosen to avoid contaminating the estimated earnings responses to each reform with the effects of other reforms. The periods used in the analysis are 1996-2008 for Reform 1 (complementary pensions reform of 2000-2005), 1985-1997 for Reform 2 (uncapping of family SSCs in 1989 and 1990), and 1977-1988 for Reform 3 (uncapping of health care SSCs in 1981 and 1983).

The only restrictions we impose for selecting workers in the reference year are to be employed during the entire year, to work full-time, and to be non executive, i.e., affiliated with the ARRCO pension scheme. The working time restrictions are necessary as we do not observe hours of work before 1993 and hence are not able to compute SSCs without error for part-time workers. The reason for restricting the sample to non executives is that executives, being affiliated with a different complementary pension scheme (AGIRC), experienced different changes in SSCs during the period, which could confuse the impact of our reforms of interest. For the first reform, we further restrict our sample to individuals who, in the reference year, were working in firms created before 1997, since the timing of the increase in SSC rates was different for firms created after this date.

In each of the panels, workers are assigned to the treatment and control groups based on their level of gross earnings relative to the SST in the reference year. Individuals with earnings just below the SST are assigned to the control group, whereas individuals with earnings just above are assigned to the treatment group.

The main trade-off in selecting the treatment group is that while expanding this group's upper earnings threshold mechanically inflates the reform-induced variation in average $\mathrm{SSC}$ rates, it also increases the likelihood of having dissimilar earnings trends between the treated and control workers. For our baseline analysis, the treatment group includes workers whose gross earnings in the reference year were between the SST and 1.4 times the SST that year, i.e., between P65 and P85 of the earnings distribution. The control group is composed of workers in a smaller range of gross earnings in the base year, between 0.9 and 1 times the SST, i.e., between P56 and P65 of the earnings distribution. This 
range is large enough to construct a control group of significant sample size, and going further down the earnings distribution would entail the risk of including workers whose earnings were affected by the diffusion effects of increases in the national minimum wage. In Section 5.3, we assess the robustness of our results to using alternative definitions of the treatment and control groups.

Table 2 presents summary statistics of the samples we use to analyze each reform. By construction, workers in the treatment groups have higher earnings than those in the control group. They are also slightly older, and more likely to be male. As the SST increased at a faster rate than median earnings during the period under study, workers in the treatment and control groups are slightly higher up in the earnings distribution when we consider the most recent reform (Reform 1$).{ }^{22}$

\subsection{Baseline Specification}

Our main specification is the empirical counterpart of Equation (1). It evaluates the impact of changes in SSCs on gross wages based on a model that we estimate using two-stage least squares (2SLS).

In the spirit of Angrist (1998) and Autor (2003), we adopt the following panel DiD specification to estimate the first-stage and reduced-form effects of the increase in employer SSCs, separately for each reform:

$$
\begin{aligned}
\log \left(1+\tau_{i, t}\right) & =\alpha+\theta_{i}+\theta_{t}+\sum_{k=-m}^{r} \beta_{k} \cdot\left(T_{i} \times \mathbb{1}\left\{t=t_{0}+k\right\}\right)+\varepsilon_{i, t}, \\
\log \left(w_{i, t}\right) & =\mu+\eta_{i}+\eta_{t}+\sum_{k=-m}^{r} \gamma_{k} \cdot\left(T_{i} \times \mathbb{1}\left\{t=t_{0}+k\right\}\right)+\nu_{i, t} .
\end{aligned}
$$

The first-stage equation (4) expresses the log of the employer SSC average rate, $\log \left(1+\tau_{i, t}\right)$, that applies to worker $i$ in year $t$, as a function of worker fixed effects $\theta_{i}$, year fixed effects $\theta_{t}$, and the full set of interactions between the year fixed effects, which include $m$ pre-reform years and $r$ post-reform years, and the treatment group indicator $T_{i}$, which takes the value one if worker $i$ 's earnings are between 1 and 1.4 times the SST in the reference year (denoted by $t_{0}$ ), and zero otherwise. The interaction term coefficients $\beta_{k}$ are normalized to zero in the reference year. The reduced-form equation (5) expresses the log of the hourly

\footnotetext{
${ }^{22}$ Workers in the treatment group for Reform 1 are between P70 and P87, compared to a range of P65-P85 for the two earlier reforms.
} 
gross wage $\log \left(w_{i, t}\right)$ as a function of the same set of variables, with $\eta_{i}$ and $\eta_{t}$ denoting individual fixed effects and year fixed effects, respectively, and with the interaction term coefficients $\gamma_{k}$ being normalized to zero in the pre-reform year.

The coefficients $\beta_{k}$ measure the post-reform log-differences in employer SSC rates between treated and control workers in year $k$, relative to the reference year, whereas the coefficients $\gamma_{k}$ measure the post-reform log-differences in wages relatively to the reference year. Assuming that the wage trends would have remained parallel for all years $k \geq 1$ in the absence of reform, one can interpret the coefficients $\beta_{k}$ and $\gamma_{k}$ for $k \geq 1$ as measuring the reform's impact on employer SSC rates and on gross wages after $k$ years. ${ }^{23}$

By construction, the estimated pass-through of employer SSCs to relative wages $k$ years after the reform, denoted by $\rho_{k}$, is equal to minus the ratio between the reform's reducedform effects on gross wages and employer SSC rates,, i.e., $\hat{\rho}_{k}=-\hat{\gamma}_{k} / \hat{\beta}_{k}$. This parameter $\rho_{k}$ can be recovered by estimating the following equation separately for each post-reform year using 2SLS:

$$
\log \left(w_{i, t}\right)=\kappa+\phi_{i}+\phi_{t}-\rho_{k} \cdot \log \left(1+\tau_{i, t}\right)+\sum_{\substack{l=-m \\ l \neq k}}^{r} \delta_{l} \cdot\left(T_{i} \times \mathbb{1}\left\{t=t_{0}+l\right\}\right)+\omega_{i, t}
$$

where $\phi_{i}$ and $\phi_{t}$ denote the worker and time fixed effects, respectively, and the interaction term $T_{i} \times \mathbb{1}\left\{t=t_{0}+k\right\}$ is used as an instrument for $\log \left(1+\tau_{i, t}\right)$.

Controlling for pre-reform trends. The model's key identifying assumption is that absent SSC reforms, average earnings among the treatment and control groups would have followed parallel trends. This assumption can be tested for the pre-reform periods by examining whether the lead coefficient estimates, $\hat{\beta}_{k}$ and $\hat{\gamma}_{k}$ for $k<0$, are significantly different from zero. This is the case - as will be shown in the next section-for Reforms 1 and 2, but not for Reform 3, which exhibits small differential pre-reform trends.

To relax the common trend assumption, we augment the baseline specification by including worker-specific linear time trends. The pass-through of employer SSCs to wages $k$ years after the reform, $\rho_{k}$, is then obtained by estimating the following equation separately

\footnotetext{
${ }^{23}$ As highlighted in the conceptual framework, treated and control workers are likely to be close substitutes. Since the equilibrium wage levels of control workers can be affected by changes in treated workers' SSCs, our treatment effects capture each reform's impact on the wage differential between treated and controls rather than a pure effect on the treated.
} 
for each post-reform year using 2SLS:

$$
\log \left(w_{i, t}\right)=\lambda+\phi_{i}+\phi_{t}+\psi_{i} \cdot t-\rho_{k} \cdot \log \left(1+\tau_{i, t}\right)+\sum_{\substack{l=1 \\ l \neq k}}^{q} \delta_{l} \cdot\left(T_{i} \times \mathbb{1}\left\{t=t_{0}+l\right\}\right)+\omega_{i, t}
$$

where $\psi_{i} \cdot t$ denote the worker-specific linear time trends and the interaction term $T_{i} \times \mathbb{1}\{t=$ $\left.t_{0}+k\right\}$ is used as an instrument for $\log \left(1+\tau_{i, t}\right) \cdot{ }^{24}$ As will be shown below, this augmented specification does not affect the results when the common trend assumption holds (Reforms 1 and 2) but provides more robust estimates for Reform 3, by accounting for worker-specific pre-reform trends.

To account for serial correlation in individual earnings, we cluster the standard errors at the worker level in all specifications.

Earnings vs. hourly wage. As we do not observe hours of work before 1993, we can only measure total earnings responses to changes in employer SSCs for Reform 2 and Reform 3. We thus carry out a modified empirical specification of Equations (6) and (7) using the log of gross earnings $\log (w h)$ as the dependent variable, where $h$ denotes the number of hours worked. In this case, our estimates capture both changes in hours of work and changes in the wage rate induced by the increase in employer SSCs. Two arguments lead us nonetheless to interpret our estimates for these reforms as incidence effects. First, in our empirical analysis, we only consider wage earners working full-time and during the entire year. This is likely to mitigate the behavioral responses that may be captured by our estimates, e.g., switching from full-time to part-time. Second, an increase in SSCs would be expected to lead to a reduction in the number of hours worked (if substitution effects dominate income effects), and hence to a reduction in total earnings. As a result, behavioral responses would tend to bias our estimates towards finding more shifting to workers, since the hours' response would be confounded with incidence effects, and therefore to overestimate the pass-through parameter $\rho$. As we will see, our estimates for Reforms 2 and 3 based on earnings suggest almost no shifting of the SSC increases to wages. As shown formally in Section A.6 of Appendix A, accounting for potential hours responses to these reforms could lead us to find even less shifting to wages, hence reinforcing our main conclusions. Moreover, the fact that we find similar estimates when

\footnotetext{
${ }^{24}$ The models including worker-specific linear trends are estimated using Sergio Correia's REGHDFE Stata package (Correia, 2014), which implements the estimator of Correia (2016).
} 
using either hourly wages or earnings to evaluate the pass-through to workers in the case of Reform 1 (see next section), and the finding that the pass-through was close to zero for Reforms 2 and 3, are not consistent with large behavioral responses.

\section{Results}

We present below our main results, which are based on the empirical approach described in the previous section. Before commenting on the estimates, we provide graphical evidence of the earnings responses to the three SSC reforms we consider in this study.

\subsection{Graphical Evidence}

The wage and earnings responses to the SSC reforms are graphically represented in Figures 3 to 5 . For each reform separately, the figures compare the evolution of real average gross earnings (upper panel) and real average labor cost (lower panel) between the treatment and control groups around the reform years. All earnings measures are normalized to 100 in the reference year, i.e., the year immediately preceding the start of the reform, which is denoted by a vertical solid line. ${ }^{25}$ The vertical dotted lines denote the reforms' start and end years.

First, as a check for the common trend assumption underlying our estimation strategy, we compare the pre-reform trends of the treatment and control groups. Reassuringly, visual inspection of the graphs suggest that those trends are well aligned in all three cases. $^{26}$

Figure 3 compares the evolution of average gross wages and hourly labor cost for the most recent reform (Reform 1). We find clear evidence of slower hourly wage growth for the workers directly affected by the increase in SSCs than for non-treated workers; their hourly labor cost grew faster during the phasing-in of the reform but converged quickly to that of the control group. When considering the two earlier uncapping reforms (Figures 4 and 5), we present similar graphical evidence using gross earnings and gross labor cost, as hours are not available for those periods. ${ }^{27}$ One observes that the treatment and control

\footnotetext{
${ }^{25}$ For Reforms 2 and 3, the reference year is set two years before the reform as the data are not available for 1990 and 1981 .

${ }^{26} \mathrm{~A}$ slight divergence is noticeable for gross earnings in the case of Reform 2, and labor cost in the case of Reform 3. This issue is addressed in the next section.

${ }^{27}$ In Section 5.3 (robustness checks), we show that graphical evidence for Reform 1 is very similar
} 
groups had a very similar evolution of gross earnings while labor costs diverged markedly after the reforms. The gap in labor cost remains up to six years after Reform 2 and up to four years after Reform 3. In the case of the oldest reform (Reform 3), treated workers only exhibit a slightly lower gross earnings growth, while the difference between the treatment and control groups is barely noticeable in the case of Reform 2.

Figures 3 to 5 provide striking evidence of different effects of SSCs on wages across the three reforms. We proceed in the next subsection to the estimation of the pass-through of employer SSCs to wages.

\subsection{Estimation Results}

We now present the results from the panel DiD specifications, which we estimate separately for each of the three reforms.

For the most recent one (Reform 1, i.e., the increase in complementary pension SSCs between 2000 and 2005), Panel A of Figure 6 plots the coefficients on the leads and lags of the log difference between the gross hourly wage and hourly labor cost of treated and control workers, relatively to the reference year (1999). The coefficients for the gross hourly wage are estimated using the reduced-form Equation (5), which does not control for worker-specific trends. The coefficients for the labor cost are estimated similarly, using hourly labor cost as the dependent variable in Equation (5).

Since the reform was very gradual, we need to look at $t_{0}+6$ to see it fully in place. The results suggest that the increase in employer SSCs was quickly shifted to treated workers: following the reform, gross hourly wages declined progressively as the reform was phased in and, conversely, after a couple of years of increase, labor costs declined and reverted to their pre-reform level. After the reform was completed, wages of treated and control workers grew at a similar rate.

The 2SLS estimates of the pass-through of employer SSCs to wages are shown in Panel B of Figure 6. The estimates shown in the left panel are based on Equation (6), which does not control for worker-specific trends. Those shown in the right panel are based on the augmented specification in Equation (7), in which we control for worker-specific trends in addition to worker and year fixed effects. The pass-through estimates at $t_{0}+8$ and $t_{0}+9$ are reported in column 1 of Table 3 . The results confirm that the increase in whether we consider earnings or hourly wages. 
pension SSCs was relatively quickly shifted to workers, with an estimated pass-through parameter that is very close to and not significantly different from 1 in the four years following the completion of the reform. At $t_{0}+9$, the estimated pass-through is 91 percent when we do not control for worker-specific trends and 106 percent when we include such controls. $^{28}$

Evidence for Reform 2, i.e., the uncapping of family SSCs, is provided in Figure 7, with the pass-through estimates reported in column 3 of Table 3. Inspection of Panel (a) in Figure 7 does not show evidence of systematically different trends between treatment and control groups, although pre-reform differences in gross earnings and labor costs are not perfectly aligned. The results are markedly different from those found in the case of Reform 1: the increase in employer SSCs led to an increase in labor cost and to a small decrease in gross earnings. Four years after completion of the reform, the impact of increased employer SSCs on labor cost is still positive and statistically different from zero. We thus find evidence of very limited shifting to relative wages, as net earnings appear to have only slightly declined after the reform. The pass-through estimates indicate no shifting of SSCs to treated workers, with a non-statistically significant estimate of 21 percent six years after the end of the reform in the baseline specification and 6 percent when we control for worker-specific trends.

Evidence for the oldest reform (Reform 3, i.e., the uncapping of health care SSCs), is shown in Figure 8, with the estimates reported in column 4 of Table 3. Contrary to the other two reforms, Panel (a) in Figure 8 shows evidence of non-parallel pre-reform trends in labor cost, which justifies the inclusion of workers-specific trends in our preferred specification. The results are qualitatively similar to those obtained for Reform 2-an increase in labor cost and less than partial shifting six years after the reform. When we do not control for worker-specific trends, the 2SLS estimates indicate a statistically significant 38 percent pass-through rate to treated workers four years after the end of the reform. ${ }^{29}$ Once we control for these trends, the pass-through estimate drops to 21 percent and is not significantly different from zero.

In a nutshell, we find evidence of quick and full shifting of employer SSCs to treated workers for Reform 1, which contrasts with the close-to-zero shifting that we estimate

\footnotetext{
${ }^{28}$ As shown in Section 5.3, the estimates are very similar when we use gross earnings and labor cost instead of hourly wage and hourly labor cost.

${ }^{29}$ The pass-through estimates with and without controlling for worker-specific trends are not significantly different from one another.
} 
for the two earlier reforms. Panel $\mathrm{C}$ of Table 3 shows that using the estimates from our preferred specification with worker-specific trends, we cannot reject the null hypothesis of an equal pass-through parameter for Reforms 2 and 3 after six years $\left(t_{0}+8\right)$ whereas we reject this hypothesis when comparing Reform 1 to either Reform 2 or Reform 3. The three reforms, therefore, yield markedly different incidence results.

In Appendix F, we report the detailed results of additional analyses performed in an attempt to investigate heterogeneous wage responses across worker and firm characteristics. Although we lack the statistical power to reach robust conclusions due to the limited size of the various subsamples, the results do not provide strong evidence of heterogeneous effects. More importantly, the marked differences obtained on the whole sample of workers between Reform 1, on the one hand, and Reform 2 or Reform 3, on the other hand, are observed in almost all subsamples we looked at, indicating that these differences are not driven by a specific group of workers or firms.

\subsection{Robustness Checks}

We performed a series of sensitivity analyses to assess the robustness of our main findings. The detailed results are reported in Appendix G.

Definition of treatment and control groups. We test the sensitivity of our results to the definitions of the treatment and control groups by systematically varying the upper and lower earnings thresholds that determine whether workers are assigned to either group in the reference year. In Appendix G.1, we report estimates for various choices of the treatment group's upper earnings threshold and of the control group's lower earnings threshold (see Figures G7 and G6). The results appear to be robust to how we define the treatment and control groups, although narrowing the earnings range inevitably entails a loss in statistical precision.

Sensitivity to relaxing sample restrictions. Our baseline estimates are obtained from a sample that excludes executive workers (since they were not affected by Reform 1) and is restricted to individuals working full-time during the entire year. We show in Appendix G.2 that our results are robust to using alternative sample definitions, such as including executive workers when analyzing the effects of Reforms 2 and 3, or including 
part-time and part-year workers when analyzing the effects of Reform 1 (see Table G8).

Earnings responses vs. wage responses. The contrasting patterns observed between Reform 1, on the one hand, and Reforms 2 and 3, on the other, could be because we are considering wage rates rather than earnings when assessing the effects of the most recent reform. In Appendix G.3, we rule out this explanation by showing that the patterns observed for Reform 1 are very similar when using the same earnings measures as for the two earlier reforms (see Figures G8 and G9).

Placebo reform. We perform a placebo test to check whether underlying inequality trends during our period of interest could disqualify the common trend assumption. To conduct this placebo test, we focus on the only sufficiently long period during which no SSC reform took place. We set the placebo reform in 1996 and define our control and treatment groups in the placebo reference year 1995. The results reported in Appendix G.4 show no evidence of differential earnings trends between the treatment and control groups (see Figure G10).

\section{Interpretation and Discussion}

This section discusses the interpretation of our results with regard to two issues. First, can tax-benefit linkage rationalize our contrasting incidence results? Second, to what extent do our estimates for Reforms 2 and 3 challenge the conventional wisdom about payroll tax incidence?

\subsection{Does Tax-Benefit Linkage Matter for Incidence?}

Our main result is that we find evidence of a rapid and full shifting of employer SSCs to workers in the case of the most recent reform (Reform 1), which contrasts with the limited shifting found for Reforms 2 and 3. How can we explain such a discrepancy?

Standard interpretation. The full pass-through of employer SSCs to treated workers in the case of Reform 1 can be rationalized in the standard model of competitive labor markets without necessarily involving tax-benefit linkage. Indeed, if the elasticity of substitution between treated and control workers is much larger than the labor supply 
elasticity $\left(\sigma \gg \eta^{S}\right)$, the pass-through parameter $\rho$ can be close to one irrespective of the value of the tax-benefit parameter $q$ (see our polar case (ii) in Section 1).

Within that framework and given such parameters, it seems however difficult to rationalize the very limited pass-through we find for Reforms 2 and 3. Assuming a labor supply elasticity of approximately $0.5^{30}$, our estimates of the pass-through rate for Reform 2 (0.06) and Reform 3 (0.21) would imply implausibly low values of the elasticity of substitution between treated and control workers, of respectively 0.03 and 0.13 . As a matter of comparison, elasticities of substitution between skilled and unskilled workers (college and high-school equivalents) in the U.S. have been estimated to be around 1.5 (e.g., Autor, Katz and Kearney, 2008) and even larger in France, with estimates ranging from 2 to almost 4 (Charnoz, Coudin and Gaini, 2011; Verdugo, 2014). Our treated and control individuals are likely to be better substitutes than college and high-school equivalents in studies of the skill premium. Indeed, the pre-reform gap between the average wages of these workers is around 25 percent, whereas the wage gap between college and high-school equivalents in France is around 50 percent, on average.

Economic conditions and institutional context. We provide evidence on incidence with and without tax-benefit linkage from reforms that have similar designs and apply to similarly paid workers in the same country. Nevertheless, these reforms occurred at different time periods and one could argue that labor market conditions changed dramatically between 1982 (the start of Reform 3) and 2005 (the end of Reform 1).

While it is hard to know exactly how economic conditions and labor market institutions may affect our estimates, two main hypotheses can be formulated. First, as nominal wage cuts are very hard to carry out (they are only legal in France under very specific conditions), it seems easier to pass on employer SSC increases to workers when inflation rates are higher. Second, in a more regulated labor market, quantities cannot adjust easily to variations in prices, implying that the adjustment from the nominal incidence of employer SSCs to their economic incidence is likely to be slower. We may also hypothesize that a higher unemployment rate tends to reduce workers' bargaining power and would therefore be expected to increase employers' ability to shift SSC increases to workers.

\footnotetext{
${ }^{30}$ Labor supply elasticity estimates are numerous and vary widely (Blundell and MaCurdy, 1999). The estimate of 0.5 is taken from the meta-analysis by Chetty (2012). For France, available estimates are lower, between 0.1 and 0.3 (Bourguignon and Magnac, 1990).
} 
When we compare the economic conditions and labor market institutions prevailing at the time of the three reforms being studied (see Table B3 in Appendix B), we do not observe large differences between the periods during which Reforms 1 and 2 were adopted, whether in terms of GDP growth, inflation, unemployment, labor force participation, or the incidence of full-time employment. Similarly, the strictness of employment protection was comparable in the three periods, while trade-union density was only slightly lower during Reform 1 and collective bargaining coverage slightly higher. It is therefore difficult to see how the observed differences between Reform 1, on the one hand, and Reforms 2 and 3 , on the other hand, could explain the marked differences in the estimated pass-through of employer SSCs. For example, if we compare the three variables that are perhaps the most likely to result in differences in pass-through, no clear prediction emerges when we compare Reforms 1 and 2: the inflation rate was 0.5 percentage point lower during Reform 1 than during Reform 2, while the unemployment rate was lower and employment protection stricter during Reform 1. If anything, these features would be expected to have increased rather than to have mitigated the pass-through of SSCs to workers following Reform 2.

We recognize that the evidence we present here is only suggestive, as other changes could have occurred across the reform periods. Nevertheless, our investigations do not point to obvious changes in labor market conditions that could account for our results.

Differences in tax-benefit linkage. As mentioned earlier, one of the main differences between Reform 1 and the two earlier reforms relates to the effective and perceived taxbenefit linkage. The complementary pension reform that was implemented in the 2000s induced several changes that were at the time considered as detrimental to employees, such as a lower rate of return on contributions. However, the increase in SSCs above the Social Security threshold was also perceived as an increase in pension rights for those concerned - it was part of trade union demands during the negotiation. We lack survey evidence of individuals' perception of the reform, and of the tax-benefit linkage, but anecdotal evidence from media reports suggests that this aspect was clearly understood. For instance, in an article from the daily newspaper Le Monde, it is stated that "the agreement also entails that wage earners whose wage is above the Social Security threshold would be able to constitute themselves a better pension: the contribution rate will be raised to 16 percent by 2005 for workers of existing firms, and as soon as 2000 for firms 
created after January 1, 1997". ${ }^{31}$ We also have exploited labor union archives to see how the reform was presented (see Appendix $\mathrm{C}$ for details). We have found numerous examples of labor union defense of the increase in SSCs as a positive aspect of the reform, because it was leading to increased pension benefits. For instance, the C.F.D.T. union was claiming to its members that "This demand from C.F.D.T. will allow 'non executives' to improve their future pensions and will translate into increased pay compensations for employers." ${ }^{32}$ By contrast, there was no tax-benefit linkage whatsoever in the case of the other two reforms and we have found no evidence suggesting any benefit of the reforms for workers-labor unions appeared at the time rather critical of the government.

With strong and salient tax-benefit linkage, a wide range of models of the labor markets predict full pass-through of employer SSCs, irrespective of the values of labor supply and substitution elasticities (see Appendix A and Table A1). This explanation thus appears as a credible candidate to rationalize the contrasting results we obtain for the three reforms.

Meta-analysis of the literature. We believe that our results can shed new light on the existing, yet relatively small, empirical literature on the incidence of employer SSCs. Studies that have found close to full pass-through of payroll taxes, e.g., Gruber (1997)'s analysis of the Chilean pension reform, have done so in contexts of strong and salient tax-benefit linkage. Conversely, results showing no shifting are based on SSC reforms with no tax-benefit linkage, e.g., the Greek reform studied by Saez et al. (2012), the French reform analyzed by Lehmann et al. (2013), and the Swedish reform analyzed by Saez et al. (2019).

A meta-analysis of the literature on payroll tax incidence shows that tax-benefit linkage is a key feature allowing to rationalize seemingly contradictory results. Figure 9 shows the estimated pass-through rate of payroll taxes to workers from published papers that rely on a proper identification of the impact of changes in payroll taxation (see Table 4 for references). ${ }^{33}$ We use the authors' description of the reforms to ascertain the degree of linkage and its likely perception. We compare 21 estimates of pass-through rates of employer SSCs and find that, among them, 7 concern SSCs with clear and salient taxbenefit linkage while 11 relate to SSCs with no linkage. We find a clear pattern whereby

\footnotetext{
31 "La baisse des retraites complémentaires est programmée," Le Monde, April 27, 1996.

${ }^{32}$ Le retraité militant C.F.D.T., No. 96.06, June 1996, pp. 6-8.

${ }^{33}$ This selection of papers on the incidence of payroll taxation is based on the survey by Melguizo and González-Páramo (2013) and the literature review in Saez et al. (2019).
} 
all of the results on a limited pass-through of payroll tax are based on natural experiments that concern SSCs with no tax-benefit linkage, and most of the studies finding full shifting consider settings with arguably strong linkage. We find an average pass-through rate of 103 percent for SSCs with strong tax-benefit linkage, compared to an average pass-through of 15 percent for SSCs with no tax-benefit linkage.

Alternative groupings of the estimates in the literature do not reveal other characteristics that could better explain the diverging results. For instance, no pattern is found according to the date of the reform studied or the level of aggregation at which the empirical analysis is performed: the average pass-through estimate is 52 percent at the individual level vs. 58 percent when estimated at the firm level.

In Table 5, we present a more formal meta-analysis of the literature by using a regression framework controlling for a variety of potential confounders. A simple regression of study-specific pass-trough estimates on indicators for the degree of linkage (none, strong, uncertain) yields a statistically significant coefficient of 0.88 on the strong linkage indicator, relative to the no linkage baseline of 0.15 (column 1). When controlling for time period (in decades) and broadly defined regions (U.S., Europe, Rest of the world), the coefficient on strong linkage is slightly reduced at 0.83 but remains statistically significant (column 2). In column 3, we add further controls for the unit of observation of the analysis (worker, firm, market level), the country's macroeconomic conditions (GDP growth, inflation rate, unemployment rate) and labor market conditions (OECD indicator of strictness of employment protection legislation, union density) during the period in which the reform took place. None of these controls shows statistical significance, whereas the coefficient on strong linkage remains significant at the 1 percent level with an estimated difference of 1.00 relative to the no linkage baseline.

This meta-analysis of the literature provides additional evidence that tax-benefit linkage, which is the distinctive institutional feature that differentiates SSCs from income taxes, is empirically relevant for explaining the heterogenous pass-through estimates found in the literature. 


\subsection{Which Model of the Labor Market is Consistent with our Pass-Through Estimates?}

In Appendix A, we derive the pass-through rate of employer SSCs under four different models of the labor market, with and without tax-benefit linkage (see Table A1). We discuss the extent to which these models can help rationalize the results of limited pass-through to workers when there is no tax-benefit linkage.

Competitive models of the labor markets. Our results would tend to reject the validity of standard competitive models at the individual level since, in the absence of a strong tax-benefit linkage, firms do not appear to shift changes in SSCs to the workers directly affected. One could, however, argue that the standard framework is more suited for analyzing incidence at the firm level. For instance, if firms do shift SSC increases to workers by imposing lower wage growth to all employees, irrespective of whether their individual SSC rates are subject to these increases, we would measure a zero pass-through to relative wages although workers would bear the full burden at the firm level. This firm-level shifting of SSCs has been evidenced by Saez et al. (2019) in the case of Sweden. ${ }^{34}$ It cannot, however, be easily rationalized using the competitive model. As shown in Appendix A, firm-level shifting of SSCs would require the elasticity of substitution between treated and control workers to be implausibly low.

Wage bargaining models. Contrary to the competitive model of the labor market, a collective wage bargaining model with an inequality-averse union is consistent with the limited individual-level pass-through of employer SSCs that we find for Reforms 2 and 3. As shown in Appendix A.5, this model predicts that in the absence of tax-benefit linkage, SSCs can be shifted to workers at the level of the firm while not being shifted at the individual level. This will occur when unions have strong bargaining power and a high degree of aversion to wage inequality within the firm. This model can be seen as an alternative to the fairness norms put forward by Saez et al. (2019) for explaining firm-level shifting of employer SSCs.

\footnotetext{
${ }^{34}$ Unfortunately, we are unable to test this hypothesis of firm-level pass-through as we only have access to a $1 / 25$ th sample of employees for the period in which Reforms 2 and 3 were put in place. We cannot, therefore, test whether the absence of pass-through of employer SSCs to individual wages is matched by a pass-through to all workers (both treated or control) at the firm level.
} 


\section{Conclusion}

We study three major SSC reforms in France over the past thirty years, all leading to marked increases in employer SSCs for wage earners above the Social Security threshold, i.e., around the 70th percentile of the earnings distribution.

Using a panel difference-in-differences framework that exploits between-worker variation in employer SSC rates over time, we find evidence of full pass-through of increases in employer SSCs to workers when there is a strong and salient relationship between contributions and expected benefits - our estimates are close to 100 percent. By contrast, we find a limited pass-through of employer SSCs to wages within five to six years after reforms that concerned SSCs with little or no tax-benefit linkage - our estimates are not significantly different from zero. We also carry out a meta-analysis of the literature, which suggests that tax-benefit linkage is a likely explanation for the differences between pass-through estimates across existing studies.

For SSCs with no or limited tax-benefit linkage, we show that firms do not shift increases in payroll taxes to workers at the individual level. Our results thus provide support to recent research suggesting that competitive models of the labor market are not well suited to explain how firm-level taxation is shifted to individual workers.

From a policy perspective, these results suggest that the efficiency argument in favor of funding social insurances with payroll taxes can only come with strong and salient tax-benefit linkage. Without these features, workers are unlikely to value Social Security contributions as deferred benefits, resulting in potentially large efficiency losses. 


\section{References}

Adam, Stuart, David Phillips, and Barra Roantree, "35 Years of Reforms: A Panel Analysis of the Incidence of, and Employee and Employer Responses to, Social Security Contributions in the UK," Journal of Public Economics, March 2019, 171, 29-50.

Alesina, Alberto and Roberto Perotti, "The Welfare State and Competitiveness," The American Economic Review, 1997, 87 (5), 921-939.

_ , Edward Glaeser, and Bruce Sacerdote, "Work and Leisure in the United States and Europe: Why So Different?," NBER Macroeconomics Annual, 2005, 20, 1-64.

Anderson, Patricia M. and Bruce D. Meyer, "The Effects of Firm Specific Taxes and Government Mandates with an Application to the U.S. Unemployment Insurance Program," Journal of Public Economics, 1997, 65 (2), 119-145.

_ and _ , "The Effects of the Unemployment Insurance Payroll Tax on Wages, Employment, Claims and Denials," Journal of Public Economics, 2000, 78 (1-2), 81-106.

Angrist, Joshua D., "Estimating the Labor Market Impact of Voluntary Military Service Using Social Security Data on Military Applicants," Econometrica, 1998, 66 (2), 249-288.

Atkinson, Anthony B. and Joseph E. Stiglitz, Lectures in Public Economics, McGraw-Hill, 1980.

Autor, David H., "Outsourcing at Will: The Contribution of Unjust Dismissal Doctrine to the Growth of Employment Outsourcing," Journal of Labor Economics, 2003, 21 (1), $1-42$.

_ , Lawrence F. Katz, and Melissa S. Kearney, "Trends in U.S. Wage Inequality: Revising the Revisionists," Review of Economics and Statistics, 2008, 90 (2), 300-323.

Baicker, Katherine and Amitabh Chandra, "The Labor Market Effects of Rising Health Insurance Premiums," Journal of Labor Economics, 2006, 24 (3), 609-634.

Bennmarker, Helge, Erik Mellander, and Björn Öckert, "Do Regional Payroll Tax Reductions Boost Employment?," Labour Economics, 2009, 16 (5), 480-489.

Blundell, Richard and Thomas MaCurdy, "Labor Supply: A Review of Alternative Approaches," Handbook of labor economics, 1999, 3, 1559-1695.

_ , Antoine Bozio, and Guy Laroque, "Labor Supply and the Extensive Margin," The American Economic Review Papers 6 Proceedings, 2011, 101 (3), 482-86.

Bourguignon, François and Thierry Magnac, "Labor Supply and Taxation in France," Journal of Human Resources, 1990, 25 (3), 358-389.

Bozio, Antoine, Thomas Breda, and Julien Grenet, "Incidence and Behavioural Responses to Social Security Contributions: Analysis of Kink Points in France," De Economist, 2017, 165 (2), 141-1639.

Brittain, John, The Payroll Tax for Social Security, Brookings Institution, 1972.

Charnoz, Pauline, Élise Coudin, and Mathilde Gaini, "Changes in the French Wage Distribution 1976-2004 : Inequalities within and between Education and Experience Groups," 2011. CREST working paper No. 2011-23.

Chetty, Raj, "Bounds on Elasticities with Optimization Frictions: a Synthesis of Micro and Macro Evidence on Labor Supply," Econometrica, 2012, 80 (3), 969-1018. 
_ , Adam Guren, Day Manoli, and Andrea Weber, "Are Micro and Macro Labor Supply Elasticities Consistent? A Review of Evidence on the Intensive and Extensive Margins," The American Economic Review, 2011, 101 (3), 471-475.

_ , Adam Looney, and Kory Kroft, "Salience and Taxation: Theory and Evidence," The American Economic Review, 2009, 99 (4), 1145-1177.

Correia, Sergio, "REGHDFE: Stata Module to Perform Linear or Instrumental-Variable Regression Absorbing any Number of High-Dimensional Fixed Effects," 2014. Statistical Software Components s124541, Boston College Department of Economics, Revised $25 / 07 / 2015$.

_ , "A Feasible Estimator for Linear Models with Multi-Way Fixed Effects," 2016. Unpublished manuscript.

Cruces, Guillermo, Sebastian Galiani, and Susana Kidyba, "Payroll Taxes, Wages and Employment: Identification through Policy Changes," Labour Economics, 2010, 17 (4), 743-749.

Daveri, Francesco, Guido Tabellini, Samuel Bentolila, and Harry Huizinga, "Unemployment, Growth and Taxation in Industrial Countries," Economic Policy, 2000, 15 (30), 49-104.

Feldstein, Martin S., "The Incidence of the Social Security Payroll Tax: Comment," The American Economic Review, 1972, 62 (4), 735-738.

_ , "Tax Incidence in a Growing Economy with Variable Factor Supply," The Quarterly Journal of Economics, 1974, 88 (4), 551-573.

Fullerton, Don and Gilbert Metcalf, "Tax Incidence," in Alan Auerbach and Martin S. Feldstein, eds., Handbook of Public Economics, Vol. 4, Elsevier/North Holland, 2002.

Gruber, Jonathan, "The Incidence of Mandated Maternity Benefits," The American Economic Review, 1994, 84 (3), 622-41.

_ , "The Incidence of Payroll Taxation: Evidence from Chile," Journal of Labor Economics, 1997, 15 (3), S72-101.

- and Alan B. Krueger, "The Incidence of Mandated Employer-Provided Insurance: Lessons from Workers' Compensation Insurance," in David Bradford, ed., Tax Policy and the Economy, Vol. 5, MIT Press, 1991, pp. 111-144.

Hamermesh, Daniel, "New Estimates of the Incidence of the Payroll Tax," Southern Economic Journal, 1979, 45, 1208-1219.

Holmlund, Bertil, "Payroll Taxes and Wage Inflation: The Swedish Experience," Scandinavian Journal of Economics, 1983, 85 (1), 1-15.

Institut des Politiques Publiques, IPP Tax and Benefit Tables, 2018. Url: www.ipp.eu/en/tools/ipp-tax-and-benefit-tables.

Kaplow, Louis, The Theory of Taxation and Public Economics, Princeton University Press, 2008.

Keane, Michael and Richard Rogerson, "Micro and Macro Labor Supply Elasticities: A Reassessment of Conventional Wisdom," Journal of Economic Literature, 2012, 50 (2), 464-476.

Kleven, Henrik Jacobsen, "How Can Scandinavians Tax So Much?," Journal of Economic Perspectives, November 2014, 28 (4), 77-98. 
Komamura, Kohei and Atsuhiro Yamada, "Who Bears the Burden of Social Insurance? Evidence from Japanese Health and Long-Term Care Insurance Data," Journal of the Japanese and International Economies, 2004, 18 (4), 565-581.

Kopczuk, Wojciech, Justin Marion, Erich Muehlegger, and Joel Slemrod, "Does Tax-Collection Invariance Hold? Evasion and the Pass-Through of State Diesel Taxes," American Economic Journal: Economic Policy, 2016, 8 (2), 251-286.

Korkeamäki, Ossi and Roope Uusitalo, "Employment and Wage Effects of a PayrollTax Cut-Evidence from a Regional Experiment," International Tax and Public Finance, 2009, 16 (6), 753-772.

Kotlikoff, Laurence J. and Lawrence H. Summers, "Tax Incidence," in Alan J. Auerbach and Martin S. Feldstein, eds., Handbook of Public Economics, Vol. 2, Elsevier, 1987, pp. 1043-1092.

Kramarz, Francis and Thomas Philippon, "The Impact of Differential Payroll Tax Subsidies on Minimum Wage Employment," Journal of Public Economics, 2001, 82 (1), 115-146.

Kugler, Adriana and Maurice Kugler, "Labor Market Effects of Payroll Taxes in Developing Countries: Evidence from Colombia," Economic Development and Cultural Change, 2009, 57 (2), 335-358.

Legros, Florence, "NDCs: A comparison of the French and German Point Systems," in Robert Holzmann and Edward Palmer, eds., Pension Reform: Issues and Prospects for Non-Financial Defined Contribution (NDC) Schemes, World Bank, 2006, chapter 10, pp. 203-222.

Lehmann, Etienne, François Marical, and Laurence Rioux, "Labor Income Responds Differently to Income-Tax and Payroll-Tax Reforms," Journal of Public Economics, 2013, 99, 66-84.

Melguizo, Ángel and José Manuel González-Páramo, "Who Bears Labour Taxes and Social Contributions? A Meta-Analysis Approach," SERIEs-Journal of the Spanish Economic Association, August 2013, 4 (3), 247-271.

Murphy, Kevin J., "The Impact of Unemployment Insurance Taxes on Wages," Labour Economics, 2007, 14 (3), 457-484.

Musgrave, Richard A., "The Role of Social Insurance in an Overall Programme for Social Welfare," in William Bowen, Frederick Harbison, Richard Lester, and Herman Somers, eds., The Princeton Symposium on The American System of Social Insurance, McGraw-Hill, 1968, pp. 23-40.

OECD, Employment Outlook, OECD Publishing, 1990.

Ohanian, Lee, Andrea Raffo, and Richard Rogerson, "Long-Term Changes in Labor Supply and Taxes: Evidence from OECD Countries, 1956-2004," Journal of Monetary Economics, November 2008, 55 (8), 1353-1362.

Ooghe, Erwin, Erik Schokkaert, and Jef Flechet, "The Incidence of Social Security Contributions: An Empirical Analysis," Empirica, 2003, 30 (2), 81-106.

Pierce, Brooks, "Compensation Inequality," The Quarterly Journal of Economics, 2001, 116 (4), 1493-1525.

Prescott, Edward C., "Why do Americans Work so Much More than Europeans?," FRB Minneaplis - Quarterly Review, 2004, (Jul), 2-13. 
Rogerson, Richard, "Taxation and Market Work: is Scandinavia an Outlier?," Economic Theory, 2007, 32 (1), 59-85.

Saez, Emmanuel, Benjamin Schoefer, and David Seim, "Payroll Taxes, Firm Behavior, and Rent Sharing: Evidence from a Young Workers' Tax Cut in Sweden," The American Economic Review, 2019, 109 (5), 1717-63.

_ , Manos Matsaganis, and Panos Tsakloglou, "Earnings Determination and Taxes: Evidence From a Cohort-Based Payroll Tax Reform in Greece," The Quarterly Journal of Economics, 2012, 127 (1), 493-533.

Slemrod, Joel, "Does It Matter Who Writes the Check to the Government? The Economics of Tax Remittance," National Tax Journal, 2008, 61 (2), 251-75.

Summers, Lawrence H., "Some Simple Economics of Mandated Benefits," The American Economic Review, 1989, 79 (2), 177-83.

Tyrväinen, Timo, "Real Wage Resistance and Unemployment," 1995. OECD Jobs Study Working papers No. 10.

Verdugo, Gregory, "The Great Compression of the French Wage Structure, 1969-2008," Labour Economics, 2014, 28, 131-144. 


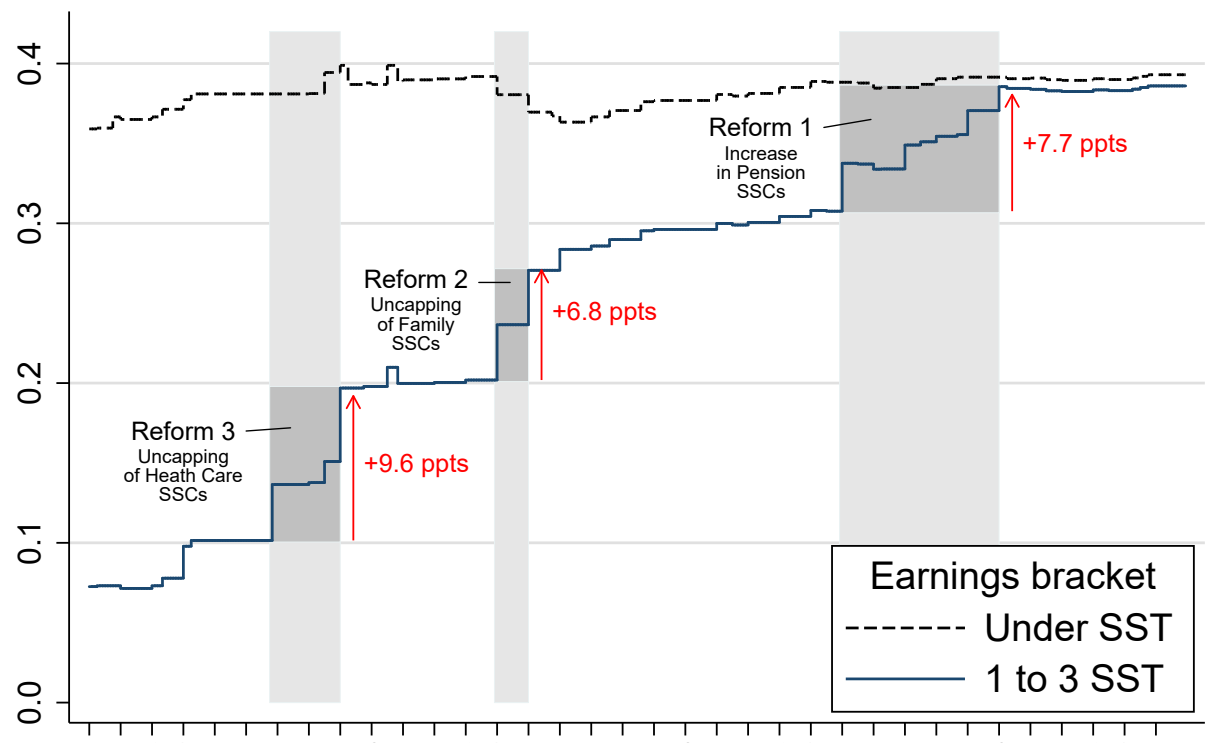

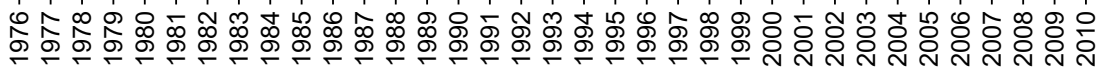

Year

Figure 1 - Marginal Employer SSC Rates, Private Sector, 1976-2010

Notes: Marginal tax rates are here expressed as a percentage of gross earnings, as they are legislated. These rates are applied to different earnings brackets, defined with respect to the Social Security threshold (SST). The rates presented here apply to non-executive workers, i.e., workers affiliated with the ARRCO pension scheme, working full-time. Sources: Institut des Politiques Publiques (2018); TAXIPP 0.4 
(a) Reform 1: 2005 vs. 1999 Employer Marginal SSC Rates

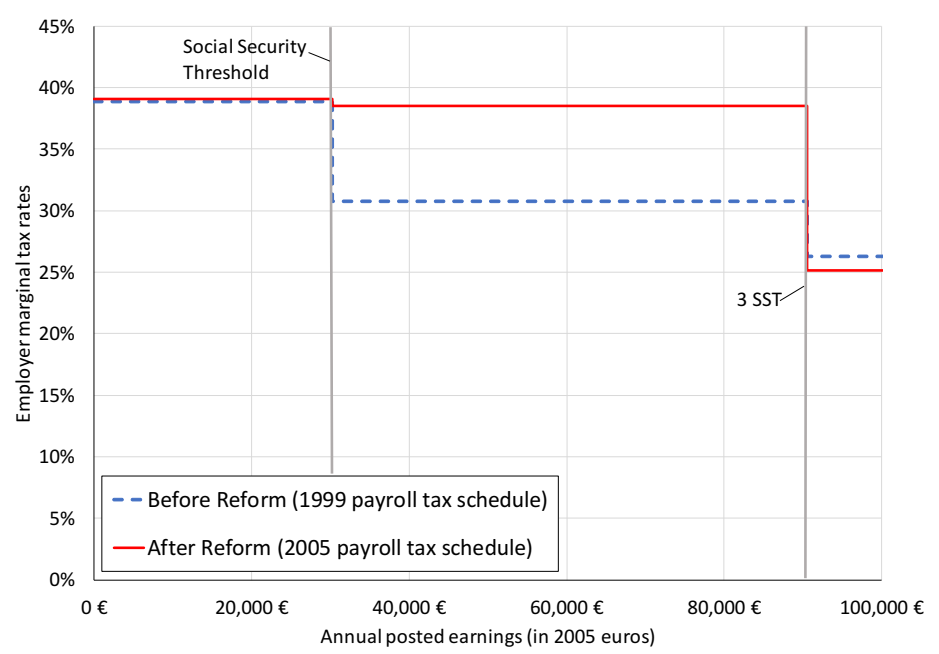

(b) Reform 2: 1991 vs. 1988 Employer Marginal SSC Rates

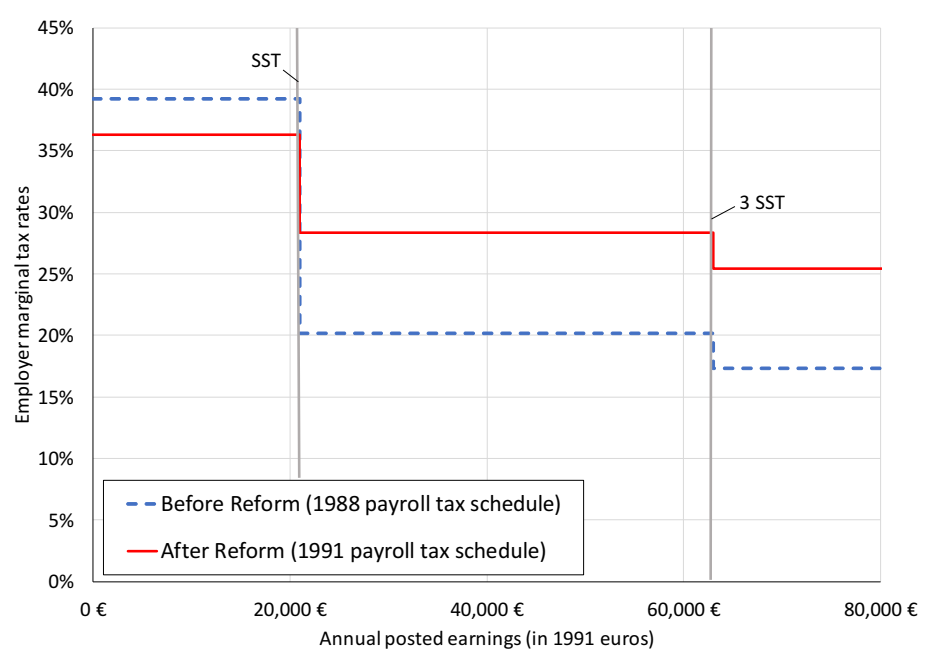

(c) Reform 3: 1984 vs. 1981 Employer Marginal SSC Rates

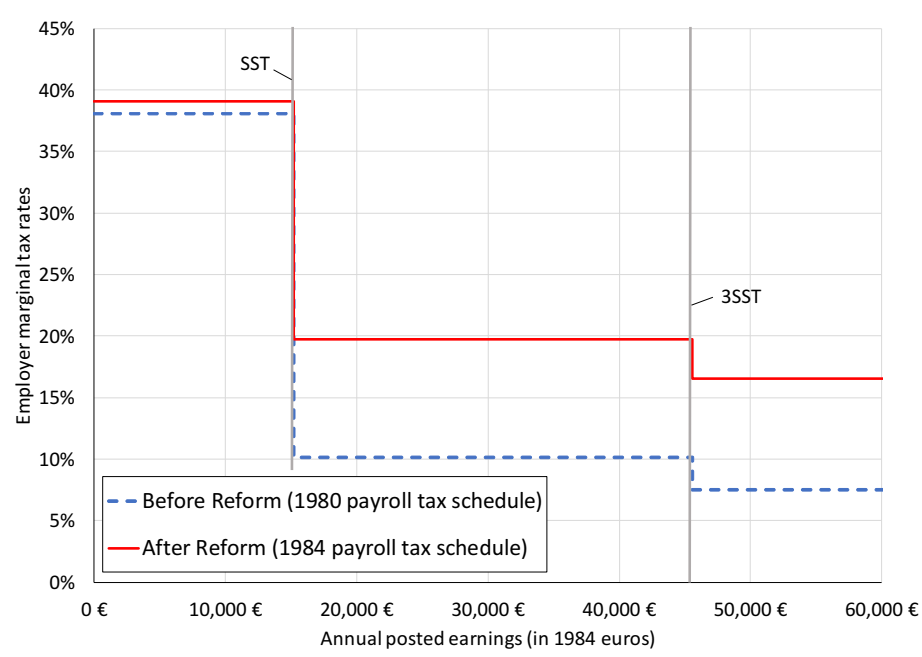

Figure 2 - Change in Payroll Tax Schedule Around Each Reform Studied

Notes: This figure shows the changes in employer marginal SSC rates around each of the three reforms under study. The rates are expressed as a function of annual posted earnings for the case of a full-time non-executive worker. Earnings level are expressed in euros of the post-reform year. Vertical bars represent the different payroll tax thresholds, i.e., the main Social Security threshold (SST) and three times the SST, which corresponds to the upper threshold of the second SSC earnings bracket for non executives. 
(a) Gross Hourly Wage $(w)$

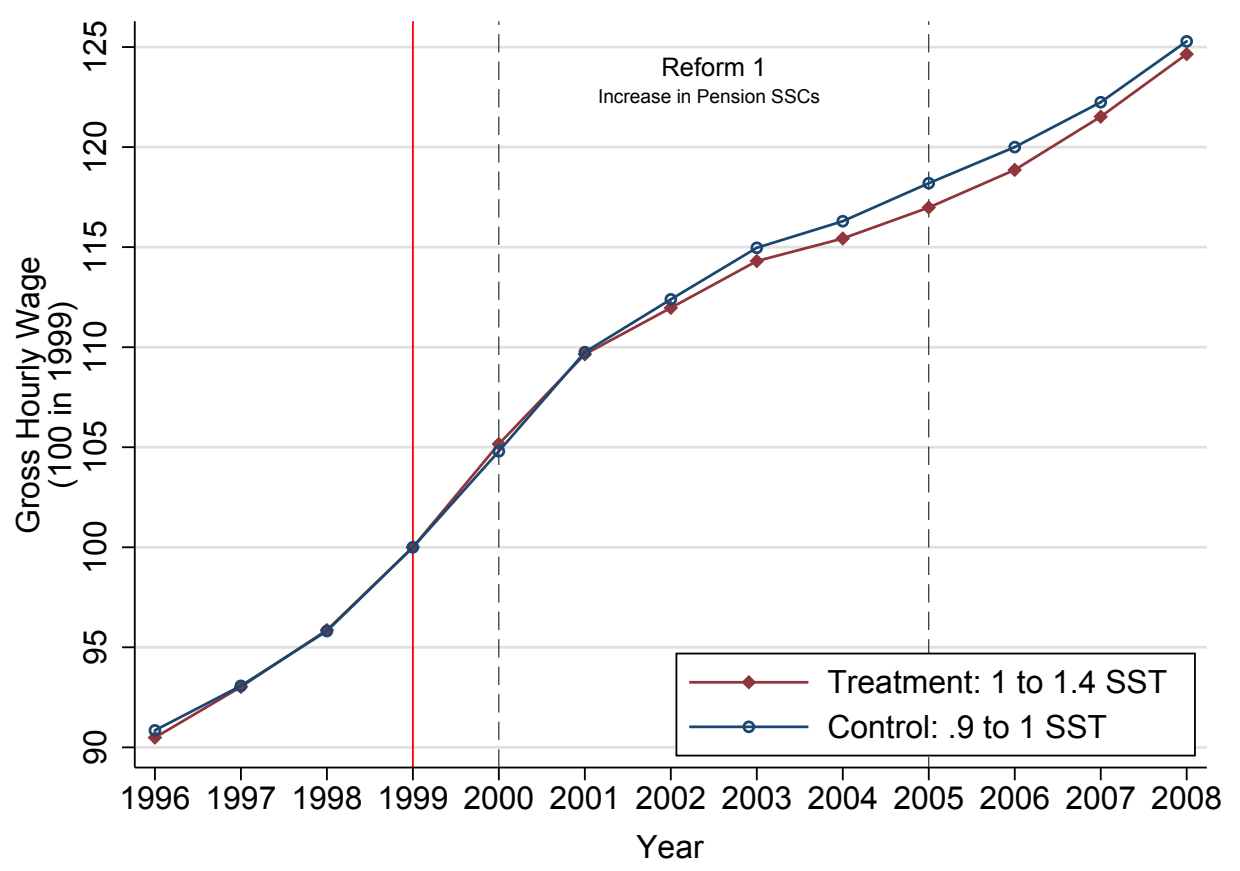

(b) Hourly Labor Cost $(z)$

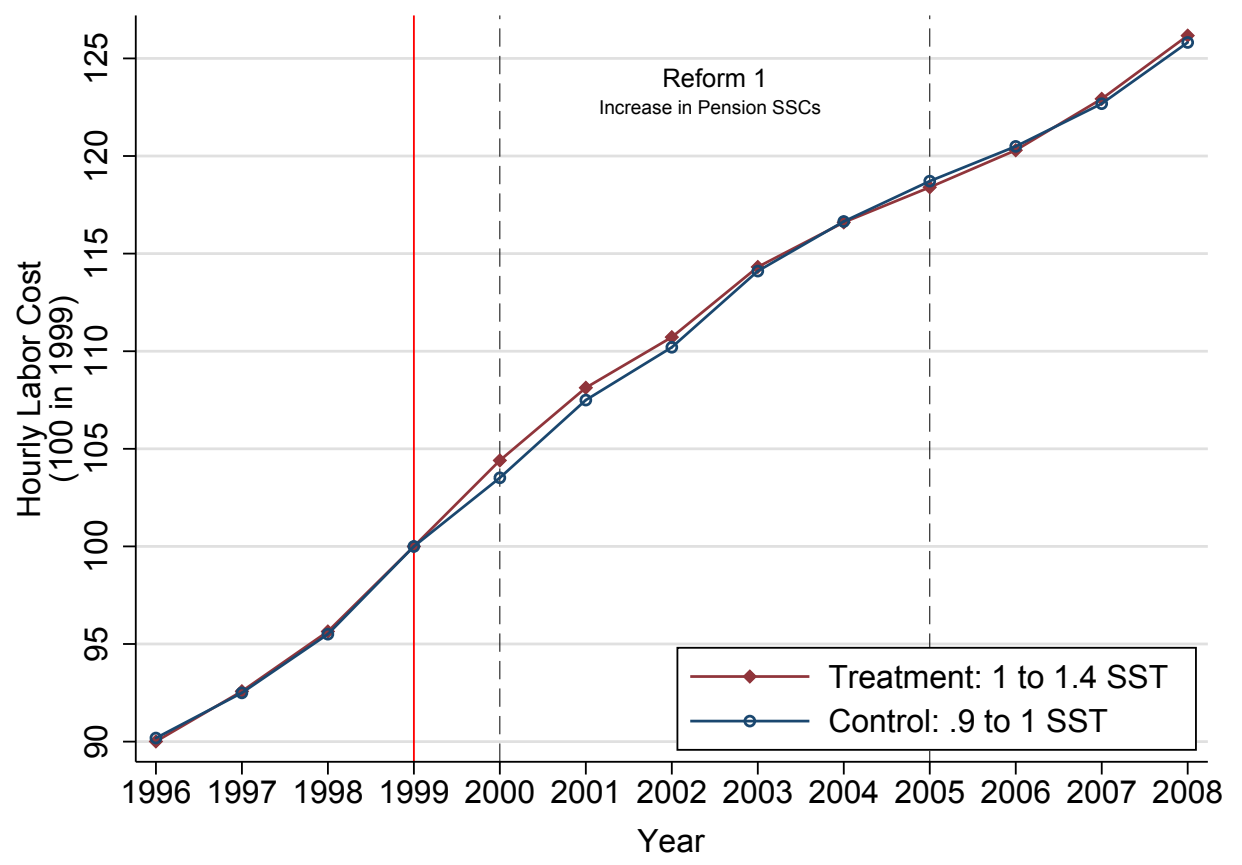

Figure 3 - Wage Responses to the Increase in Pension SSCs (Reform 1)

Notes: The figure shows the evolution of average real gross wage (Panel a) and average real hourly labor cost (Panel b) between 1996 and 2008 for two groups of workers that were affected differently by the increase in the pension SSCs for non executives between 2000 and 2005 . The figure is based on an unbalanced panel of workers who are observed in the last pre-reform year (denoted by a vertical solid line) and at least another year. The vertical dashed lines denote the reform years (start and end). Earnings levels are normalized to 100 for both groups in the reference year (1999). The treatment group includes workers whose gross earnings in 1999 were 1 to 1.4 times the SST that year. These workers experienced an increase in their average SSC rate due to the reform. The control group includes workers whose gross earnings in 1999 were 0.9 to 1 times the SST that year. These workers did not experience a change in their average SSC rate due to the reform. Sources: DADS Panel 2010; TAXIPP 0.4. 
(a) Gross Earnings $(w h)$

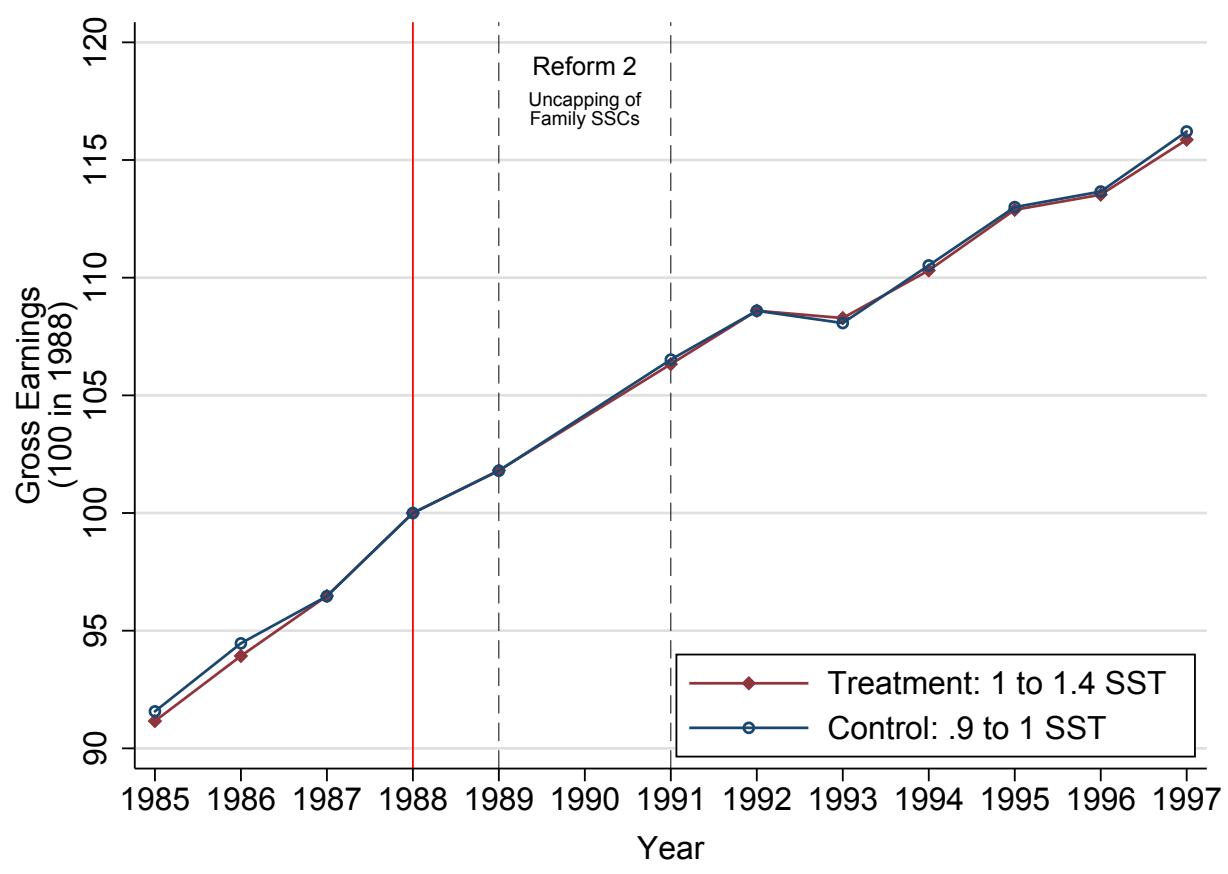

(b) Labor Cost $(z h)$

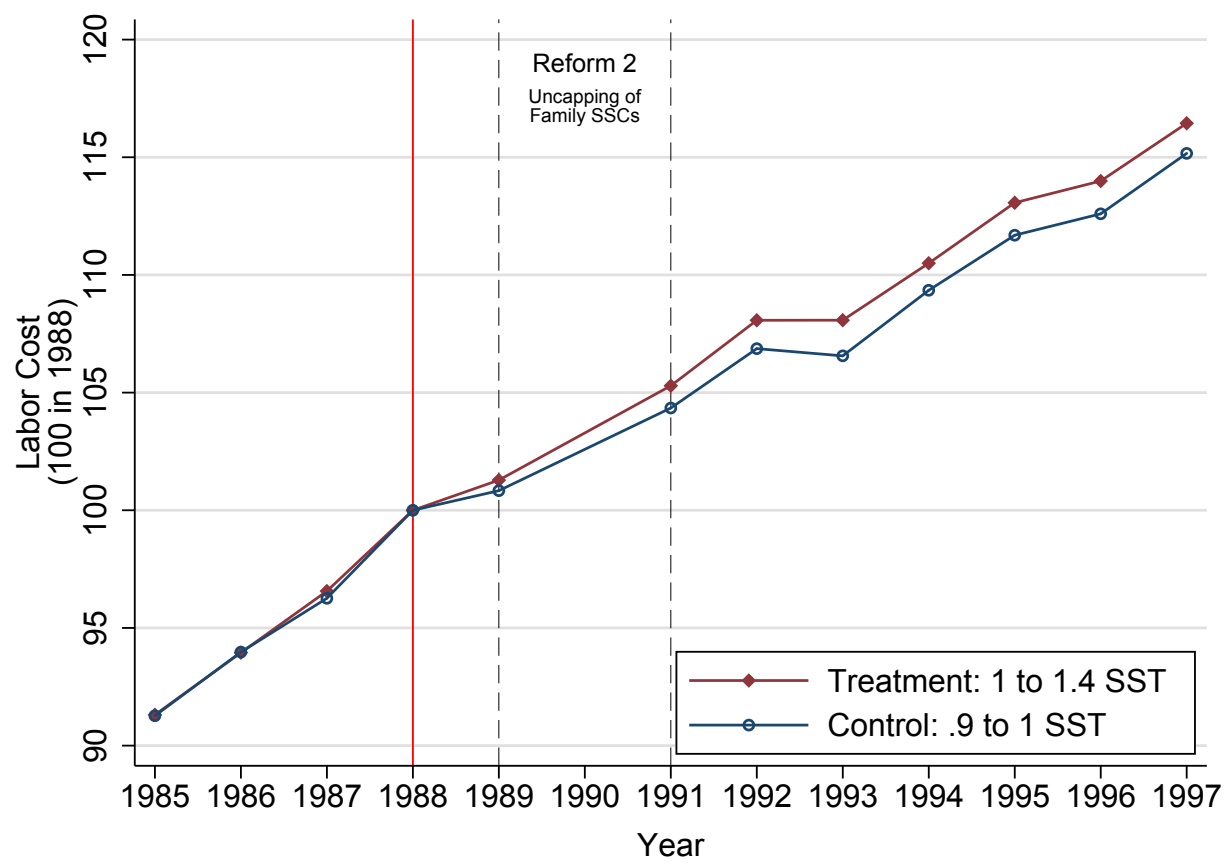

Figure 4 - Earnings Responses to the Uncapping of Family SSCs (Reform 2)

Notes: The figure shows the evolution of average real gross earnings (Panel a) and average real labor cost (Panel b) between 1985 and 1986 for two groups of workers that were affected differently by the uncapping of family SSCs in 1989 and 1990. The figure is based on an unbalanced panel of workers who are observed in the last pre-reform year (denoted by a vertical solid line) and at least another year. The vertical dashed lines denote the reform years (start and end). Earnings levels are normalized to 100 for both groups in the reference year (1988). The treatment group includes workers whose gross earnings in 1988 were 1 to 1.4 times the SST that year. These workers experienced an increase in their average SSC rate due to the reform. The control group includes workers whose gross earnings in 1988 were 0.9 to 1 times the SST that year. These workers did not experience a change in their average SSC rate due to the reform.

Sources: DADS Panel 2010; TAXIPP 0.4. 
(a) Gross Earnings $(w h)$

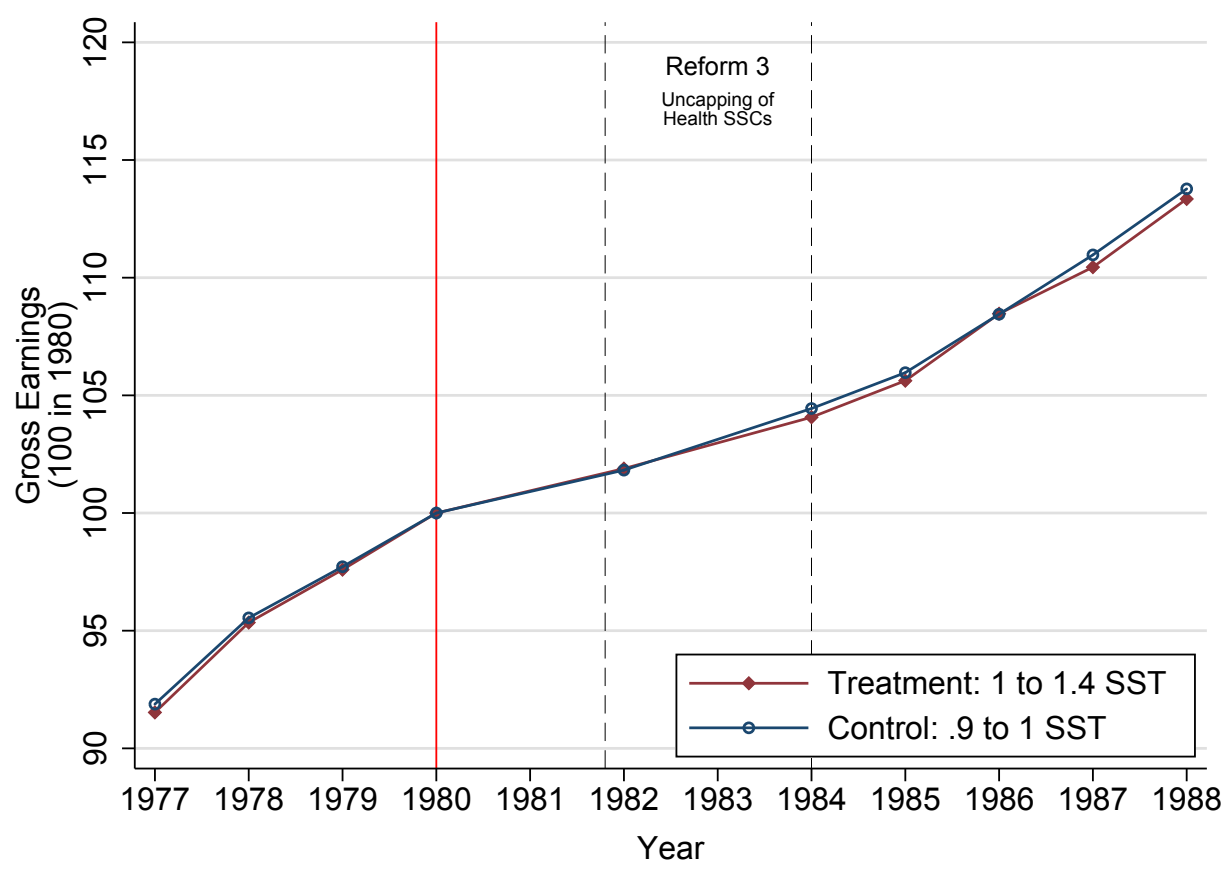

(b) Labor Cost $(z h)$

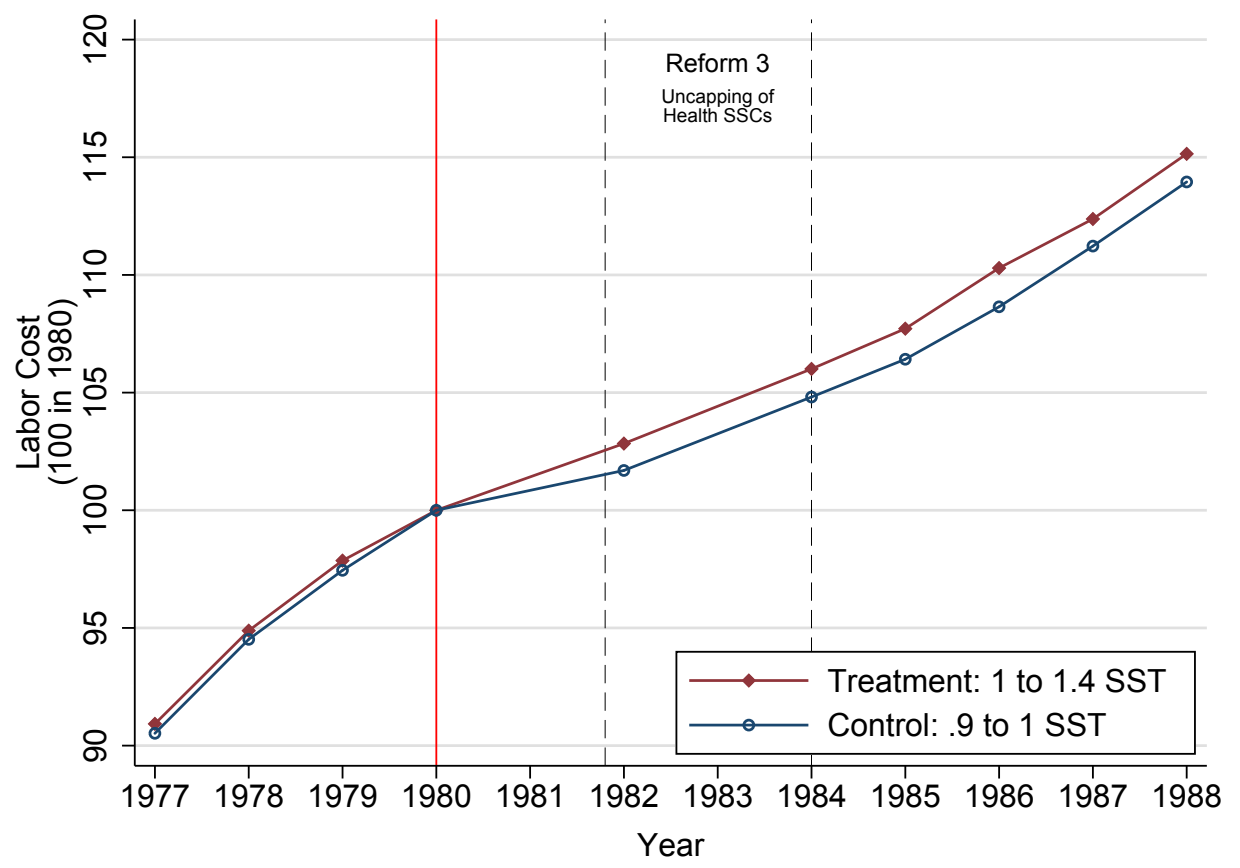

Figure 5 - Earnings Responses to the Uncapping of Health Care SSCs (Reform 3)

Notes: The figure shows the evolution of average real gross earnings (Panel a) and average real labor cost (Panel b) between 1977 and 1988 for two groups of workers that were affected differently by the uncapping of health care SSCs in 1981 and 1983. The figure is based on an unbalanced panel of workers who are observed in the last pre-reform year (denoted by a vertical solid line) and at least another year. The vertical dashed lines denote the reform years (start and end). Earnings levels are normalized to 100 for both groups in the reference year (1980). The treatment group includes workers whose gross earnings in 1980 were 1 to 1.4 times the SST that year. These workers experienced an increase in their average SSC rate due to the reform. The control group includes workers whose gross earnings in 1980 were 0.9 to 1 times the SST that year. These workers did not experience a change in their average SSC rate due to the reform. Sources: DADS Panel 2010; TAXIPP 0.4 
(a) Log Difference in Gross Wage and Hourly Labor Cost

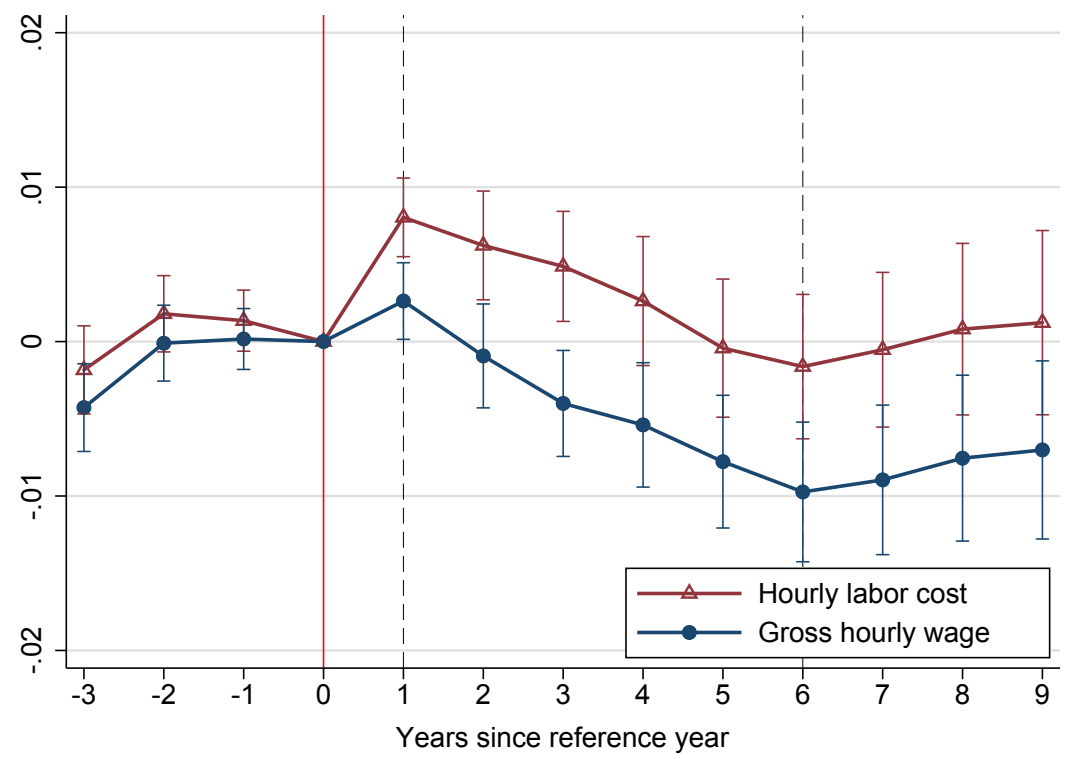

(b) Pass-Through to Workers (2SLS)

Baseline specification

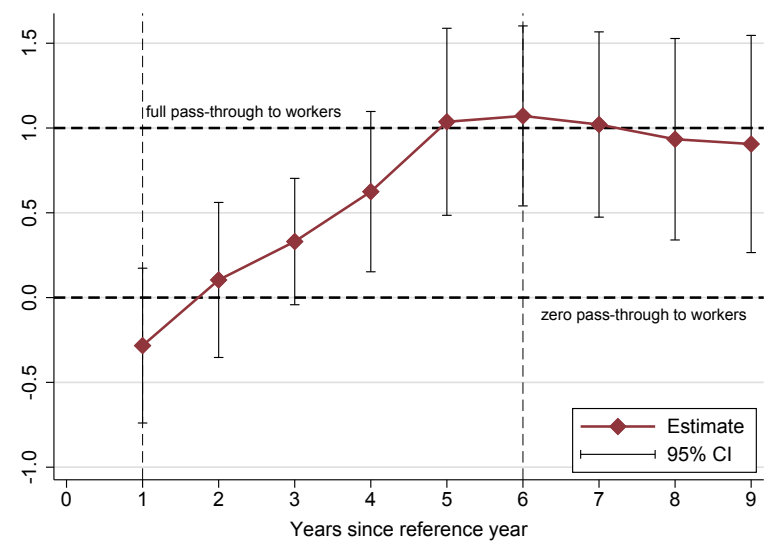

Controlling for worker-specific trends

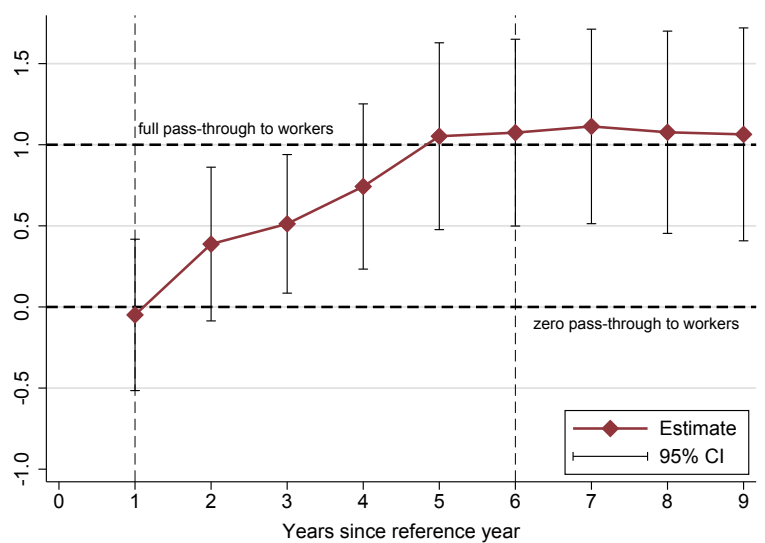

Figure 6 - Reform 1: Estimated Pass-Through Rate to Workers (Hourly Wage)

Notes: Panel (a) shows the estimated log differences between the average real gross wage (circle markers) and the average real hourly labor cost (triangle markers) of two groups of workers that were affected differently by the increase in the pension SSCs for non executives between 2000 and 2005. The vertical dashed lines denote the reform years (start and end). The difference-in-differences estimation is performed on an unbalanced panel of workers who are observed in the last pre-reform year and at least another year. The treatment group includes workers whose gross earnings in the last pre-reform year (1999) were 1 to 1.4 times the SST that year. These workers experienced an increase in their average SSC rate due to the reform. The control group includes workers whose gross earnings in 1999 were 0.9 to 1 times the SST that year. These workers did not experience a change in their average SSC rate due to the reform. The markers represent the parameter estimates on the interaction between the treatment group and year dummies, which is normalized to zero in the reference year (1999). The vertical T-bars show the 95 percent confidence intervals around the point estimates, with standard errors clustered at the individual level. Panel (b) shows the estimated pass-through rate of employer SSCs to the wage of treated workers relative to control workers over a period up to 8 years after the reform. The vertical dashed lines denote the reform years (start and end). The estimated pass-through to workers of the increase in employer SSCs is obtained from a 2SLS regression of $\log$ (gross wage) on $\log (1+\mathrm{SSC}$ rate $)$, where $\log (1+\mathrm{SSC}$ rate $)$ is instrumented by the interaction between the treatment group and year dummies. The estimation is performed separately for each of the post-reform years based on Equation (6) in the main text. The pass-through estimates reported in the left panel are obtained from a specification that does not control for worker-specific trends in addition to worker and year fixed effects. The pass-through estimates reported in the right panel obtained from an augmented specification that controls for worker-specific trends in addition to worker and year fixed effects. The diamond markers represent the estimated pass-through rate while the vertical T-bars denote the 95 percent confidence intervals around the point estimates, with standard errors clustered at the individual level. The full set of estimates can be found in Appendix Table E6.

Sources: DADS Panel 2010; TAXIPP 0.4. 
(a) Log Difference in Gross Earnings and Labor Cost

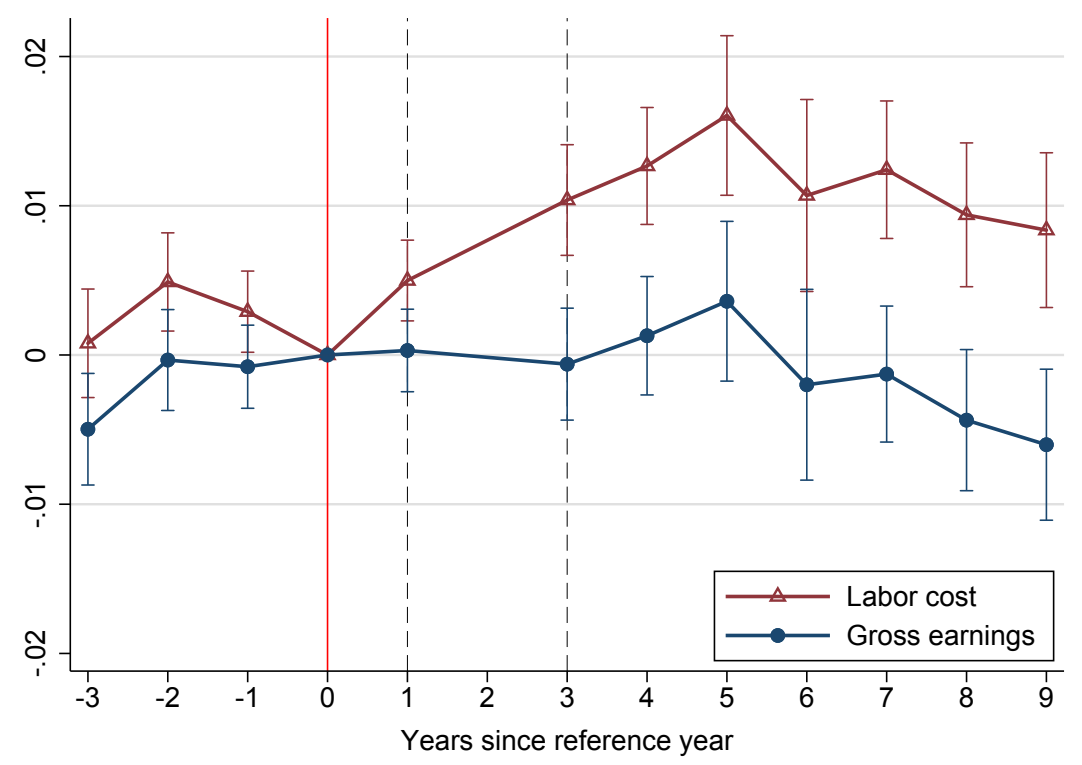

(b) Pass-Through to Workers (2SLS)

Baseline specification

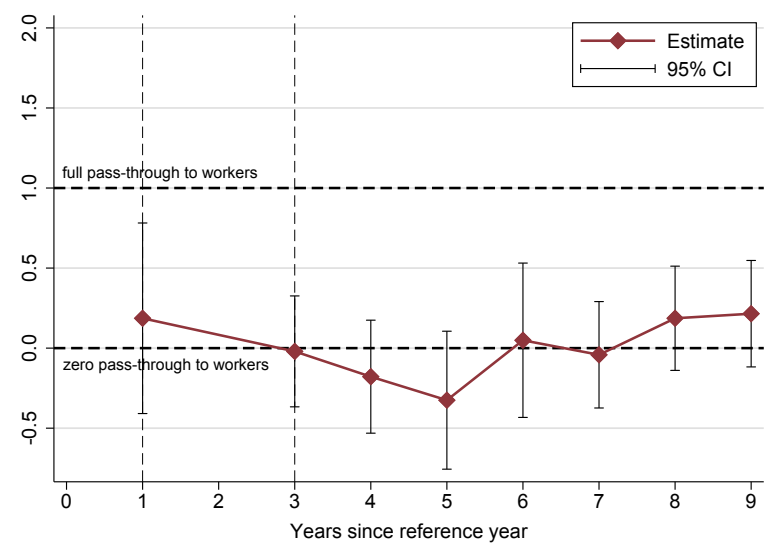

Controlling for worker-specific trends

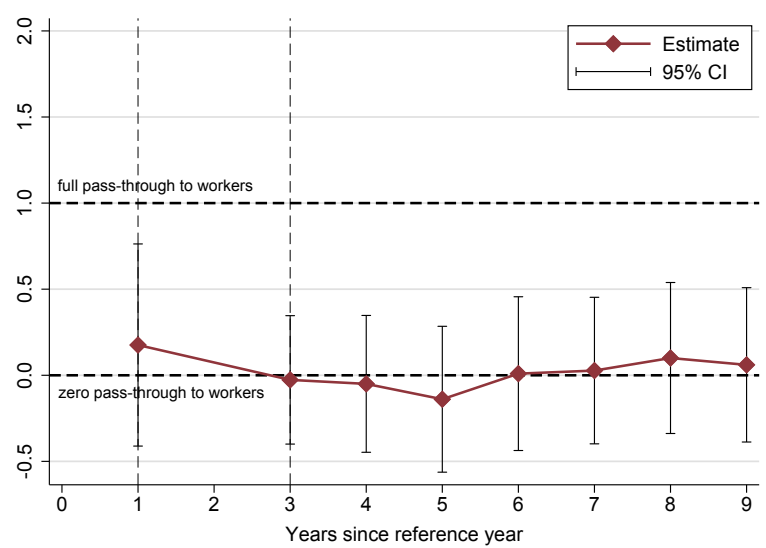

Figure 7 - Reform 2: Estimated Pass-Through Rate to Workers (Earnings)

Notes: Panel (a) shows the estimated log differences between the average real gross earnings (circle markers) and the average real labor cost (triangle markers) of two groups of workers that were affected differently by the uncapping of family SSCs in 1989 and 1990. The vertical dashed lines denote the reform years (start and end). The difference-in-differences estimation is performed on an unbalanced panel of workers who are observed in the last pre-reform year and at least another year. The treatment group includes workers whose gross earnings in the last pre-reform year (1988) were 1 to 1.4 times the SST that year. These workers experienced an increase in their average SSC rate due to the reform. The control group includes workers whose gross earnings in 1988 were 0.9 to 1 times the SST that year. These workers did not experience a change in their average SSC rate due to the reform. The markers represent the parameter estimates on the interaction between the treatment group and year dummies, which is normalized to zero in the reference year (1988). The vertical T-bars show the 95 percent confidence intervals around the point estimates, with standard errors clustered at the individual level. Panel (b) shows the estimated pass-through rate of employer SSCs to the earnings of treated workers relative to control workers over a period up to 8 years after the reform. The vertical dashed lines denote the reform years (start and end). The estimated pass-through to workers of the increase in employer SSCs is obtained from a 2SLS regression of $\log$ (gross earnings $)$ on $\log (1+\mathrm{SSC}$ rate $)$, where $\log (1+\mathrm{SSC}$ rate $)$ is instrumented by the interaction between the treatment group and year dummies. The estimation is performed separately for each of the post-reform years based on Equation (6) in the main text. The pass-through reported in the left panel are obtained from a specification that does not control for worker-specific trends in addition to worker and year fixed effects. The pass-through estimates reported in the right panel obtained from an augmented specification that controls for worker-specific trends in addition to worker and year fixed effects. The diamond markers represent the estimated pass-through rate while the vertical T-bars denote the 95 percent confidence intervals around the point estimates, with standard errors clustered at the individual level. The full set of estimates can be found in Appendix Table E6.

Sources: DADS Panel 2010; TAXIPP 0.4. 
(a) Log Difference in Gross Earnings and Labor Cost

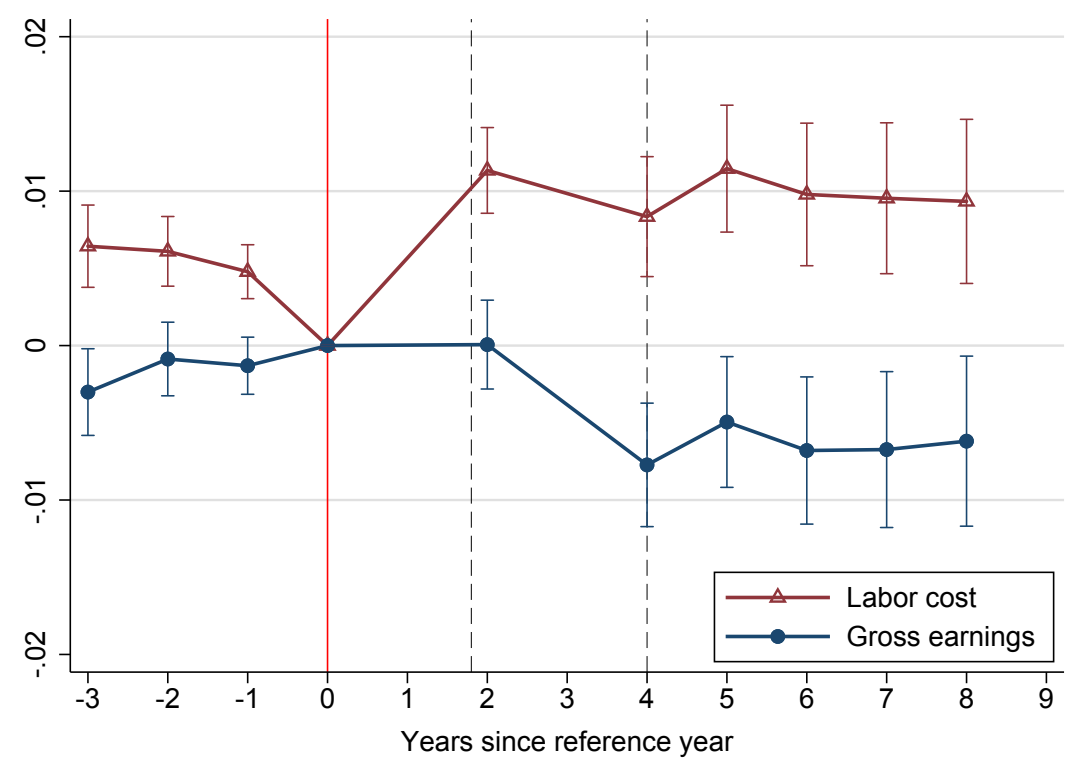

(b) Pass-Through to Workers (2SLS)

Baseline specification

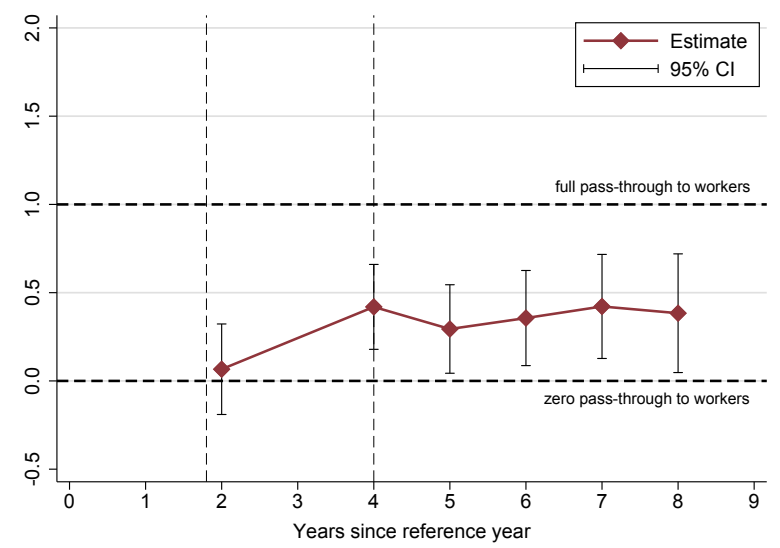

Controlling for worker-specific trends

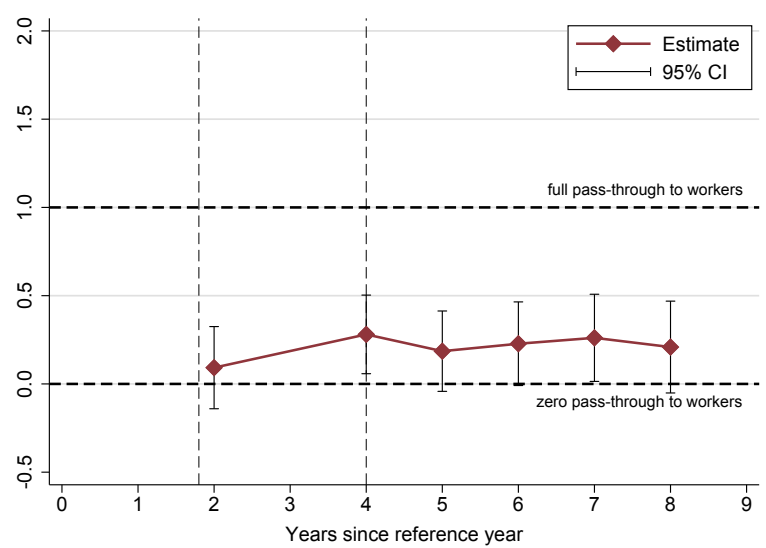

Figure 8 - Reform 3: Estimated Pass-Through to Workers (Earnings)

Notes: Panel (a) shows the estimated log differences between the average real gross earnings (circle markers) and the average real labor cost (triangle markers) of two groups of workers that were affected differently by the uncapping of health care SSCs in 1981 and 1983. The vertical dashed lines denote the reform years (start and end). The difference-in-differences estimation is performed on an unbalanced panel of workers who are observed in the last pre-reform year and at least another year. The treatment group includes workers whose gross earnings in the last pre-reform year (1980) were 1 to 1.4 times the SST that year. These workers experienced an increase in their average SSC rate due to the reform. The control group includes workers whose gross earnings in 1980 were 0.9 to 1 times the SST that year. These workers did not experience a change in their average SSC rate due to the reform. The markers represent the parameter estimates on the interaction between the treatment group and year dummies, which is normalized to zero in the reference year (1980). The vertical T-bars show the 95 percent confidence intervals around the point estimates, with standard errors clustered at the individual level. Panel (b) shows the estimated pass-through rate of employer SSCs to the earnings of treated workers relative to control workers over a period up to 7 years after the reform. The vertical dashed lines denote the reform years (start and end). The estimated pass-through to workers of the increase in employer SSCs is obtained from a 2SLS regression of $\log$ (gross earnings) on $\log (1+\mathrm{SSC}$ rate $)$, where $\log (1+\mathrm{SSC}$ rate $)$ is instrumented by the interaction between the treatment group and year dummies. The estimation is performed separately for each of the post-reform years based on Equation (6) in the main text. The pass-through reported in the left panel are obtained from a specification that does not control for worker-specific trends in addition to worker and year fixed effects. The pass-through estimates reported in the right panel obtained from an augmented specification that controls for worker-specific trends in addition to worker and year fixed effects. The diamond markers represent the estimated pass-through rate while the vertical T-bars denote the 95 percent confidence intervals around the point estimates, with standard errors clustered at the individual level. The full set of estimates can be found in Appendix Table E6.

Sources: DADS Panel 2010; TAXIPP 0.4 


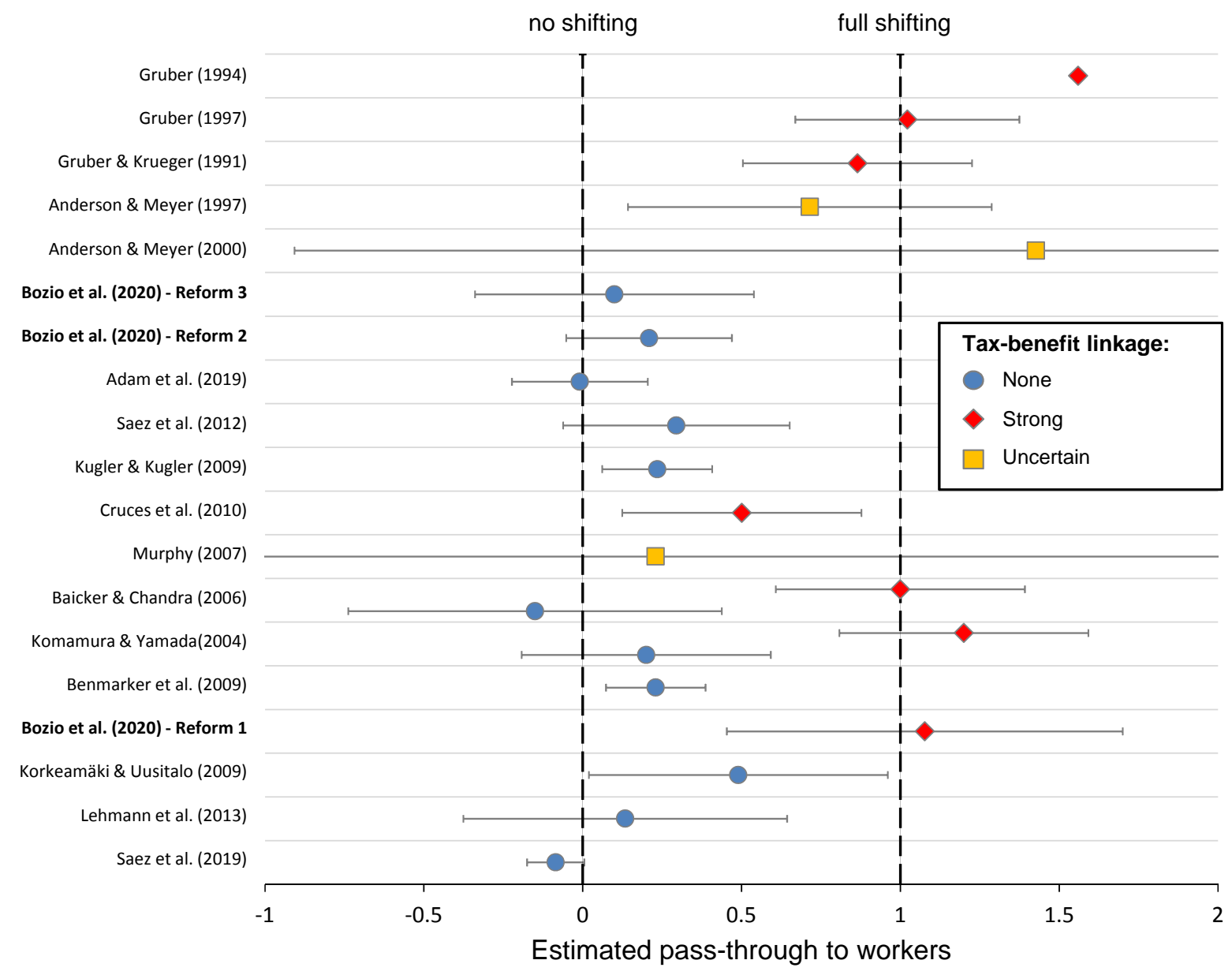

Figure 9 - Meta-Analysis of Employer Payroll Tax Shifting to Workers

Notes: The sources used to construct this figure can be found in Table 4. The papers are ordered by the corresponding year/period of the reform(s) being studied, from the oldest (top) to the most recent (bottom). The markers show the studyspecific estimated pass-through rate of employer payroll taxes to workers. The horizontal T-bars denote the 95 percent confidence intervals around the point estimates. 
Table 1 - Marginal Social Security Contribution Rates Before and After each Reform

\begin{tabular}{|c|c|c|c|c|c|c|}
\hline & \multicolumn{3}{|c|}{ Employer SSCs } & \multicolumn{3}{|c|}{ Employee SSCs } \\
\hline & $\begin{array}{c}\text { Under SST } \\
(1)\end{array}$ & $\begin{array}{c}1 \text { to } 3 \mathrm{SST} \\
(2)\end{array}$ & $\begin{array}{c}\text { Difference } \\
(3)\end{array}$ & $\begin{array}{c}\text { Under SST } \\
(4)\end{array}$ & $\begin{array}{c}1 \text { to } 3 \mathrm{SST} \\
(5)\end{array}$ & $\begin{array}{c}\text { Difference } \\
(6)\end{array}$ \\
\hline \multicolumn{7}{|c|}{ Panel A. Reform 1: Increase in pension SSCs (2000-2005) } \\
\hline \multicolumn{7}{|c|}{ Arrco pension $S S C$} \\
\hline 1999 & 4.5 & 4.5 & 0.0 & 3.0 & 3.0 & 0.0 \\
\hline 2005 & 4.5 & 12.0 & 7.5 & 3.0 & 8.0 & 5.0 \\
\hline Difference & 0.0 & 7.5 & 7.5 & 0.0 & 5.0 & 5.0 \\
\hline \multicolumn{7}{|l|}{ Total SSCs } \\
\hline 1999 & 38.9 & 30.8 & -8.1 & 13.4 & 7.4 & -6.0 \\
\hline 2005 & 39.1 & 38.5 & -0.6 & 13.6 & 12.1 & -1.4 \\
\hline Difference & 0.2 & 7.7 & 7.5 & 0.2 & 4.7 & 4.5 \\
\hline \multicolumn{7}{|c|}{ Panel B. Reform 2: Uncapping of family SSCs (1989 and 1990) } \\
\hline \multicolumn{7}{|c|}{ Family $S S C$} \\
\hline 1988 & 9.0 & 0.0 & -9.0 & & & \\
\hline 1990 & 7.0 & 7.0 & 0.0 & & & \\
\hline Difference & -2.0 & 7.0 & 9.0 & & & \\
\hline \multicolumn{7}{|l|}{ Total SSCs } \\
\hline 1988 & 39.2 & 20.2 & -19.0 & 17.0 & 10.9 & -6.1 \\
\hline 1990 & 36.9 & 27.1 & -9.8 & 18.0 & 10.9 & -7.1 \\
\hline Difference & -2.3 & 6.8 & 9.2 & 1.0 & 0.0 & -1.0 \\
\hline \multicolumn{7}{|c|}{ Panel C. Reform 3: Uncapping of health care SSCs (1981 and 1983) } \\
\hline \multicolumn{7}{|c|}{ Health care $S S C$} \\
\hline 1980 & 13.4 & 4.5 & -8.9 & 5.5 & 5.5 & 0.0 \\
\hline 1984 & 12.6 & 12.6 & 0.0 & 5.5 & 5.5 & 0.0 \\
\hline Difference & -0.8 & 8.1 & 8.9 & 0.0 & 0.0 & 0.0 \\
\hline \multicolumn{7}{|l|}{ Total SSCs } \\
\hline 1980 & 38.1 & 10.2 & -28.0 & 12.8 & 8.1 & -4.7 \\
\hline 1984 & 39.0 & 19.7 & -19.3 & 15.2 & 9.7 & -5.5 \\
\hline Difference & 0.9 & 9.6 & 8.7 & 2.4 & 1.6 & -0.8 \\
\hline
\end{tabular}

Notes: Marginal Social Security contribution rates are here expressed as a percentage of gross (posted) earnings, as they are legislated. These rates are applied to different earnings brackets, defined with respect to the Social Security threshold (SST).

Sources: Institut des Politiques Publiques (2018); TAXIPP 0.4. 
Table 2 - Summary Statistics for the Treatment and Control Groups in the Reference Year

\begin{tabular}{lccccc}
\hline Sample: & \multicolumn{2}{c}{ Control Group } & & \multicolumn{2}{c}{ Treatment Group } \\
Gross earnings: & \multicolumn{2}{c}{0.9 to 1 SST } & & \multicolumn{2}{c}{1 to 1.4 SST } \\
\cline { 2 - 3 } \cline { 5 - 6 } & Mean & S.D. & & Mean & S.D. \\
& $(1)$ & $(2)$ & & $(3)$ & $(4)$
\end{tabular}

Panel A. Reform 1: Increase in pension SSCs (2000-2005)

Reference year $\left(t_{0}\right): 1999$

Percentile rank in the earnings distribution

[P62-P70]

Age

Male

Annual gross earnings

Annual labor cost

Average employer SSC rate

Number of individuals

Number of observations
41.4
0.72
30,329
43,799
0.307
19,626
183,018

[P70-P87]

$(8.9)$

$(0.45)$

$(918)$

$(1,699)$

(0.015)

43.1

0.75

36,761

52,749

0.303

33,605

314,506

\section{Panel B. Reform 2: Uncapping of family SSCs (1989 and 1990)}

Reference year $\left(t_{0}\right): 1988$

Percentile rank in the earnings distribution

[P58-P67]

Age

$$
39.0
$$

0.74

26,074

Annual gross earnings

37,598

0.306

24,388

Average employer SSC rate

203,872

[P67-P85]

$$
\begin{array}{r}
40.6 \\
0.77 \\
31,805 \\
45,123 \\
0.295 \\
46,575 \\
393,516
\end{array}
$$

\section{(1981 and 1983)}

Reference year $\left(t_{0}\right): 1980$

Percentile rank in the earnings distribution

[P56-P65]

[P65-P85]

Age

Male

$$
38.0
$$

$$
0.76
$$

22,409

31,957

Annual labor cost

Average employer SSC rate

0.299

30,979

Number of individuals

209,432

$(10.7)$
$(0.43)$
$(683)$
$(1,045)$
$(0.008)$

(10.7)

$(1,045)$

$(0.008)$
(10.1)
63,109

438,286

\footnotetext{
Notes: Each panel corresponds to a different SSCs reform: the increase in pension SSCs between 2000 and 2005 (Panel A); the uncapping of family SSCs in 1989 and 1990 (Panel B); and the uncapping of health care SSCs in 1981 and 1983 (Panel C). Summary statistics are presented for the reference year and for the baseline sample of full-time and full-year workers. They are provided separately for workers whose earnings in the pre-reform year were in the range of 1 to 1.4 times the SST (treatment group) and for workers whose earnings in the pre-reform year were in the range of 0.9 to 1 times the SST (control group). Gross earnings and labor cost are expressed in 2010 euros. Standard deviations are shown in parentheses. Mean differences between the treatment and control groups are significant at the 1 percent level for all variables. Sources: DADS Panel 2010; TAXIPP 0.4.
} 
Table 3 - Pass-Through of Employer SSCs to Workers: Difference-in-Differences Estimates

\begin{tabular}{|c|c|c|c|c|}
\hline Reference year $\left(t_{0}\right)$ : & $\begin{array}{r}\text { Refo } \\
\text { Increase } \\
\text { SSCs abo } \\
(19\end{array}$ & $\begin{array}{l}\text { pension } 1 \\
\text { the SST } \\
\text { ) }\end{array}$ & $\begin{array}{c}\text { Reform } 2 \\
\text { Uncapping of } \\
\text { Family SSCs } \\
(1988)\end{array}$ & $\begin{array}{c}\text { Reform } 3 \\
\text { Uncapping of } \\
\text { Health Care SSCs } \\
(1980)\end{array}$ \\
\hline Dependent variable: & $\begin{array}{c}\log (\text { hourly wage }) \\
\text { (1) }\end{array}$ & $\begin{array}{c}\log (\text { earnings }) \\
(2)\end{array}$ & $\begin{array}{c}\log (\text { earnings }) \\
(3)\end{array}$ & $\begin{array}{c}\log (\text { earnings }) \\
(4)\end{array}$ \\
\hline
\end{tabular}

\section{Panel A. Baseline specification}

Pass-through estimates:

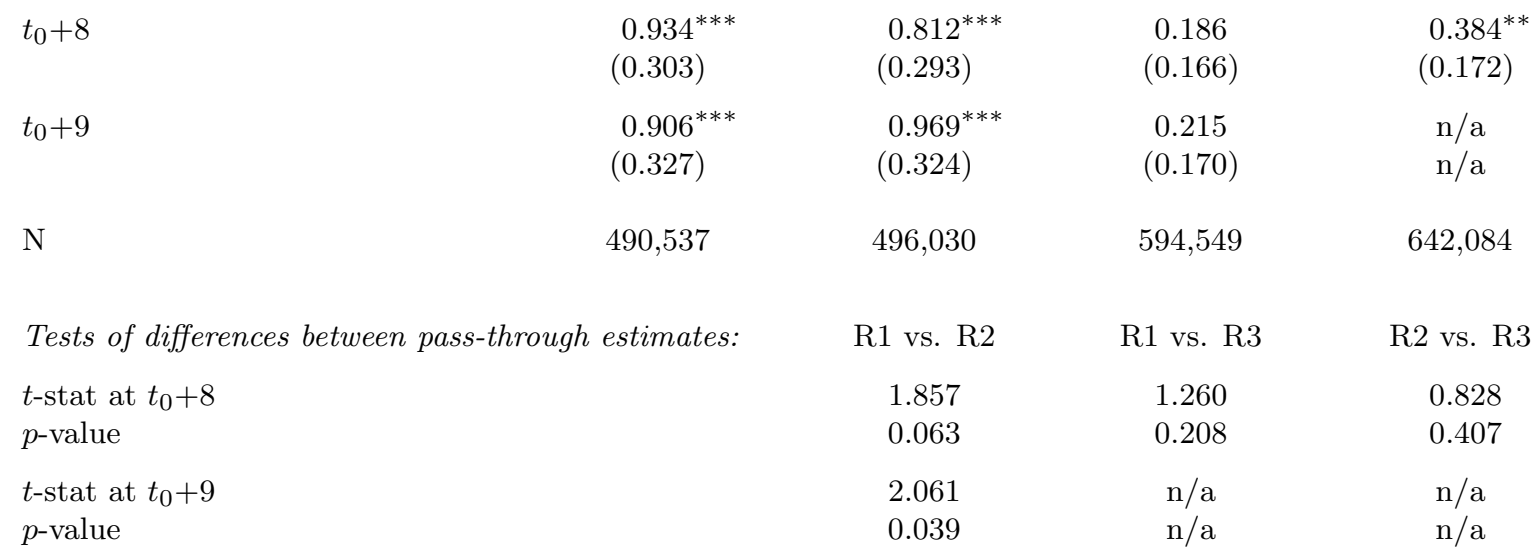

Panel B. Controlling for worker-specific trends

Pass-through estimates:

\begin{tabular}{|c|c|c|c|c|}
\hline$t_{0}+8$ & $\begin{array}{l}1.077^{* * *} \\
(0.318)\end{array}$ & $\begin{array}{l}1.112^{\text {*** }} \\
(0.291)\end{array}$ & $\begin{array}{c}0.100 \\
(0.224)\end{array}$ & $\begin{array}{c}0.209 \\
(0.133)\end{array}$ \\
\hline$t_{0}+9$ & $\begin{array}{l}1.064^{* * *} \\
(0.335)\end{array}$ & $\begin{array}{l}1.157^{* * *} \\
(0.308)\end{array}$ & $\begin{array}{c}0.061 \\
(0.229)\end{array}$ & $\begin{array}{l}n / a \\
n / a\end{array}$ \\
\hline $\mathrm{N}$ & 490,537 & 496,030 & 594,549 & 642,084 \\
\hline Tests of differences between pass-through & estimates: & $\mathrm{R} 1$ vs. $\mathrm{R} 2$ & R1 vs. R3 & $\mathrm{R} 2$ vs. R3 \\
\hline$t$-stat at $t_{0}+8$ & & 2.760 & 2.822 & 0.420 \\
\hline$p$-value & & 0.006 & 0.005 & 0.675 \\
\hline$t$-stat at $t_{0}+9$ & & 2.856 & $\mathrm{n} / \mathrm{a}$ & $\mathrm{n} / \mathrm{a}$ \\
\hline$p$-value & & 0.004 & $\mathrm{n} / \mathrm{a}$ & $\mathrm{n} / \mathrm{a}$ \\
\hline
\end{tabular}

Notes: The different columns correspond to different SSCs reforms: the increase in pension SSCs between 2000 and 2005 (columns 1 and 2); the uncapping of family SSCs in 1989 and 1990 (column 3); and the uncapping of health care SSCs in 1981 and 1983 (column 4). The estimates are obtained from a difference-in-difference specification using an unbalanced panel of workers who are observed in the last pre-reform year and at least another year. The treatment group includes workers whose gross earnings in the last pre-reform year were 1 to 1.4 times the SST that year. These workers experienced an increase in their average SSC rate due to the reform under study. The control group includes workers whose gross earnings in the last pre-reform year were 0.9 to 1 times the SST that year. These workers did not experience a change in their average SSC rate due to the reform. In Panel A, the estimated pass-through to workers of the increase in employer SSCs is obtained from a 2SLS regression of $\log$ (gross hourly wage) (column 1) or $\log$ (gross earnings) (columns 2 to 4 ) on $\log (1+$ SSC rate), where $\log (1+\mathrm{SSC}$ rate) is instrumented by the interaction between the treatment group and year dummies. In Panel B, the pass-through estimates are obtained from an augmented specification that controls for worker-specific trends in addition to individual and year fixed effects. Standard errors clustered at the individual level are shown in parentheses. Both panels report $t$-tests of between-reform differences in the estimated pass-through rates on $\log ($ earnings $)$ at $t_{0}+8$ and $t_{0}+9 .{ }^{* * *} \mathrm{p}<0.01,{ }^{* *} \mathrm{p}<0.05,{ }^{*} \mathrm{p}<0.1$.

Sources: DADS Panel 2010; TAXIPP 0.4. 
Table 4 - Summary of Empirical Studies of Payroll Tax Incidence using Micro Data

\begin{tabular}{|c|c|c|c|c|c|c|}
\hline Study & Country & Payroll Tax/Reform & Tax-benefit linkage? & Method & $\begin{array}{c}\text { Unit of } \\
\text { observation }\end{array}$ & $\begin{array}{c}\text { Estimated rate of } \\
\text { pass-through to workers }\end{array}$ \\
\hline $\begin{array}{l}\text { Gruber and } \\
\text { Krueger (1991) }\end{array}$ & U.S. & $\begin{array}{l}\text { Expansion of workers' } \\
\text { compensation insurance program } \\
\text { during the period 1979-1988 }\end{array}$ & Strong & $\begin{array}{l}\text { DD: variation in workers' compensation } \\
\text { rates across states and over time }\end{array}$ & Worker & $\begin{array}{l}0.865(0.184) \\
\text { (Table } 5, \text { column } 7)\end{array}$ \\
\hline Gruber (1994) & U.S. & $\begin{array}{l}\text { State and federal mandated } \\
\text { maternity benefits during the } \\
\text { period 1975-1979 }\end{array}$ & Strong & $\begin{array}{l}\text { DDD: variation in cost of mandate between } \\
\text { different groups of workers across states } \\
\text { and over time }\end{array}$ & Worker & $\begin{array}{l}1.09 / 1.56 / 2.14 \\
(\text { Table } 5, \text { columns (i)-(iii)) }\end{array}$ \\
\hline Gruber (1997) & Chile & $\begin{array}{l}\text { Reduction in employer payroll } \\
\text { taxes induced by privatization of } \\
\text { Social Security system in } 1981\end{array}$ & Strong & $\begin{array}{l}\text { DDD: variation in payroll tax rates } \\
\text { between white-collar and blue-collar } \\
\text { workers across firms over time }\end{array}$ & Firm & $\begin{array}{l}1.022(0.180) \\
\text { (Table } 3 \text {, column } 1)\end{array}$ \\
\hline $\begin{array}{l}\text { Anderson and } \\
\text { Meyer (1997) }\end{array}$ & U.S. & $\begin{array}{l}\text { Unemployment insurance over } \\
\text { the period } 1978-1984\end{array}$ & Uncertain & $\begin{array}{l}\text { DD: variation in unemployment insurance } \\
\text { tax rates across firms over time }\end{array}$ & Firm & $\begin{array}{l}0.715(0.292) \\
\text { (Table } 3, \text { column } 1)\end{array}$ \\
\hline $\begin{array}{l}\text { Anderson and } \\
\text { Meyer (2000) }\end{array}$ & U.S. & $\begin{array}{l}\text { Adoption of experience-rated } \\
\text { unemployment insurance by } \\
\text { Washington State in } 1985\end{array}$ & Uncertain & $\begin{array}{l}\text { DD: variation in unemployment insurance } \\
\text { tax rates across firms over time }\end{array}$ & Worker & $\begin{array}{l}1.427(1.191) \\
\text { (Table } 3, \text { column } 1)\end{array}$ \\
\hline $\begin{array}{l}\text { Komamura and } \\
\text { Yamada (2004) }\end{array}$ & Japan & $\begin{array}{l}\text { Introduction of mandatory } \\
\text { long-term care insurance in } 2000\end{array}$ & $\begin{array}{l}\text { Yes (health insurance) } \\
\text { No (long-term care) }\end{array}$ & $\begin{array}{l}\text { DD: variation in employers' contribution } \\
\text { rates to health insurance and long-term } \\
\text { care insurance over time }\end{array}$ & Firm & $\begin{array}{l}\text { Health insurance: } 1.20(0.2) \\
\text { Long-term care insurance: } 0.2(0.2) \\
\text { (Tables } 1 \text { and } 2, \text { FE model) }\end{array}$ \\
\hline $\begin{array}{l}\text { Baicker and } \\
\text { Chandra (2006) }\end{array}$ & U.S. & $\begin{array}{l}\text { Employer-provided health } \\
\text { insurance over the period } \\
1996-2002\end{array}$ & Strong & $\begin{array}{l}\text { IV: malpractice payments used as } \\
\text { instrumental variable for health premiums }\end{array}$ & Worker & $\begin{array}{l}\text { Covered workers: } 1.00(0.20) \\
\text { Non-covered workers: }-0.15(0.30) \\
\text { (based on Table 4. columns } 1 \text { and } 3)^{a}\end{array}$ \\
\hline Murphy (2007) & U.S. & $\begin{array}{l}\text { Unemployment insurance over } \\
\text { the period } 1992-2002\end{array}$ & Uncertain & $\begin{array}{l}\text { DD: variation in unemployment insurance } \\
\text { tax rates across firms over time }\end{array}$ & Worker & $\begin{array}{l}0.23(1.01) \\
\text { (Table 6, Panel A, column 3) }\end{array}$ \\
\hline $\begin{array}{l}\text { Kugler and Kugler } \\
(2009)\end{array}$ & Columbia & $\begin{array}{l}\text { Sharp increase in payroll taxes } \\
\text { for pensions and health following } \\
\text { the } 1993 \text { Social Security reform }\end{array}$ & None & $\begin{array}{l}\text { DD: variation in payroll tax rates across } \\
\text { firms over time }\end{array}$ & Firm & $\begin{array}{l}0.2346(0.0883) \\
\text { (Table } 3, \text { column } 1)\end{array}$ \\
\hline $\begin{array}{l}\text { Korkeamäki and } \\
\text { Uusitalo (2009) }\end{array}$ & Finland & $\begin{array}{l}\text { Payroll tax reduction in Northern } \\
\text { Finland between } 2003 \text { and } 2005\end{array}$ & None & $\begin{array}{l}\text { DD: reform-induced variation in payroll } \\
\text { taxes between target and control regions } \\
\text { and over time }\end{array}$ & Firm & $\begin{array}{l}0.49(0.24) \\
(\text { based on Table } 7, \text { column } 2)^{b}\end{array}$ \\
\hline $\begin{array}{l}\text { Bennmarker et al. } \\
(2009)\end{array}$ & Sweden & $\begin{array}{l}\text { Payroll tax reduction in Northern } \\
\text { Sweden in } 2002\end{array}$ & None & $\begin{array}{l}\text { DD: reform-induced variation in payroll } \\
\text { taxes between target and control regions } \\
\text { and over time }\end{array}$ & Firm & $\begin{array}{l}0.23(0.08) \\
\text { (Table } 4, \text { column } 3)\end{array}$ \\
\hline $\begin{array}{l}\text { Cruces et al. } \\
(2010)\end{array}$ & Argentina & $\begin{array}{l}\text { Reform mandating new fully } \\
\text { funded pension system in } 1993\end{array}$ & Strong & $\begin{array}{l}\text { DD: variation in payroll taxes across } \\
\text { geographical areas and over time }\end{array}$ & $\begin{array}{l}\text { Area-level } \\
\text { aggregates }\end{array}$ & $\begin{array}{l}0.501(0.192) \\
\text { (Table 4, column 2) }\end{array}$ \\
\hline Saez et al. (2012) & Greece & $\begin{array}{l}\text { Cohort-based payroll tax increase } \\
\text { in } 1992\end{array}$ & None & $\begin{array}{l}\text { Regression discontinuity based on date of } \\
\text { entry in the labor force }\end{array}$ & Worker & $\begin{array}{l}0.295(0.182) \\
(\text { based on Table } 5, \text { column } 1)^{c}\end{array}$ \\
\hline $\begin{array}{l}\text { Lehmann et al. } \\
(2013)\end{array}$ & France & $\begin{array}{l}\text { Reduction of payroll tax around } \\
\text { the minimum wage during the } \\
\text { period 2003-2006 }\end{array}$ & None & $\begin{array}{l}\text { IV regression using predicted change in tax } \\
\text { rates }\end{array}$ & Worker & $\begin{array}{l}0.134(0.260) \\
(\text { based on Table } 2, \text { column } 3)^{d}\end{array}$ \\
\hline Adam et al. (2019) & U.K. & $\begin{array}{l}\text { Reforms of National Insurance } \\
\text { Contributions between } 1982 \text { and } \\
2015\end{array}$ & None & $\begin{array}{l}\text { IV regression using predicted change in tax } \\
\text { rates }\end{array}$ & Worker & $\begin{array}{l}-0.009(0.109) \\
(\text { based on Table } 3, \text { column } 6)^{e}\end{array}$ \\
\hline Saez et al. (2019) & Sweden & $\begin{array}{l}\text { Payroll tax reduction for young } \\
\text { workers (aged } 26 \text { or less) between } \\
2007 \text { and } 2009\end{array}$ & None & $\begin{array}{l}\text { DD: variation in payroll tax rates between } \\
\text { age groups and over time }\end{array}$ & Worker & $\begin{array}{l}\text { Medium run: } 0.085(0.046) \\
(\text { based on Table } 1 \text {, Panel A) }\end{array}$ \\
\hline
\end{tabular}

Notes: DD: differences-in-differences. DDD: triple differences. IV: instrumental variables. Standard errors of point estimates are shown in parentheses. ${ }^{a}$ : The estimated pass-through rate in Baicker and Chandra (2006) is computed using the fact that health insurance premiums are about 20 percent of wage and salary income at the mean. ${ }^{b}$ : The estimated pass-through rate in Korkeamäki and Uusitalo (2009) is computed using the fact that the Finnish payroll tax experiment reduced payroll taxes by 4.1 percent on average. ${ }^{c}$ : The estimated pass-through rate in Saez et al. (2012) is computed as (minus) the ratio between the estimated discontinuity in the $\log$ of posted earnings $w$ and the estimated discontinuity in log $\left(1+\tau_{R}\right)$, where $\tau_{R}$ denotes the employer marginal payroll tax rate, and the standard error of the estimated pass-through rate is computed using the delta method. $d$ : the estimated pass-through rate to workers in Lehmann et al. (2013) is computed as one minus the estimated pass-through rates to firms (absolute value of coefficient $\beta_{\rho}^{P}$ ). ${ }^{e}$ : the estimated pass-through rate to workers in Adam et al. (2019) is computed as one minus the estimated pass-through rates to firms (absolute value of coefficient $\beta_{X, \rho}^{R, 0}$ ). ${ }^{f}:$ the estimated pass-through rate to workers in Saez et al. (2019) is computed as one minus the estimated pass-through rate to firms. 
Table 5 - Meta-Analysis: Regression Estimates

\begin{tabular}{lccc}
\hline & \multicolumn{3}{c}{ Dependent variable: estimated pass-through of SSCs to workers } \\
\cline { 2 - 4 } & $(1)$ & $(2)$ & $(3)$ \\
\hline Constant & $0.150^{* *}$ & 0.300 & 0.364 \\
& $(0.056)$ & $(0.208)$ & $(0.485)$
\end{tabular}

Tax-benefit linkage

None

ref

ref.

ref.

Strong

$\begin{array}{ccc}0.882^{* * *} & 0.834^{* * *} & 1.002^{* * *} \\ (0.134) & (0.140) & (0.146) \\ 0.641^{*} & 0.581^{*} & 0.384 \\ (0.312) & (0.328) & (0.201)\end{array}$

Uncertain

$(0.312)$

(0.328)

$(0.201)$

Country/Region

U.S.

ref.

ref.

Europe

$-0.041$

$-0.308$

Rest of the world

(0.231)

(0.994)

Time period

1970s and 1980s

ref.

ref.

1990s

$-0.269$

(0.194)

$-0.194$

$-0.036$

(0.381)

$2000 \mathrm{~s}$

(0.189)

$-0.121$

(0.296)

Unit of observation

Worker

ref.

Firm

0.231

$(0.605)$

Market-level

0.555

$(0.752)$

GDP growth

0.035

$(0.476)$

Inflation

0.026

(0.051)

Unemployment rate

$-0.056$

(0.064)

Strictness of employment protection

0.310

(0.343)

Union density

$-0.002$

$(0.006)$

Adjusted $R$-squared

0.644

0.621

0.379

$\mathrm{N}$

21

21

21

Notes: This table reports the results of the meta-regression analysis of the literature on payroll tax incidence. The models are linear regressions with the study-specific pass-through estimate as dependent variable. The time period refers to the decade when the earliest reform being analyzed in the study took place. Control variables are computed as means over the post-reform years considered in each study. All control variables are mean centered. Robust standard errors are shown in parentheses. In column 3, an arbitrary value is assigned to missing values for the OECD indicators of strictness of employment protection legislation and union density, and a set of dummy variables is created with each variable being equal to one if the corresponding information is missing. ${ }^{* *} \mathrm{p}<0.01,{ }^{* *} \mathrm{p}<0.05,{ }^{*} \mathrm{p}<0.1$.

Sources: The pass-through estimates and the assessment of tax-benefit linkage for each study can be found in Table 4 . The data sources for the control variables are detailed in Appendix Table D5. 
(For Online Publication)

Appendix to

\title{
Does Tax-Benefit Linkage Matter for the Incidence of Social Security Contributions?
}

\author{
Antoine Bozio Thomas Breda Julien Grenet
}

July 2020

This Appendix provides complements to the theoretical framework presented in Section 2 (Appendix A), institutional details (Appendix B), perceptions of the reforms from press and labor union archives (Appendix C), information on the data sources (Appendix D), additional pass-through estimates (Appendix E), an analysis of heterogeneity (Appendix F), and robustness checks (Appendix $\mathrm{G}$ ).

\section{List of Appendices}

A Theory Appendix $\quad$ A-2

$\begin{array}{lll}\text { B Institutional Details } & \text { A-16 }\end{array}$

$\begin{array}{ll}\text { C Perceptions of the SSC Reforms } & \text { A-25 }\end{array}$

$\begin{array}{ll}\text { D Data Sources } & \text { A-29 }\end{array}$

$\begin{array}{ll}\text { E Pass-Through Estimates } & \text { A-34 }\end{array}$

$\begin{array}{lll}\text { F Heterogeneity Analysis } & \text { A-35 }\end{array}$

$\begin{array}{ll}\text { G Robustness Checks } & \text { A-38 }\end{array}$

$\begin{array}{lr}\text { Appendix References } & \text { A-47 }\end{array}$ 


\section{A Theory Appendix}

This appendix derives general formulas for the pass-through to workers of employer SSCs with tax-benefit linkage under four different labor market models: (i) partial equilibrium in competitive labor markets, (ii) general equilibrium in competitive labor market with two types of workers, (iii) individual-level bargaining, and (iv) collective bargaining with two types of workers.

Section A.1 presents the general setup, specifies our definition of the tax-benefit linkage, and provides a general incidence result in the case of full linkage. Sections A.2 to A.5 derive the pass-through formulas under the four different models. A final independent section clarifies the relationship between the pass-through rate of SSCs to wages and the elasticity of taxable earnings that we measure for Reform 2 and Reform 3.

\section{A.1 Setup and General Overview}

Production function. We consider a representative firm that uses $n+1$ factors of production: capital (denoted by $K$ ) and $n$ types of labor inputs, which we denote by $L_{1}$ to $L_{n}$. In particular, the labor inputs include those of the treated and control workers that we consider in the empirical analysis, which are denoted by $L_{T}$ and $L_{C}$, respectively. The firm's production function $F\left(K, L_{1}, \ldots, L_{n}\right)$ is assumed to be homogeneous of degree one and to exhibit positive and diminishing marginal products.

A potential caveat when linking the theory to our research design is that we empirically define treated and control workers based on their wage levels rather than on an exogenous measure of skills such as educational attainment. The models discussed in this appendix are used to study the market response to changes in SSCs, and the treatment and control groups are empirically defined as a function of wages prior to the reforms, which can be considered as exogenous to the SSC increases. Our approach, therefore, consists in defining workers with different pre-reform wage levels as different inputs in production, and to evaluate how their wages respond to changes in SSCs under alternative models.

For simplicity, we assume that all SSCs are nominally paid by the firm and we denote by $w_{k}$ the posted wage (or gross wage, which is here equal to the net wage) of each worker of type $k$. The corresponding labor cost to the firm is denoted by $z_{k} \equiv w_{k}\left(1+\tau_{k}\right)$, where $\tau_{k}$ is the rate of SSCs that are nominally paid by the firm for a worker with a posted wage $w_{k}$.

The firm's after-tax profit is given by

$$
\Pi=p F\left(K, L_{1}, \ldots, L_{n}\right)-r K-\sum_{k} z_{k} L_{k}
$$

where $p$ is the output price and $r$ is the cost of capital. Corporate taxes are ignored for simplicity. When computing the pass-through formulas under the general competitive equilibrium and the collective bargaining models, we will assume that there are only two types of inputs, which are the theoretical counterparts of the control $\left(L_{C}\right)$ and treated $\left(L_{T}\right)$ workers in our empirical analysis. We further normalize the output price $p$ to be 1 without loss of generality. 
Labor supply with tax-benefit linkage. On the supply side, we denote by $\tilde{w}_{k} \equiv$ $w_{k}\left(1+q \tau_{k}\right)$ the perceived wage of workers of type $k$, i.e., their gross wage augmented by the perceived benefits from employer SSCs. The tax-benefit linkage is modeled as a reduced-form parameter $q$ whose value lies in the interval $[0,1]$. This parameter, which is assumed to be constant across worker types, measures the extent to which workers value employer SSCs relative to cash income. It subsumes two dimensions of tax-benefit linkage that we do not model separately: (i) the actuarial fairness of SSCs, which determines the degree of linkage between SSCs and future benefit entitlements at the individual level, and (ii) the salience of this linkage to workers.

If one assumes perfect information (strong salience), the degree of tax-benefit linkage can be measured as the ratio between the expected flow of benefits accrued from additional SSCs paid, and the value of this flow if it had been instead saved at the market rate of return $r$ (in the context of pension SSCs, see Lindbeck and Persson, 2003). This purely actuarial approach neglects the fact that SSCs may force workers to over-save in comparison to their counterfactual savings in the absence of social insurance. It also ignores that forcing agents to save may be beneficial if they are too myopic to fully internalize the future benefits of their savings. Measuring the salience of tax-benefit linkage (the extent to which agents are informed of and understand the linkage) and its exact consequences on workers' utility is a challenging task. For these reasons, we simply model the linkage through a single reduced-form parameter $q$ that enters the indirect utility function and represents the present value of the SSCs paid in monetary terms. This indirect utility may be seen as the result from the maximization of a utility function $U\left(C_{k}, L_{k}\right)$, which depends on consumption $C_{k}$ and employment $L_{k}$, under the constraint $C_{k} \leq w_{k}\left(1+q \tau_{k}\right) L_{k}+R_{k}$, where $R_{k}$ denotes non-labor income. The case with $q=1$ represents fully salient linkage, i.e., a situation akin to the quid pro quo tax described in the classic public finance literature (Musgrave, 1968). The opposite polar case with $q=0$ means that there is no linkage or that there is linkage but that future benefits are not perceived by workers because of lack of salience.

We model the extensive margin of labor supply by assuming that workers of type $k$ have an indirect utility function $V\left(\tilde{w}_{k}, R_{k}\right)=V\left(w_{k}\left(1+q \tau_{k}\right), R_{k}\right)$, which is increasing in their perceived wage $\tilde{w}_{k}$ and non-labor income $R_{k}$. The labor supply of a worker of type $k$ can then be expressed as

$$
L_{k}^{S}=L_{k}^{S}\left(\tilde{w}_{k}, R_{k}\right)=L_{k}^{S}\left(w_{k}\left(1+q \tau_{k}\right), R_{k}\right), \quad k=1, \ldots, n .
$$

Denoting $\eta_{k}^{S}$ the labor supply elasticity of workers of type $k$, we have

$$
\eta_{k}^{S} \equiv \frac{\mathrm{d} \ln L_{k}^{S}}{\mathrm{~d} \ln w_{k}}=\left(1+q \tau_{k}\right) w_{k} \frac{l_{k}^{S}}{L_{k}^{S}} \quad k=1, \ldots, n
$$

where we use $l_{k}^{S} \equiv \partial L_{k}^{S} / \partial \tilde{w}_{k}$ to denote the partial derivative of the labor supply of type- $k$ workers with respect to the perceived wage $\tilde{w}_{k}$. Since non-labor income $R_{k}$ is assumed to be independent of SSCs, it will be omitted in future notations. 
Definition of SSC pass-through: individual vs. firm level. In our setup, we consider two groups of workers: treated workers $\left(L_{T}\right)$, for whom employer SSCs change as the result of the reform being studied, and control workers $\left(L_{C}\right)$, whose employer SSCs are unchanged.

We define the pass-through of employer SSCs to workers at the individual level as the pass-through of SSCs to the wages of treated workers relative to control workers. This corresponds to the main empirical specification in the paper. Pass-through is understood at the individual level as the individual wages of the treated workers are directly affected by the change in SSCs.

We define the pass-through of employer SSCs to workers at the firm level as the pass-through of employer SSCs to control workers, i.e., to workers in a firm affected by the change in employer SSCs but whose labor cost is nominally unchanged by the reform under study. This tax shifting can be understood as firm-level pass-through in the sense that individual-level pass-through can be zero (no change in the relative wages of treated and control workers) while employer SSCs are shifted to all workers in the firm, whether treated or control.

A general statement on the effect of tax-benefit linkage. Before deriving the formulas for the pass-through rate of SSCs to workers under various models of the labor market, we provide a general statement regarding the effect of tax-benefit linkage in these models. Under full tax-benefit linkage $(q=1)$, it is straightforward to show that SSCs are fully passed through to workers at the individual level, in the form of lower wages.

With full tax-benefit linkage, the firm's surplus and profit functions, as well as its labor demand for workers of type $k$, depend on the labor cost, $z_{k}$, and on the price of other inputs. Similarly, with full tax-benefit linkage, the indirect utility and labor supply of type- $k$ workers depend on $z_{k}\left(=\tilde{w}_{k}\right)$ as well as on non-labor income, $R_{k}$.

Assume that the economy is initially at equilibrium, with the (unique) equilibrium resulting from the equalization of demand and supply for all types of labor and non-labor inputs, or from Nash bargaining, i.e., the maximization of a surplus function that depends on workers' utility function and the representative firm's profit function. Let $z_{k}^{*}$ denote the equilibrium labor cost of workers of type $k$. Now consider a small perturbation to the SSC rate that applies to workers of type $k$, which we denote by $\mathrm{d} \tau_{k}$. The key point is that this tax change does not affect the equations describing the labor market equilibrium. This is because all relevant quantities (supply, demand or surpluses that are jointly maximized by firms and workers) depend on $z_{k}^{*}$ and other parameters that are not impacted by the tax change. As a consequence, $z_{k}^{*}$ continues to satisfy the equilibrium conditions and the former equilibrium remains unchanged. To put it differently, if $z_{k}$ does not vary following the tax change, supply and demand functions are not affected, nor is the surplus function that is bargained over in the bargaining setting, implying that $z_{k}^{*}$ remains an equilibrium solution. This implies that with full tax-benefit linkage, changes in the SSCs of workers of type $k$ are fully passed through to these workers in the form of lower wages.

General overview of the results. Before discussing the details of the four models, Table A1 presents an overview of the results by showing the predicted pass-through of 
employer SSCs under several polar cases. A pass-through equal to one indicates full shifting to workers. When we consider individual-level pass-through, this means that treated workers bear the full impact of the change in employer SSCs relative to control workers. When we consider firm-level pass-through, a value of one means that control and treated workers collectively bear the full impact of the change in SSCs.

Table A1 - Pass-through of Employer SSCs to Workers for Different Models of the Labor Market: Polar Cases

Models

Partial General Individual Collective

Equilibrium Equilibrium Bargaining Bargaining

(1)

(2)

(3)

(4)

Panel A. Case with full tax-benefit linkage $(q=1)$

Individual-level pass-through (relative pass-through)

Labor demand $\left(\eta^{D}\right)$ vs. labor supply $\left(\eta^{S}\right)$ elasticities :

- $\left|\eta^{D}\right| \ll\left|\eta^{S}\right|$

- $\left|\eta^{D}\right| \gg\left|\eta^{S}\right|$

Elasticity of substitution $(\sigma)$ vs. elasticity of labor supply $\left(\eta^{S}\right)$ :

- Low $\left(\sigma \ll \eta^{S}\right)$

- High $\left(\sigma \gg \eta^{S}\right)$

Worker's bargaining power $\left(\phi_{k}\right)$ :

- Low $\left(\phi_{k}=0\right)$

- High $\left(\phi_{k}=1\right)$

Unions' aversion to inequality $(\theta)$ :

- Low $(\theta \rightarrow 0)$

- High $(\theta \rightarrow \infty)$

Panel B. Case with no tax-benefit linkage $(q=0)$

Individual-level pass-through (relative pass-through)

Labor supply $\left(\eta^{S}\right)$ vs. labor demand elasticity $\left(\eta^{D}\right)$ :

$-\left|\eta^{D}\right| \ll\left|\eta^{S}\right|$

Elasticity of substitution $(\sigma)$ vs. elasticity of labor supply $\left(\eta^{S}\right)$ :

- Low $\left(\sigma \ll \eta^{S}\right)$

- High $\left(\sigma \gg \eta^{S}\right)$

Worker's bargaining power $\left(\phi_{k}\right)$ :

- Low $\left(\phi_{k}=0\right)$

- High $\left(\phi_{k}=1\right)$

Unions' aversion to inequality $(\theta)$ :

- Low $(\theta \rightarrow 0)$

- High $(\theta \rightarrow \infty)$

Firm-level pass-through (impact on non-treated workers)

Labor supply $\left(\eta^{S}\right)$ vs. substitution elasticity $(\sigma)$ :

- Low $\left(\sigma \ll \eta^{S}\right)$

- High $\left(\sigma \gg \eta^{S}\right)$

Unions' aversion to inequality $(\theta)$ and bargaining power $(\phi)$ :

$-\phi=0$

- $\phi=1 ; \theta \rightarrow 0$

- $\phi=1 ; \theta \rightarrow \infty$

Panel A of Table A1 presents the results in the case with full tax-benefit linkage. In all four models, we have full shifting to workers at the individual level, in line with the general 
statement mentioned above. This result does not depend on the values of the elasticity parameters or on workers' bargaining power. It is straightforward to show that in this case, control workers are not affected by changes in SSCs and hence that the firm-level pass-through is zero in all models (results are omitted in the table).

Panel B presents the results in the case of no tax-benefit linkage. Here, the pass-through of SSCs depends on the model and the values of specific parameters. With models of competitive labor markets, the standard prediction is that SSCs are fully passed through to workers at the individual level if either the elasticity of labor demand (partial equilibrium) or the elasticity of substitution between treated and control workers (general equilibrium) are much larger than the labor supply elasticity. Conversely, results of limited pass-through at the individual level can only be rationalized in these models by assuming that the labor demand or substitution elasticities are much smaller than the labor supply elasticity. Collective bargaining models provide an alternative rationalization for why SSCs could not be shifted to workers at the individual level while being shifted at the level of the firm, in the case where unions have strong bargaining power and a high degree of aversion to wage inequality within the firm.

\section{A.2 Partial Equilibrium with Market Clearing and Linkage}

For the sake of completeness, we start by deriving the simple partial equilibrium formula for the pass-through of SSCs with tax-benefit linkage (Kotlikoff and Summers, 1987; Gruber, 1997).

The labor supply of workers of type $k$ is given by Equation (A.1). On the demand side, the partial equilibrium approach ignores possible substitutions between inputs and assumes that the labor demand for workers of type $k$ depends only on their labor cost, i.e.,

$$
L_{k}^{D}=L_{k}^{D}\left(z_{k}\right)=L_{k}^{D}\left(w_{k}\left(1+\tau_{k}\right)\right), \quad k=1, \ldots, n
$$

Denoting $\eta_{k}^{D}$ the labor demand elasticity of workers of type $k$, we have

$$
\eta_{k}^{D} \equiv \frac{\mathrm{d} \ln L_{k}^{D}}{\mathrm{~d} \ln w_{k}}=\left(1+q \tau_{k}\right) w_{k} \frac{l_{k}^{D}}{L_{k}^{D}}, \quad k=1, \ldots, n,
$$

where $l_{k}^{D} \equiv \partial L_{k}^{D} / \partial z_{k}$ denotes the partial derivative of the labor supply of type- $k$ workers with respect to the labor cost $z_{k}$.

Totally differentiating the labor supply and demand conditions (A.1) and (A.3) yields

$$
\mathrm{d} \ln \left(L_{k}^{S}\right)=\eta_{k}^{S}\left(\mathrm{~d} \ln \left(w_{k}\right)+\mathrm{d} \ln \left(1+q \tau_{k}\right)\right), \quad k=1, \ldots, n
$$

and

$$
\mathrm{d} \ln \left(L_{i}^{D}\right)=\eta_{k}^{D}\left(\mathrm{~d} \ln \left(w_{k}\right)+\mathrm{d} \ln \left(1+\tau_{k}\right)\right), \quad k=1, \ldots, n,
$$

where $\eta_{k}^{S}$ and $\eta_{k}^{D}$ are the labor supply and labor demand elasticities for workers of type $k$.

Equating variations in supply and demand and rearranging terms, we obtain the 
following formula for the pass-through rate of SSCs to workers:

$$
\frac{\mathrm{d} \ln w_{k}}{\mathrm{~d} \ln \left(1+\tau_{k}\right)}=-\frac{\eta_{k}^{D}-q \frac{1+\tau_{k}}{1+q \tau_{k}} \eta_{k}^{S}}{\eta_{k}^{D}-\eta_{k}^{S}}, \quad k=1, \ldots, n
$$

In the absence of tax-benefit linkage $(q=0)$, this expression simplifies to the standard incidence formula in which the pass-through rate of SSCs to workers depends solely on the relative magnitude of the labor supply and labor demand elasticities: if $\left|\eta_{k}^{D}\right| \gg\left|\eta_{k}^{S}\right|$, SSCs are fully passed through to workers; if $\left|\eta_{k}^{D}\right| \ll\left|\eta_{k}^{S}\right|$, the pass-through to workers is zero. With full linkage $(q=1)$, SSCs are fully passed through to workers irrespective of the labor demand and supply elasticities.

\section{A.3 General Equilibrium in Competitive Labor Markets}

In this section, we adapt Feldstein (1974)'s general equilibrium model of tax incidence to incorporate the tax-benefit linkage in the analysis of the pass-through of SSCs to workers.

We assume a one sector model in which the representative firms' output is produced using two labor inputs $\left(L_{T}\right.$ and $\left.L_{C}\right)$ with constant returns to scale:

$$
Y=F\left(L_{T}, L_{C}\right)
$$

The assumption of perfectly competitive markets implies that both types of workers are paid their marginal products. Denoting $F_{T}$ (resp. $F_{C}$ ) the partial derivative of the production function $F$ with respect to $L_{T}$ (resp. $L_{C}$ ), we have

$$
\begin{aligned}
& F_{T}=w_{T}\left(1+\tau_{T}\right), \\
& F_{C}=w_{C}\left(1+\tau_{C}\right) .
\end{aligned}
$$

The system is completed by the two labor supply equations:

$$
\begin{aligned}
& L_{T}^{S}=L_{T}^{S}\left(\tilde{w}_{T}\right)=L_{T}^{S}\left(w_{T}\left(1+q \tau_{T}\right)\right), \\
& L_{C}^{S}=L_{C}^{S}\left(\tilde{w}_{C}\right)=L_{C}^{S}\left(w_{C}\left(1+q \tau_{T}\right)\right) .
\end{aligned}
$$

We consider a small change in the rate of SSCs that applies to treated workers, $\mathrm{d} \tau_{T}$. The effects of this tax change on the equilibrium wages of treated and control workers can be analyzed by totally differentiating equations (A.5) through (A.9):

$$
\begin{aligned}
F_{T T} \cdot \mathrm{d} L_{T}+F_{C T} \cdot \mathrm{d} L_{C} & =\mathrm{d} w_{T}\left(1+\tau_{T}\right)+\mathrm{d} \tau_{T} \cdot w_{T} \\
F_{C T} \cdot \mathrm{d} L_{T}+F_{C C} \cdot \mathrm{d} L_{C} & =\mathrm{d} w_{C}\left(1+\tau_{C}\right), \\
\mathrm{d} L^{T} & =l_{T}^{S} \cdot\left[\mathrm{d} w_{T}\left(1+q \tau_{T}\right)+q \mathrm{~d} \tau_{T} \cdot w_{T}\right], \\
\mathrm{d} L^{C} & =l_{C}^{S} \cdot\left[\mathrm{d} w_{C}\left(1+q \tau_{C}\right)\right] .
\end{aligned}
$$

Note that because $F(\cdot, \cdot)$ is homogeneous of degree 1 , the marginal products $F_{T}$ and $F_{C}$ 
are homogeneous of degree 0. By Euler's theorem, this implies

$$
F_{C T}=\frac{F_{T T} \cdot F_{C C}}{F_{C T}}
$$

Pass-through to treated workers. Using Equation (A.14) to substitute for $F_{C T}$ in the system formed by equations (A.10) to (A.13), one obtains the following expression for the change in the wage rate of treated workers that results from a one percent change in the rate of SSCs that are levied on their wage:

$$
\frac{\mathrm{d} \ln w_{T}}{\mathrm{~d} \ln \left(1+\tau_{T}\right)}=\frac{1+\tau_{T}}{w_{T}} \cdot \frac{\mathrm{d} w_{T}}{\mathrm{~d} \tau_{T}}=-\frac{\left[F_{C C} \cdot l_{C}^{S}\left(\frac{1+q \tau_{C}}{1+\tau_{C}}\right)-1\right]+q F_{T T} \cdot l_{C}^{T}}{\left[F_{C C} \cdot l_{C}^{S}\left(\frac{1+q \tau_{C}}{1+\tau_{C}}\right)-1\right]+\left(\frac{1+q \tau_{T}}{1+\tau_{T}}\right) F_{T T} \cdot l_{T}^{S}}
$$

This expression can be rewritten as a function of economically meaningful parameters. Let $\alpha_{T} \equiv\left(1+\tau_{T}\right) w_{T} L_{T} / Y$ denote the labor share of treated workers. Using Euler's equations, the local elasticity of substitution between treated and control workers, which we denote by $\sigma$, can be shown to satisfy the following equations: ${ }^{\text {A.1 }}$

$$
\sigma=-\frac{\left(1+\tau_{T}\right) w_{T}\left(1-\alpha_{T}\right)}{F_{T T} \cdot L_{T}}
$$

and

$$
\sigma=-\frac{\left(1+\tau_{C}\right) w_{C} \alpha_{T}}{F_{C C} \cdot L_{C}}
$$

Using Equation (A.2) to replace the labor supply elasticities of treated and control workers in the elasticity of substitution formulas (A.16) and (A.17) yields

$$
F_{T T} \cdot l_{T}^{S}\left(\frac{1+q \tau_{T}}{1+\tau_{T}}\right)=-\left(1-\alpha_{T}\right)\left(\eta_{T}^{S} / \sigma\right)
$$

and

$$
F_{C C} \cdot l_{C}^{S}\left(\frac{1+q \tau_{C}}{1+\tau_{C}}\right)=-\alpha_{T}\left(\eta_{C}^{S} / \sigma\right)
$$

Plugging equations (A.18) and (A.19) into (A.15) and rearranging terms yields the following formula for the pass-through rate of SSCs to treated workers:

$$
\frac{\mathrm{d} \ln w_{T}}{\mathrm{~d} \ln \left(1+\tau_{T}\right)}=-\frac{1+\alpha_{T}\left(\eta_{C}^{S} / \sigma\right)+q\left(\frac{1+\tau_{T}}{1+q \tau_{T}}\right)\left(1-\alpha_{T}\right)\left(\eta_{T}^{S} / \sigma\right)}{1+\alpha_{T}\left(\eta_{C}^{S} / \sigma\right)+\left(1-\alpha_{T}\right)\left(\eta_{T}^{S} / \sigma\right)} .
$$

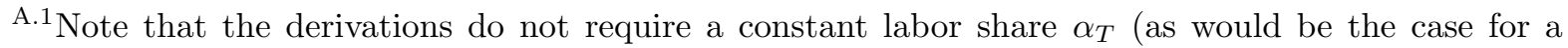
Cobb-Douglas production function) nor a constant elasticity of substitution (as for a CES production function); these parameters are only used to describe a local property of the production function in the neighborhood where the economy is operating when the tax change is introduced.
} 
Full tax-benefit linkage $(q=1)$ implies that SSCs are entirely shifted to treated workers. In the absence of linkage $(q=0)$, the pass-through rate depends on the relative magnitudes of the labor supply elasticities of treated and control workers, $\eta_{T}^{S}$ and $\eta_{C}^{S}$, and the elasticity of substitution between worker types, $\sigma$. If $\sigma$ is very large relative to $\eta_{T}^{S}$ and $\eta_{C}^{S}$, changes in SSCs are full passed through to treated workers. If, instead, $\eta_{T}^{S} \approx \eta_{C}^{S} \gg \sigma$, SSCs are passed through to treated workers in proportion of their share $\alpha_{T}$ in total output.

Pass-through to control workers. Using similar calculations as for the treated workers, we obtain the following formula for the pass-through of treated workers' SSCs to control workers:

$$
\frac{\mathrm{d} \ln w_{C}}{\mathrm{~d} \ln \left(1+\tau_{T}\right)}=-\frac{\alpha_{T}\left(\eta_{T}^{S} / \sigma\right)\left(\frac{1-q}{1+q \tau_{T}}\right)}{1+\alpha_{T}\left(\eta_{C}^{S} / \sigma\right)+\left(1-\alpha_{T}\right)\left(\eta_{T}^{S} / \sigma\right)} .
$$

Full tax-benefit linkage $(q=1)$ implies that control workers' wages are unaffected by changes in treated workers' SSCs. In the absence of linkage $(q=0)$, the pass-through to control workers depends on the relative magnitude of the labor supply elasticities of treated and control workers, $\eta_{T}^{S}$ and $\eta_{C}^{S}$, and the elasticity of substitution between both types of workers, $\sigma$. If $\sigma$ is very large relative to $\eta_{T}^{S}$, the wages of control workers are unaffected by changes in treated workers' SSCs. In the case where $\eta_{T}^{S} \approx \eta_{C}^{S}$, the pass-through to control workers simplifies to $\alpha_{T} /\left(1+\sigma / \eta_{T}^{S}\right)$. In this case, when labor supply elasticities are large relatively to $\sigma$, treated workers' SSCs are shifted to control workers in proportion of the labor share of treated workers $\alpha_{T}$ in total output.

Individual-level pass-through (relative wages). Combining equations (A.20) and (A.21) yields the following formula for the pass-through of an increase in the SSCs of treated workers to the relative wages of treated and control workers, which is the parameter that we estimate in our empirical analysis:

$$
\frac{\mathrm{d} \ln \left(\frac{w_{T}}{w_{C}}\right)}{\mathrm{d} \ln \left(1+\tau_{T}\right)}=-\frac{1+\alpha_{T}\left(\eta_{C}^{S} / \sigma\right)+\left(q\left(\frac{1+\tau_{T}}{1+q \tau_{T}}\right)-\alpha_{T}\right)\left(\eta_{T}^{S} / \sigma\right)}{1+\alpha_{T}\left(\eta_{C}^{S} / \sigma\right)+\left(1-\alpha_{T}\right)\left(\eta_{T}^{S} / \sigma\right)} .
$$

Full tax-benefit linkage $(q=1)$ implies a 100 percent pass-through of treated workers' SSCs to the wage ratio between treated and control workers. In the absence of linkage $(q=0)$, the pass-through rate depends on the relative magnitudes of the labor supply elasticities of treated and control workers, $\eta_{T}^{S}$ and $\eta_{C}^{S}$, and on the elasticity of substitution between worker types, $\sigma$. If $\sigma$ is very large, changes in treated workers' SSCs are fully passed through to the relative wages of treated workers. If $\eta_{T}^{S} \approx \eta_{C}^{S} \gg \sigma$, the relative wages of treated and control workers are unaffected by the tax change.

In the special case where the labor supply elasticities of treated and control workers 
are equal (i.e., $\eta_{T}^{S}=\eta_{C}^{S}=\eta^{S}$ ), the above pass-through formulas simplify to

$$
\begin{aligned}
& \frac{\mathrm{d} \ln w_{T}}{\mathrm{~d} \ln \left(1+\tau_{T}\right)}=-\frac{\sigma+\eta^{S}\left[\alpha_{T}+q\left(\frac{1+\tau_{T}}{1+q \tau_{T}}\right)\left(1-\alpha_{T}\right)\right]}{\sigma+\eta^{S}} \approx-\frac{\sigma+\eta^{S}\left[\alpha_{T}+q\left(1-\alpha_{T}\right)\right]}{\sigma+\eta^{S}}, \\
& \frac{\mathrm{d} \ln w_{C}}{\mathrm{~d} \ln \left(1+\tau_{T}\right)}=-\frac{\eta^{S} \cdot \alpha_{T}\left(\frac{1-q}{1+q \tau_{T}}\right)}{\sigma+\eta^{S}}, \\
& \frac{\mathrm{d} \ln \left(\frac{w_{T}}{w_{C}}\right)}{\mathrm{d} \ln \left(1+\tau_{T}\right)}=-\frac{\sigma+\eta^{S} \cdot q\left(\frac{1+\tau_{T}}{1+q \tau_{T}}\right)}{\sigma+\eta^{S}} \approx-\frac{\sigma+\eta^{S} \cdot q}{\sigma+\eta^{S}} .
\end{aligned}
$$

where the approximations hold when the SSC rate $\tau_{T}$ is small. Equation (A.25) corresponds to Equation (1) in the main text and clarifies the theoretical interpretation of our empirical estimates when a competitive labor market equilibrium is assumed (ignoring capital as well as interactions with the product market). Note that this relatively simple expression for the pass-through of employer SSCs to relative wages does not require a specific functional form for the production function as it holds for any function with constant returns to scale.

Firm-level pass-through (impact on control workers). Firm-level shifting of SSCs with limited effects on the relative wages of treated and control workers cannot be easily rationalized within the competitive model. To simplify the discussion, we consider the special case where the elasticity of labor supply is constant across worker types, i.e., $\eta_{T}^{S}=\eta_{C}^{S}=\eta^{S}$. It follows immediately from Equation (A.24) that in the case of full tax-benefit linkage $(q=1)$, the wages of control workers are not affected by a change in the tax levied on treated workers.

Let us now assume no linkage $(q=0)$. Equation (A.24) shows that the extent to which a tax change for treated workers is passed through to control workers depends on the labor share of treated workers, $\alpha_{T}$, and the relative magnitude of the elasticity of substitution, $\sigma$, and of the labor supply elasticity, $\eta^{S}$. The wage of control workers will respond only if the labor share of treated workers, $\alpha_{T}$, is large enough and if $\sigma$ is not too large relative to $\eta^{S}$. As discussed in the main text, the literature provides estimates of the elasticity of substitution between skilled and unskilled workers that are much larger than the range of accepted values for labor supply elasticities. The two groups of workers we consider in our study are defined according to their pre-reform wage levels. Our definition of these groups is such that the wage ratio between treated and control workers before the reform cannot exceed 50 percent. They appear close enough to be better substitutes than high- and low-skills workers in studies of the skill premium (who are typically defined as workers with at least some college education vs. workers with at most a high-school diploma). Based on Equation (A.25), this observation leads us to conclude that the limited pass-through of employer SSCs to the relative wages of treated and control workers that we find in the cases of Reforms 2 and 3 is difficult to reconcile with the standard competitive model of the labor market - unless implausible assumptions are made regarding the elasticity of substitution 
between control and treated workers. Similarly, our formula for the pass-through to control workers (Equation A.24) makes a large pass-through to control workers hardly plausible in the context of the standard model.

\section{A.4 Individual Wage Bargaining}

We now turn to models with wage bargaining (see Rogerson, Shimer and Wright, 2005, for a survey) and consider first a static individual-level Nash bargaining model in which firms and workers bargain over a matching rent.

Each worker of type $k$ aims at maximizing the wage premium generated by individual bargaining with the firm. This wage premium is equal to the difference between the worker's perceived wage $w_{k}\left(1+q \tau_{k}\right)$, i.e., her net wage plus her perceived benefits from additional SSCs, and her outside option, $\bar{w}_{k}$, which for simplicity is assumed to be fixed. Denoting $Q_{k}$ the output of a worker of type $k$ in the firm, the additional profit earned by the firm from employing the worker is $\pi_{k}=Q_{k}-w_{k}\left(1+\tau_{k}\right)$.

The surplus to be shared is $\left(1+q \tau_{k}\right) w_{k}-\bar{w}_{k}+\pi_{k}$. We assume Nash bargaining with worker bargaining power $\phi_{k} \in[0,1]$, so that the solution the bargaining problem is given by

$$
w_{k}^{*}=\underset{w_{k}}{\arg \max } \quad \phi_{k} \ln \left(\left(1+q \tau_{k}\right) w_{k}-\bar{w}_{k}\right)+\left(1-\phi_{k}\right) \ln \pi_{k}, \quad k=1, \ldots, n .
$$

The first order condition for the bargaining problem yields

$$
w_{k}^{*}=\left(1-\phi_{k}\right) \frac{\bar{w}_{k}}{1+q \tau_{k}}+\phi_{k} \frac{Q_{k}}{1+\tau_{k}}, \quad k=1, \ldots, n \text {. }
$$

Consider a small change in the SSC rate of type- $k$ workers, $d \tau_{k}$. After some algebra, the pass-through of SSCs to type- $k$ workers is found to be

$$
\frac{\mathrm{d} \ln w_{k}^{*}}{\mathrm{~d} \ln \left(1+\tau_{k}\right)}=-\frac{\left(1-\phi_{k}\right) q\left(\frac{1+\tau_{k}}{1+q \tau_{k}}\right)^{2} \bar{w}_{k}+\phi_{k} \cdot Q_{k}}{\left(1-\phi_{k}\right)\left(\frac{1+\tau_{k}}{1+q \tau_{k}}\right) \bar{w}_{k}+\phi_{k} \cdot Q_{k}}, \quad k=1, \ldots, n
$$

With perfect tax-benefit linkage $(q=1)$, there is a full pass-through of SSCs to workers. In the absence of linkage $(q=0)$, the pass-through formula simplifies to $-\frac{\phi_{k} \cdot Q_{k}}{\left(1-\phi_{k}\right)\left(1+\tau_{k}\right) \bar{w}_{k}+\phi_{k} \cdot Q_{k}}$. When workers have no bargaining power $\left(\phi_{k}=0\right)$, the pass-through to workers is zero. This is because employers capture the whole surplus and workers get their outside option. Tax increases lowering the surplus are therefore entirely shifted to employers. Indeed, even a small pass-through to workers would bring their wage below their outside option and cannot, therefore, be observed (the worker-firm match would not exist).

Conversely, if workers have full bargaining power $\left(\phi_{k}=1\right)$, SSCs are fully passed through to workers. The intuition for this result is similar: when workers have full bargaining power, they capture the entire surplus and any change in the surplus induced by tax changes is shifted to them. 


\section{A.5 Collective Wage Bargaining}

We now assume bargaining between a firm and a union or a coalition of unions representing all workers in the firm, who are of two types (treated and control).

We assume that the union's objective function $\Omega$ has the following form

$$
\Omega=\left(L_{T}\left[\left(1+q \tau_{T}\right) w_{T}-\bar{w}_{T}\right]^{1-\theta}+L_{C}\left[\left(1+q \tau_{C}\right) w_{C}-\bar{w}_{C}\right]^{1-\theta}\right)^{\frac{1}{1-\theta}},
$$

i.e., the union seeks to maximize the sum of workers' wage premiums but at the same time is averse to wage inequalities between the two types of workers. This functional form corresponds to a special class of functions characterized by constant relative inequality aversion as proposed by Atkinson (1970) in the context of inequality measurement. The union's degree of inequality aversion is captured by the parameter $\theta$. When $\theta=0$, the union has no aversion to inequality and simply seeks to maximize the total wage premium; as $\theta$ rises, the union attaches more importance to the group of workers with the lowest wage premium; at the other extreme, when $\theta \rightarrow \infty$, the union's objective is to maximize $\min \left(\left(1+q \tau_{T}\right) w_{T}-\bar{w}_{T},\left(1+q \tau_{C}\right) w_{C}-\bar{w}_{C}\right)$, i.e., the wage premium of the worker type with the lowest premium.

As in the efficient bargaining model (McDonald and Solow, 1981), we assume that wages and employment are bargained jointly by the union and the firm. The firm's profit $\Pi$ is given by

$$
\Pi=F\left(L_{T}, L_{C}\right)-w_{T}\left(1+\tau_{T}\right) L_{T}-w_{C}\left(1+\tau_{C}\right) L_{C} .
$$

The outcome of the bargaining process is given by

$$
w_{T}^{*}, w_{C}^{*}, L_{T}^{*}, L_{C}^{*}=\underset{w_{T}, w_{C}, L_{T}, L_{C} / \Omega \geq 0, \Pi \geq 0}{\arg \max } \phi \cdot \ln \Omega+(1-\phi) \ln \Pi,
$$

where $\phi \in(0,1)$ denotes the union's bargaining power. The bargaining problem's first-order conditions with respect to wages are

$$
\phi\left(\frac{\left(1+q \tau_{k}\right)\left[\left(1+q \tau_{k}\right) w_{k}^{*}-\bar{w}_{k}\right]^{-\theta}}{L_{T}\left[\left(1+q \tau_{T}\right) w_{T}^{*}\right]^{1-\theta}+L_{C}\left[\left(1+q \tau_{C}\right) w_{C}^{*}\right]^{1-\theta}}\right)=(1-\phi) \frac{1+\tau_{k}}{\Pi}, \quad k=T, C .
$$

Combining the above expressions for $k=T$ and $k=C$ yields the following equation for the relative wage premium of treated and control workers when $\phi \in] 0,1[$ :

$$
\frac{\left(1+q \tau_{T}\right) w_{T}^{*}-\bar{w}_{T}}{\left(1+q \tau_{C}\right) w_{C}^{*}-\bar{w}_{C}}=\left(\frac{1+\tau_{T}}{1+\tau_{C}}\right)^{-\frac{1}{\theta}}\left(\frac{1+q \tau_{T}}{1+q \tau_{C}}\right)^{\frac{1}{\theta}} .
$$

To derive a closed-form formula for the pass-through of SSCs to relative wages, we make the simplifying assumption that $\bar{w}_{T}=\bar{w}_{C}=0$. After some algebra, the pass-through of 
SSCs to relative wages is found to be

$$
\frac{\mathrm{d} \ln \left(\frac{w_{T}^{*}}{w_{C}^{*}}\right)}{\mathrm{d} \ln \left(1+\tau_{T}\right)}=-\frac{1}{\theta}-\left(\frac{\theta-1}{\theta}\right) \frac{q\left(1+\tau_{T}\right)}{1+q \tau_{T}} .
$$

With perfect tax-benefit linkage $(q=1)$, there is a full pass-through to workers. In the absence of linkage $(q=0)$, the pass-through formula simplifies to $-1 / \theta$. The stronger the union's inequality aversion, $\theta$, the fewer SSC increases are passed through to the treated workers relative to the control workers. In the extreme case where the union is completely averse to wage inequality between workers $(\theta \rightarrow \infty)$, the relative wages of treated and control workers are unaffected by differential increases in SSCs. Interestingly, this result does not depend on the union's bargaining power but only on its aversion to inequality.

Firm-level pass-through. An appealing feature of the collective bargaining model is that its resolution can be decomposed into two independent sub-problems: (i) determining the union's share of the total surplus; and (ii) determining how this share is split between treated and control workers.

The solution to the second problem is simply obtained from the two first-order conditions of the bargaining problem with respect to treated and control workers' wages. It is given by Equation (A.28) which shows that the splitting of the surplus between the two types of workers does not depend on the union's bargaining power. It only depends on the SSC rates, the degree of tax-benefit linkage, the union's degree of inequality aversion, and the workers' outside options (which may differ, for example, because of differences in workers' productivity). ${ }^{\text {A.2 }}$

Let $S=\Omega+\Pi$ denote the surplus. We have

$$
\frac{\phi}{\Omega} \frac{\mathrm{d} \Omega}{\mathrm{d} X}+\frac{1-\phi}{S-\Omega} \frac{\mathrm{d} \Pi}{\mathrm{d} X}=0, \quad X=w_{T}, w_{C}, L_{T}, L_{C}
$$

which leads to the following expression for the union's equilibrium share of the surplus:

$$
\Omega^{*}=\phi S\left(\frac{\frac{\mathrm{d} \Omega}{\mathrm{d} X}}{\phi \frac{\mathrm{d} \Omega}{\mathrm{d} X}+(1-\phi)\left(-\frac{\mathrm{d} \Pi}{\mathrm{d} X}\right)}\right), \quad X=w_{T}, w_{C}, L_{T}, L_{C} .
$$

While is not possible to provide a closed-form solution for $\Omega^{*}$ without making parametric assumptions on the production function, Equation (A.30) shows that the union's share of the surplus tends to 0 when $\phi$ tends to 0 and to $S$ when $\phi$ tends to $1 .{ }^{\text {A.3 }}$ When the union has full bargaining power $(\phi \rightarrow 1)$, it captures the entire surplus, leaving zero profit to the firm (its outside option). Conversely, if the firm has full bargaining power $(\phi \rightarrow 0)$, it captures the entire surplus and the union remains at its outside option. The key point is

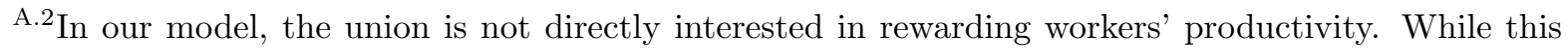
assumption does not seem at odds with unions' real-world objectives, one could adapt the union's objective function to include productivity parameters (for example, the wages of treated and control workers could be standardized by their respective productivity levels in the union's objective function).

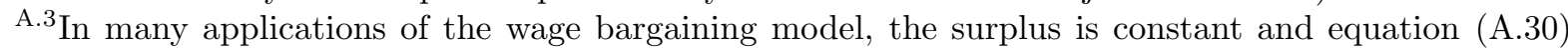
simplifies to $\Omega=\phi S$. In our case, $\Omega / S$ is likely to be increasing with $\phi$.
} 
that in the bargaining model, a change in the SSC rate of treated workers, $\mathrm{d} \tau_{T}$, affects the surplus but leaves the union's and the firm's outside options unchanged. Hence it must be shifted to workers proportionately to their share of the surplus, which depends on their bargaining power.

We can highlight the following polar cases when analyzing the pass-through of SSCs levied on treated workers in the collective bargaining model:

(1) $q=1$ : SSCs levied on treated workers are entirely passed through to treated workers while control workers' wages are unaffected.

(2) $q=0$ and $\phi \approx 0:$ SSCs are neither passed through to treated workers nor to control workers (both types receive wages close to their outside options).

(3) $q=0$ and $\phi \approx 1:$ SSCs are entirely passed through to workers. The split of the pass-through between treated and control workers depends on the union's degree of inequality aversion:

- if the union has a low aversion to inequality $(\theta \rightarrow 0)$, SSCs levied on treated workers are only passed through to treated workers. ${ }^{\text {A.4 }}$

- if the union is strongly averse to inequality $(\theta \rightarrow \infty)$, SSCs levied on treated workers are passed through at the firm level to both treated and control workers (as the relative wage of treated and control workers remains unchanged).

Collective bargaining with an egalitarian union hence appears as a potential explanation for the absence of individual-level pass-through combined with full shifting of employer SSCs to workers at the firm level. It can be seen as an alternative to the fairness norms put forward by Saez et al. (2019) for explaining their result - similar to ours - of no individual-level shifting in the case of no tax-benefit linkage. A.5

\section{A.6 Elasticity of Taxable Earnings vs. Pass-Through}

This final section clarifies the relationship between the elasticity of taxable earnings that we measure for Reforms 2 and 3, and the pass-through rate of employer SSCs that has been analyzed in the previous sections and that can be measured directly in the case of Reform 1.

Our conceptual framework is the standard analysis of the incidence of earnings taxation. We denote by $w$ the worker's gross (or posted) wage per unit of effort and by $h$ the worker's

\footnotetext{
${ }^{\text {A. }}{ }^{4}$ In the extreme case where the union can perfectly substitute the utility of treated and control workers, it will set the most costly group (the one that is subject to the highest SSC rate) to its outside option and will assign the whole surplus to the other group. In that case, the pass-through to treated workers is null as long as they remain the cheapest input and tends to infinity when they become more costly than control workers.

A.5 The competitive model in Saez et al. (2019) is similar in spirit to the one we present above, except that the authors use a CES production function and that the two groups of workers are young and old workers. Fairness norms are included by imposing an ad hoc constraint on the relative wage of young and old workers. Therefore, in Saez et al. (2019)'s model, the relative wage of young and old workers is directly fixed by fairness norms while in the collective bargaining model we present, it is still the result of a bargaining process.
} 
level of effort, which could be physical hours, work intensity, or any other intensive margin of labor supply. The quantity wh thus corresponds to the worker's net wage earnings.

We are interested in the proportional change in the worker's gross wage earnings that results from a one percent change in the rate of employer SSCs $\tau$, i.e., $\frac{d \ln w h}{d \ln (1+\tau)}$. We refer to this quantity as the elasticity of taxable earnings (ETE). It is straightforward to show that the ETE combines the pass-through rate with workers' behavioral responses along the intensive margin of effort choice:

$$
\begin{aligned}
\mathrm{ETE} & =\frac{\mathrm{d} \ln w h}{\mathrm{~d} \ln (1+\tau)} \\
& =\frac{\mathrm{d} \ln w}{\mathrm{~d} \ln (1+\tau)}+\frac{\mathrm{d} \ln h}{\mathrm{~d} \ln w} \cdot \frac{\mathrm{d} \ln w}{\mathrm{~d} \ln (1+\tau)} \\
& =\underbrace{\frac{\mathrm{d} \ln w}{\mathrm{~d} \ln (1+\tau)}}_{\begin{array}{c}
\text { pass-through } \\
\text { rate }
\end{array}}(1+\underbrace{\frac{\mathrm{d} \ln h}{\mathrm{~d} \ln w}}_{\begin{array}{c}
\text { intensive } \\
\text { margin } \\
\text { response }
\end{array}}) .
\end{aligned}
$$

In the elasticity of taxable income literature (e.g., Gruber and Saez, 2002; Saez et al., 2012; Kleven and Schultz, 2014), the common (mostly implicit) assumption is that SSCs are fully passed through to workers. In that case, the earnings response purely captures behavioral responses. Otherwise, the earnings response captures both incidence and behavioral responses. If, as is commonly found in the empirical labor supply literature, income effects are small, then $\frac{\mathrm{d} \ln h}{\mathrm{~d} \ln w}>0$, which implies that the ETE can be interpreted as an upper bound for the pass-through rate of employer SSCs to workers. Given that our ETE estimates for Reforms 2 and 3 are not statistically different from zero, we can safely conclude that our empirical estimates reject individual-level shifting of employer SSCs in these two cases. 


\section{B Institutional Details}

This Appendix provides institutional details on the design of the Social Security system in France (Section B.1), the structure of the Social Security contribution schedule (Section B.2), the degree of tax-benefit linkage (Section B.3), and the labor market conditions prevailing during each of the reforms being studied (Section B.4).

\section{B.1 Social Security Design in France}

The French Social Security system is composed of a large number of different schemes, each financed through a specific Social Security contribution (SSC). Social Security schemes vary according to the insured risk, their governance, and the population covered. They all have a separate budget from the French State and are characterized by a strict earmarking of tax revenues.

Risk covered. As in most European countries, the main risks covered by French social insurance schemes are old-age pensions, health care, and unemployment insurance. In addition, there exists in France a separate scheme which funds child benefits and child care provisions through employer SSCs. Smaller specific schemes are dedicated to survival benefits, elderly care, and training or apprenticeship.

Governance. The different SSC schemes have different types of governance. One has to separate out the proper Social Security schemes, which are largely under the control of the French government (even if they have a completely separate budget from the French State), from the social insurances schemes that are managed by employer and employee unions. $^{\text {A.6 }}$

Social Security schemes encompass the main old-age scheme (Caisse nationale d'assurance vieillesse, CNAV), health-care insurance (Caisse nationale d'assurance maladie, CNAM), and family-related benefits (Caisse nationale des allocations familiales, CNAF). Schemes managed by unions include (i) the unemployment insurance scheme (UNEDIC) and (ii) complementary pension schemes. These schemes are run by employer and employee unions, independently from the French government - they do not appear within the French budget, although national accounts consider them as part of Social Security administrations.

Coverage. Schemes also differ according to the population coverage, with large variations between public and private sector employees, as well as the self-employed (see Table B2). Within the private sector, executives (cadres, in French) have different complementary pension schemes than non executives (non cadres): A.7 the Association pour le régime de retraite complémentaire des salariés (ARRCO), for non executives, and the Association

\footnotetext{
A.6 The French budget submitted to Parliament is composed of two documents, one concerning the French State (Loi de finances), while the other concerns the Social Security budget (Loi de financement de la Sécurité sociale).

A.7 The French definition of cadre is more extensive than the English translation of executives. It includes non executives with high-level qualifications and job occupations with intellectual expertise. For instance, it includes researchers even if they do not have any management responsibilities.
} 
générale des institutions de retraite des cadres (AGIRC), for executives. While originally voluntary, these complementary pension schemes have progressively been made mandatory between 1972 and 1976, and their coverage was extended to all wage earners in the private sector.

\section{B.2 Structure of the SSC Schedule}

Basic structure. The French SSC schedule follows the same structure for most of the schemes. The tax base is gross (or posted) earnings, with different marginal SSC rates corresponding to different thresholds. The reference threshold, which is referred to as the Social Security threshold (SST) (plafond de la sécurité sociale or PSS, in French), corresponds roughly to mean gross earnings, i.e., around the 70th percentile of the earnings distribution (40,500 euros of gross annual earnings in 2019). The threshold is adapted to the actual hours of work and duration of the job spell, leading to different thresholds for wages expressed in hourly, weekly, quarterly, or annual amounts. For instance, a job spell of only one hour will be subject to a specific hourly threshold.

SSC thresholds. The French SSC schedule is composed of four different thresholds (expressed as multiples of the SST), which depend on the population considered - the main distinction being between executives and non executives in the private sector. For executives, different marginal SSC rates apply to four wage brackets: (i) below the SST; (ii) between the SST and 4 times the SST; (iii) between 4 and 8 times the SST; and (iv) above 8 times the SST. For non executives, SSC rates apply to a different splitting of the SSC schedule: (i) below the SST; (ii) between the SST and 3 times the SST; (iii) between 3 and 4 times the SST; and (iv) above 4 times the SST.

(a) Executives

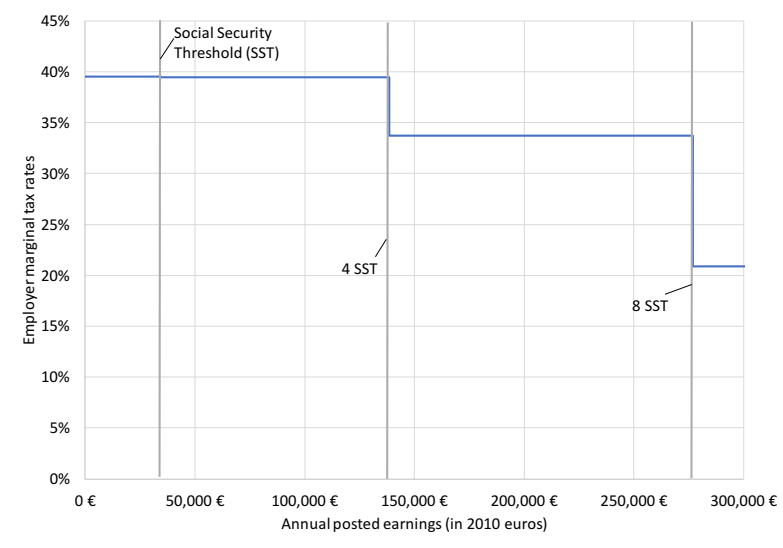

(b) Non executives

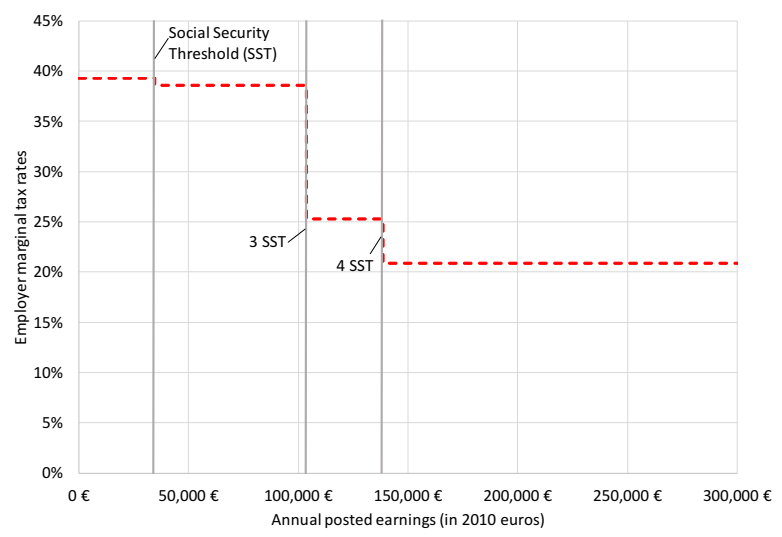

Figure B1 - Marginal Employer SSC rates by Earnings Levels in 2010

Notes: This figure shows the employer marginal SSC rates in 2010 for private sector workers. The rates are expressed as a function of annual posted earnings, for the case of a full-time worker. Panel (a) presents the case of an executive worker affiliated with the complementary pension scheme AGIRC, while Panel (b) presents the case of a non-executive worker affiliated with the ARRCO pension scheme. Vertical bars represent the different payroll tax brackets expressed as a fraction of the Social Security threshold (SST) which amounted to 34,620 euros in 2010. For non executives, the relevant thresholds are the SST, 3 times the SST, and 4 times the SST. For non executives, the relevant thresholds are the SST, 4 times the SST, and 8 times the SST. 
Figure B1 present the employer SSC schedule as a function of earnings level for the year 2010. Panel A shows the cas of non-executive workers, while Panel B shows the case of executives. Like most SSC schedules around the world, French SSCs are capped but the upper threshold is much higher than in most countries. For non executives, the upper threshold of four times the SST (138,000 euros of gross annual earnings in 2010) corresponds to the 99th percentile of the earnings distribution of full-time wage earners in the private sector. For executives, the upper threshold of eight times the SST $(277,000$ euros of gross annual earnings in 2010) corresponds to the 99.9th percentile of the same earnings distribution.

Evolution of SSC rates (1945-2015). Figure B2 displays the evolution of total employee and employer marginal SSC rates between 1945 and 2015. Panels (a) and (b) show the evolutions for non executives, while Panels (c) and (d) are for executives, separately for the different earnings brackets that are specific to each group. One notices three striking features of French employer SSCs over the period. First, SSC rates under the reference threshold (the SST) have increased considerably since World War II, especially in the 1960s and 1970s. Employer SSCs below the SST increased from 16 percent in 1948 to 38 percent in 1979 and have remained stable thereafter. Second, employer SSCs have always been significantly higher than employee SSCs, reflecting the uneven split (typically 60:40) in many schemes and the fact that some schemes only involve employer SSCs (e.g., family-related SSCs). Third, employer SSC rates above the SST remained low until the end of the 1970s and have since increased dramatically to converge to the rate observed below the reference threshold, i.e., around 40 percent.

The period 1979-2006, during which employer SSCs above the SST increased sharply as a result of major reforms, is the key period of study in this paper. The difference between the marginal SSC rates below and above the SST declined from 35.80 percent in 1978 to 2.05 percent in 2005 . This overall decline of 27 percentage points was the result of the three main reforms that we exploit in this paper: (i) the uncapping of health care SSCs in 1981 and 1984 (Reform 2); (ii) the uncapping of family benefit SSCs in 1989 and 1990 (Reform 3); and (iii) the increase in complementary pension SSC rates between 2000 and 2005 (Reform 1).

Table B2 lists the main SSCs for a wage earner in the private sector between 1976 and 2010, distinguishing for each scheme the coverage, the legal liability, and the rates that apply to the different earnings brackets. The table highlights the trend that we exploit in this paper, namely the uncapping of several SSCs above the main threshold during the period under study. 
(a) Employee SSC rates (non executives)

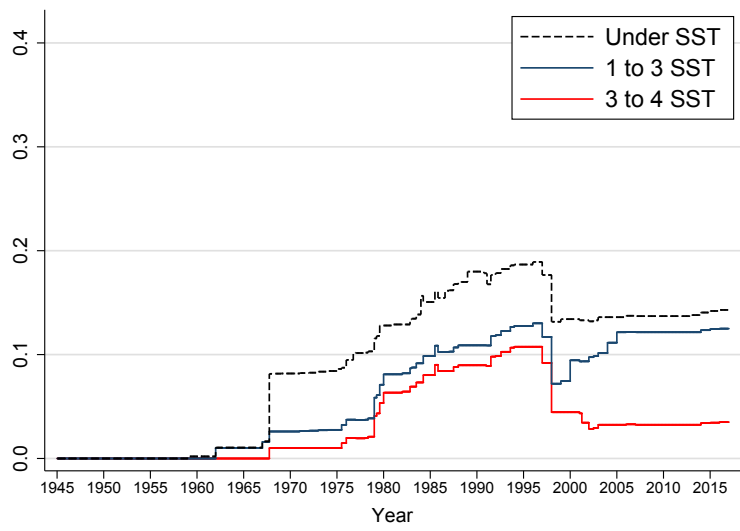

(c) Employee SSC rates (executives)

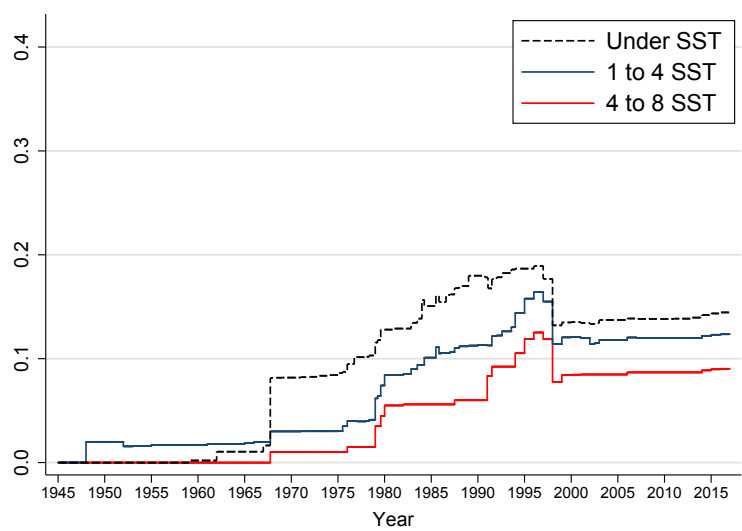

(b) Employer SSC rates (non executives)

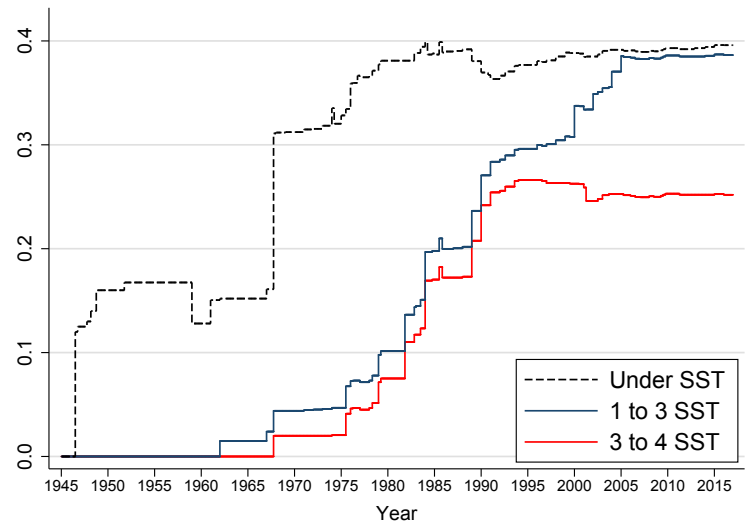

(d) Employer SSC rates (executives)

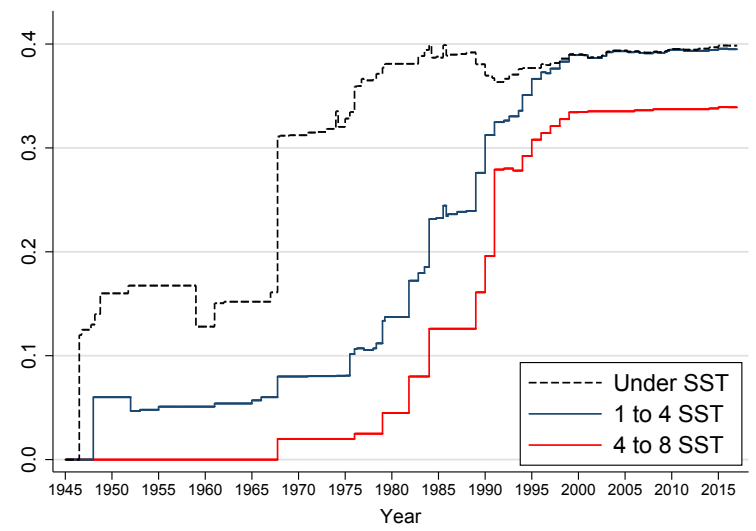

Figure B2 - Total SSC Marginal Tax Rates in France (1945-2015)

Notes: Marginal Social Security contribution rates are here expressed as a percentage of gross earnings, as they are legislated. These rates are applied to different earnings brackets, which are defined with respect to the Social Security threshold (SST). Sources: IPP Tax and Benefit Tables (2018) ; TAXIPP 0.4. 
Table B2 - Social Security Contributions Rates in France, Private Sector, 1976-2010

\begin{tabular}{|c|c|c|c|c|c|c|c|c|c|c|c|c|}
\hline \multirow{2}{*}{ SSC designation } & \multirow{2}{*}{ French acronym } & \multirow{2}{*}{ Workers concerned } & \multirow{2}{*}{ Legal liability } & \multirow{2}{*}{ Earnings bracket } & \multicolumn{8}{|c|}{ Rates (in percent) } \\
\hline & & & & & 1976 & 1980 & 1985 & 1990 & 1995 & 2000 & 2005 & 2010 \\
\hline \multicolumn{13}{|l|}{ Panel A. Pension schemes } \\
\hline Old-age pension scheme & CNAV & $\begin{array}{l}\text { all private sector } \\
\text { all private sector } \\
\text { all private sector } \\
\text { all private sector }\end{array}$ & $\begin{array}{l}\text { employee } \\
\text { employer } \\
\text { employee } \\
\text { employer }\end{array}$ & $\begin{array}{l}\quad<\mathrm{SST} \\
<\mathrm{SST} \\
\text { all earnings } \\
\text { all earnings }\end{array}$ & $\begin{array}{l}3.25 \\
7.50 \\
- \\
-\end{array}$ & $\begin{array}{l}4.70 \\
8.20 \\
- \\
-\end{array}$ & $\begin{array}{l}5.70 \\
8.20 \\
- \\
-\end{array}$ & $\begin{array}{l}7.60 \\
8.20 \\
- \\
-\end{array}$ & $\begin{array}{c}6.55 \\
8.20 \\
- \\
1.60\end{array}$ & $\begin{array}{l}6.55 \\
8.20 \\
- \\
1.60\end{array}$ & $\begin{array}{l}6.55 \\
8.20 \\
0.10 \\
1.60\end{array}$ & $\begin{array}{l}6.65 \\
8.30 \\
0.10 \\
1.60\end{array}$ \\
\hline Widows' pension scheme & VEUVAGE & $\begin{array}{l}\text { all private sector } \\
\text { all private sector }\end{array}$ & $\begin{array}{l}\text { employee } \\
\text { employee }\end{array}$ & $\begin{array}{l}<\mathrm{SST} \\
\text { all earnings }\end{array}$ & $\begin{array}{l}- \\
-\end{array}$ & $\begin{array}{l}- \\
-\end{array}$ & $\begin{array}{c}- \\
0.10\end{array}$ & $\overline{-}$ & $\begin{array}{c}- \\
0.10\end{array}$ & $\begin{array}{c}- \\
0.10\end{array}$ & $\begin{array}{l}- \\
-\end{array}$ & $\begin{array}{l}- \\
-\end{array}$ \\
\hline Complementary pension scheme & $\mathrm{ARRCO}$ & $\begin{array}{l}\text { non executives } \\
\text { non executives } \\
\text { non executives } \\
\text { non executives } \\
\text { non executives } \\
\text { non executives }\end{array}$ & $\begin{array}{l}\text { employee } \\
\text { employer } \\
\text { employee } \\
\text { employer } \\
\text { employee } \\
\text { employer }\end{array}$ & $\begin{array}{c}<\mathrm{SST} \\
<\mathrm{SST} \\
1-3 \mathrm{SST} \\
1-3 \mathrm{SST} \\
1-3 \mathrm{SST} \\
1-3 \mathrm{SST}\end{array}$ & $\begin{array}{l}1.76 \\
2.64 \\
1.76 \\
2.64 \\
- \\
-\end{array}$ & $\begin{array}{l}1.76 \\
2.64 \\
1.76 \\
2.64 \\
- \\
-\end{array}$ & $\begin{array}{l}1.84 \\
2.76 \\
1.84 \\
2.76 \\
- \\
-\end{array}$ & $\begin{array}{l}1.92 \\
2.88 \\
1.92 \\
2.88 \\
- \\
-\end{array}$ & $\begin{array}{l}2.00 \\
3.00 \\
2.00 \\
3.00 \\
- \\
-\end{array}$ & $\begin{array}{c}3.00 \\
4.50 \\
5.00 \\
7.50 \\
8.00 \\
12.00\end{array}$ & $\begin{array}{c}3.00 \\
4.50 \\
8.00 \\
12.00 \\
8.00 \\
12.00\end{array}$ & $\begin{array}{c}3.00 \\
4.50 \\
8.00 \\
12.00 \\
8.00 \\
12.00\end{array}$ \\
\hline Complementary pension scheme & AGIRC & $\begin{array}{l}\text { executives } \\
\text { executives } \\
\text { executives } \\
\text { executives }\end{array}$ & $\begin{array}{l}\text { employee } \\
\text { employer } \\
\text { employee } \\
\text { employer }\end{array}$ & $\begin{array}{l}1-4 \mathrm{SST} \\
1-4 \mathrm{SST} \\
4-8 \mathrm{SST} \\
4-8 \mathrm{SST}\end{array}$ & $\begin{array}{l}2.00 \\
6.00 \\
- \\
-\end{array}$ & $\begin{array}{l}2.06 \\
6.18 \\
- \\
-\end{array}$ & $\begin{array}{l}2.06 \\
6.18 \\
- \\
-\end{array}$ & $\begin{array}{l}2.34 \\
7.02 \\
- \\
-\end{array}$ & $\begin{array}{c}5.00 \\
10.00 \\
5.00 \\
10.00\end{array}$ & $\begin{array}{c}7.50 \\
12.50 \\
7.50 \\
12.50\end{array}$ & $\begin{array}{c}7.50 \\
12.50 \\
7.50 \\
12.50\end{array}$ & $\begin{array}{c}7.70 \\
12.60 \\
7.70 \\
12.60\end{array}$ \\
\hline Early retirement complementary pension scheme & AGFF & $\begin{array}{l}\text { all private sector } \\
\text { all private sector } \\
\text { non executives } \\
\text { non executives } \\
\text { executives } \\
\text { executives }\end{array}$ & $\begin{array}{l}\text { employee } \\
\text { employer } \\
\text { employee } \\
\text { employer } \\
\text { employee } \\
\text { employer }\end{array}$ & $\begin{array}{c}<\mathrm{SST} \\
<\mathrm{SST} \\
1-3 \mathrm{SST} \\
1-3 \mathrm{SST} \\
1-4 \mathrm{SST} \\
1-4 \mathrm{SST}\end{array}$ & $\begin{array}{l}- \\
- \\
- \\
- \\
- \\
-\end{array}$ & $\begin{array}{l}- \\
- \\
- \\
- \\
- \\
-\end{array}$ & $\begin{array}{l}- \\
- \\
- \\
- \\
- \\
-\end{array}$ & $\begin{array}{l}- \\
- \\
- \\
- \\
- \\
-\end{array}$ & $\begin{array}{l}- \\
- \\
- \\
- \\
- \\
-\end{array}$ & $\begin{array}{l}- \\
- \\
- \\
- \\
- \\
-\end{array}$ & $\begin{array}{l}0.80 \\
1.20 \\
0.90 \\
1.30 \\
0.90 \\
1.30\end{array}$ & $\begin{array}{l}0.80 \\
1.20 \\
0.90 \\
1.30 \\
0.90 \\
1.30\end{array}$ \\
\hline Additional complementary pension scheme & CET & $\begin{array}{l}\text { non executives } \\
\text { non executives }\end{array}$ & $\begin{array}{l}\text { employee } \\
\text { employer }\end{array}$ & $\begin{array}{l}4-8 \mathrm{SST} \\
4-8 \mathrm{SST}\end{array}$ & $\begin{array}{l}- \\
-\end{array}$ & $\begin{array}{l}- \\
-\end{array}$ & $\begin{array}{l}- \\
-\end{array}$ & $\begin{array}{l}- \\
-\end{array}$ & $\begin{array}{l}- \\
-\end{array}$ & $\begin{array}{l}0.11 \\
0.17\end{array}$ & $\begin{array}{l}0.13 \\
0.22\end{array}$ & $\begin{array}{l}0.13 \\
0.22\end{array}$ \\
\hline \multicolumn{13}{|l|}{ Panel B. Unemployment insurance } \\
\hline Unemployment insurance scheme & UNEDIC & $\begin{array}{l}\text { all private sector } \\
\text { all private sector } \\
\text { all private sector } \\
\text { all private sector }\end{array}$ & $\begin{array}{l}\text { employee } \\
\text { employee } \\
\text { employer } \\
\text { employer }\end{array}$ & $\begin{array}{c}<\mathrm{SST} \\
1-4 \mathrm{SST} \\
<\mathrm{SST} \\
1-4 \mathrm{SST}\end{array}$ & $\begin{array}{l}0.48 \\
0.48 \\
1.92 \\
1.92\end{array}$ & $\begin{array}{l}0.84 \\
0.84 \\
2.76 \\
2.76\end{array}$ & $\begin{array}{l}1.12 \\
1.62 \\
2.88 \\
2.88\end{array}$ & $\begin{array}{l}1.67 \\
2.17 \\
3.23 \\
3.23\end{array}$ & $\begin{array}{l}2.42 \\
2.97 \\
4.18 \\
4.18\end{array}$ & $\begin{array}{l}2.21 \\
2.71 \\
3.97 \\
3.97\end{array}$ & $\begin{array}{l}2.40 \\
2.40 \\
4.00 \\
4.00\end{array}$ & $\begin{array}{c}2.4 \\
2.4 \\
4.00 \\
4.00\end{array}$ \\
\hline Early retirement scheme & ASF & $\begin{array}{l}\text { all private sector } \\
\text { all private sector } \\
\text { all private sector } \\
\text { all private sector }\end{array}$ & $\begin{array}{l}\text { employee } \\
\text { employer } \\
\text { employee } \\
\text { employer }\end{array}$ & $\begin{array}{c}<\mathrm{SST} \\
<\mathrm{SST} \\
1-4 \mathrm{SST} \\
1-4 \mathrm{SST}\end{array}$ & $\begin{array}{l}- \\
- \\
- \\
-\end{array}$ & $\begin{array}{l}- \\
- \\
- \\
-\end{array}$ & $\begin{array}{l}0.80 \\
1.20 \\
0.80 \\
1.20\end{array}$ & $\begin{array}{l}0.80 \\
1.20 \\
0.80 \\
1.20\end{array}$ & $\begin{array}{l}0.80 \\
1.16 \\
0.89 \\
1.29\end{array}$ & $\begin{array}{l}0.80 \\
1.16 \\
0.89 \\
1.29\end{array}$ & $\begin{array}{l}- \\
- \\
- \\
-\end{array}$ & $\begin{array}{l}- \\
- \\
- \\
-\end{array}$ \\
\hline Job placement for executives & APEC & $\begin{array}{l}\text { executives } \\
\text { executives } \\
\text { executives } \\
\text { executives }\end{array}$ & $\begin{array}{l}\text { employee } \\
\text { employer } \\
\text { employee } \\
\text { employer }\end{array}$ & $\begin{array}{l}1-4 \mathrm{SST} \\
1-4 \mathrm{SST} \\
<\mathrm{SST} \\
<\mathrm{SST}\end{array}$ & $\begin{array}{l}0.024 \\
0.036 \\
- \\
-\end{array}$ & $\begin{array}{l}0.024 \\
0.036 \\
- \\
-\end{array}$ & $\begin{array}{l}0.024 \\
0.036 \\
- \\
-\end{array}$ & $\begin{array}{l}0.024 \\
0.036 \\
- \\
-\end{array}$ & $\begin{array}{c}0.024 \\
0.036 \\
- \\
-\end{array}$ & $\begin{array}{l}0.024 \\
0.036 \\
- \\
-\end{array}$ & $\begin{array}{l}0.024 \\
0.036 \\
- \\
-\end{array}$ & $\begin{array}{l}0.024 \\
0.036 \\
- \\
-\end{array}$ \\
\hline \multicolumn{13}{|l|}{ Panel C. Health care } \\
\hline Health insurance scheme & MMID & $\begin{array}{l}\text { all private sector } \\
\text { all private sector } \\
\text { all private sector } \\
\text { all private sector }\end{array}$ & $\begin{array}{l}\text { employee } \\
\text { employer } \\
\text { employee } \\
\text { employer }\end{array}$ & $\begin{array}{l}\quad<\mathrm{SST} \\
<\mathrm{SST} \\
\text { all earnings } \\
\text { all earnings }\end{array}$ & $\begin{array}{c}2.50 \\
10.45 \\
1.50 \\
2.50\end{array}$ & $\begin{array}{l}- \\
8.95 \\
5.50 \\
4.50\end{array}$ & $\begin{array}{c}- \\
- \\
5.50 \\
12.60\end{array}$ & $\begin{array}{c}- \\
- \\
5.90 \\
12.60\end{array}$ & $\begin{array}{c}- \\
- \\
6.8 \\
12.80\end{array}$ & $\begin{array}{c}- \\
- \\
0.75 \\
12.80\end{array}$ & $\begin{array}{c}- \\
- \\
0.75 \\
12.80\end{array}$ & $\begin{array}{c}- \\
- \\
0.75 \\
12.80\end{array}$ \\
\hline \multicolumn{13}{|l|}{ Panel D. Family benefits } \\
\hline Family benefits & CNAF & $\begin{array}{l}\text { all wage earners } \\
\text { all wage earners }\end{array}$ & $\begin{array}{l}\text { employer } \\
\text { employer }\end{array}$ & $\begin{array}{l}<\mathrm{SST} \\
\text { all earnings }\end{array}$ & $\begin{array}{l}9.00 \\
-\end{array}$ & $\begin{array}{c}9.00 \\
-\end{array}$ & $\begin{array}{c}9.00 \\
-\end{array}$ & - & - & 5.40 & - & 5.40 \\
\hline
\end{tabular}

Notes: SST refers to the social Security threshold (plafond de la sécurité sociale, in French) and 4 SST to four times this threshold. The SSCs presented in this table are the main SSCs for private sector wage earners. They do not include specific schemes such as regional schemes or various payroll taxes. Description of French acronyms for each scheme: CNAV: Caisse nationale d'assurance vieillesse; ARRCO: Association pour le régime de retraite complémentaire des salariés; AGIRC: Association générale des institutions de retraite des cadres; CET Cotisation exceptionnelle et temporaire; UNEDIC: Union nationale interprofessionnelle pour l'emploi dans l'industrie et le commerce; ASF: Association pour la gestion de la structure financière; APEC: Association pour l'emploi des cadres; MMID: maladie, maternité, invalidité, décès; CNAF: Caisse nationale des allocations familiales. Details for every year with legislative references are available on the website of the Institut des Politiques Publiques (IPP): https://www.ipp.eu/en/tools/ipp-tax-and-benefit-tables/social-security-contributions/. 


\section{B.3 Tax-benefit Linkage in French Social Security Schemes}

Definition of tax-benefit linkage. Tax-benefit linkage is often loosely defined as the earmarking of tax revenues to specific spending or schemes. ${ }^{\text {A. } 8}$ In that respect, all French SSCs have relatively strict earmarking with a separate budget for each scheme identified by a separate SSC, which appears distinctively (on a separate line) on the payslip of wage earners. But if one more precisely describes tax-benefit linkage as the relationship between the amount of benefit, $B$, and the amount of contributions, $S S C$, it is the function $B=f(S S C)$ that defines the degree of tax-benefit linkage. We use the following definitions to distinguish between weak and strong tax-benefit linkage:

(a) A weak tax-benefit linkage is when the benefit $B$ is simply conditional on $S S C>\alpha$, i.e., on the contribution being high enough to justify a benefit.

(b) A strong tax-benefit linkage is when the marginal benefit is positively related to the marginal contribution, i.e., $\frac{\mathrm{d} B}{\mathrm{~d} S S C}=\lambda>0$. The parameter $\lambda$ can be seen as a measure of the effective degree of tax-benefit linkage, with $\lambda=1$ being the reference of perfect tax-benefit linkage, very much like the quid pro quo tax mentioned by Musgrave (1968).

Tax-benefit linkage in French SSCs. French SSCs show various degrees of tax-benefit linkage. At one extreme, family SSCs are earmarked to finance child benefits through the Caisse nationale des allocations familiales (Child Benefit Social Security scheme) and exhibit no tax-benefit linkage. The scheme offers child benefits to all French residents with at least two children, irrespective of their actual contributions. Benefits vary with the number of children and their age, but not as a function of the amount of contributions paid. Even from the outset of the scheme, parents outside the labor force could claim child benefits provided they could justify the reasons for inactivity. ${ }^{\text {A.9 }}$

Health care SSCs are only very loosely related to benefits. Originally, health care insurance was restricted to individuals who had paid SSCs (and were hence insured) but this coverage was extended from the outset to family members (spouse, children), as well as to periods of unemployment. The only population not covered were individuals outside the labor market (neither in paid work nor covered by unemployment insurance). In 1999, a law extended coverage to all French residents to provide universal health care insurance. ${ }^{\text {A.10 }}$ This form of tax-benefit linkage is relatively weak, as the marginal linkage parameter $\lambda$ is equal to zero: higher health care SSC rates or higher earnings lead to higher SSCs without affecting the health care coverage.

The basic pension scheme for private sector earners (CNAV) is the example of an intermediary case of tax-benefit linkage, which is relatively common in other countries. The CNAV scheme is a defined benefit pay-as-you-go pension scheme managed by the Social Security administration. The pension benefit has an implicit contributory link since pensions are computed with a reference to the average earnings over the best 25 years;

\footnotetext{
${ }^{\text {A.8 }}$ In OECD publications, for instance, SSCs are defined based on the earmarking of revenues rather than actual tax-benefit linkage.

A.9 Law of August 22, 1946 published in the Journal Officiel of August 23, 1946.

${ }^{\text {A.10}}$ Law 99-641 of July 27, 1999, published in the Journal Officiel of July 28, 1999.
} 
but the scheme also includes some elements of redistribution (e.g., a minimum guaranteed pension for low earners). The relation between the marginal benefit and the marginal contribution, $\lambda$, is generally positive but with wide dispersion: higher contributions in early years (not included in the best years selected for calculating the pension) do not impact the level of benefits, whereas higher earnings just before retirement are more likely to lead to a positive $\lambda$ (in some cases, above 1). The impact of an increase in the CNAV SSC rate is unclear, as the relationship between funding needs and changes in benefits is far from being one-to-one. Historical examples abound with policy decisions to increase benefits with no corresponding increases in rates; conversely, SSC rates have often been increased while benefits were being reduced as a means to achieve financial balance. Moreover, part of the pension benefit - which is capped at the SST - is funded through a specific SSC that applies to all earnings (without any cap) for redistributive purposes.

Alongside the basic scheme, complementary pension schemes (ARRCO and AGIRC in the private sector) exhibit very salient tax-benefit linkage. Although these pension schemes are also unfunded, they function according to a point-based system with much stronger actuarial fairness. SSCs are converted into points using a shadow price (valeur d'achat or salaire de référence). Accumulated points can be converted into an annuity pension by using another shadow price of points (valeur de service). The system bears some resemblance with both the German point system and the Swedish Notional Defined Contribution (NDC) system insofar as the benefit level is strictly proportional to past contributions. ${ }^{\text {A.11 }}$ In particular, the relation between the marginal benefit and the marginal contribution, $\lambda$, is positive and larger than 1 given that a real rate of return is applied to contributions by the PAYGO system.

Implicit taxation of PAYGO pension schemes. It is well known that pay-as-you-go pension schemes can offer a positive internal rate of return equal to the growth rate of the tax base $g$ (Samuelson, 1958), but this does not prevent some implicit taxation by unfunded schemes when the return on contributions is lower than the market return individuals could have earned, $r$. The literature has shown that the implicit tax rate from an unfunded pension is equal to $\tau_{S S C}(r-g) /(1+r)$, i.e., the $\mathrm{SSC}$ rate $\tau_{S S C}$ times the difference between market return and the growth rate of the economy (Feldstein and Liebman, 2002; Lindbeck and Persson, 2003).

To quantify the size of this implicit tax through pension contributions, one can consider in Figure B3 the empirical difference $r-g$ in France over the period 1960 to 2015. Until the beginning of the 1980s, $r-g$ was, in fact, negative with relatively high nominal wage growth compared to long-term interest rates. Between 1984 and 1995, the difference becomes positive, hovering around 5 percent, before declining to below 1 percent from 2000 onwards. This means that Reform 1 studied in the paper (the increase in complementary pension SSC rates between 2000 and 2005) was adopted during a period with relatively low (but not null) implicit taxation.

\footnotetext{
A.11 There are some important differences, though. In the German point system, for instance, the number of points accumulated does not depend on the SSC rate, but only on the level of earnings relative to average earnings.
} 


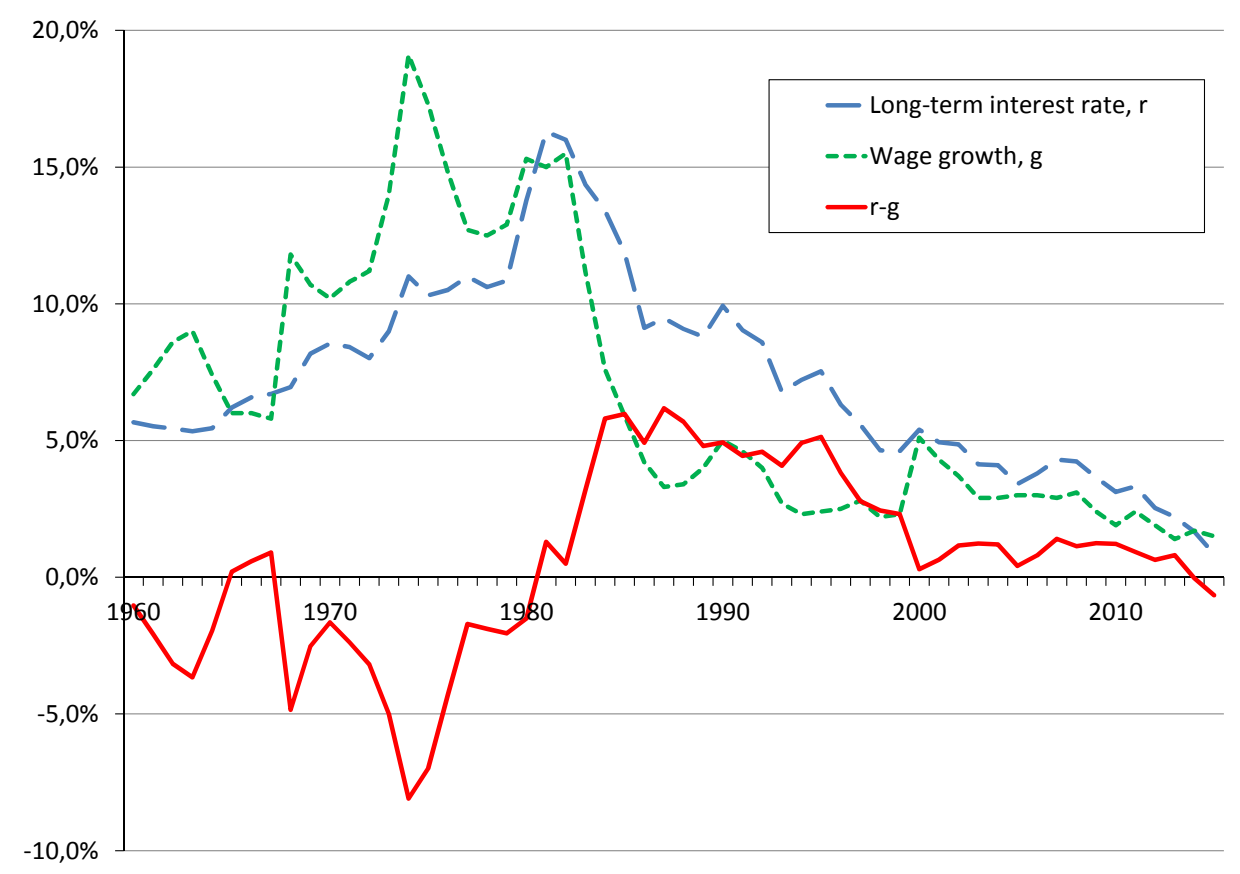

Figure B3 - Wage Growth vs. Interest Rates in France, 1960-2015

Sources: OECD (2019), Long term interest rate (indicator) doi:10.1787/4e01728c-fr; wage growth from Insee, Séries longues sur les salaires (1950-2010), Insee Résultats, No. 143, (2017).

\section{B.4 Labor Market Conditions during each of the Reforms}

In Table B3, we present some indicators of the labor market conditions prevailing when each of the three reforms we study took place. We distinguish between general economic conditions (inflation, GDP growth, unemployment, etc.) and specific labor market indicators (OECD employment protection index, labor union density, collective bargaining coverage, etc.). The striking fact that emerges from these comparisons is that labor market conditions changed markedly between Reform 3 and Reform 2, but much less so between Reform 2 and Reform 3, whereas we find a marked difference between a very low pass-through of employer SSCs to workers in the cases of Reforms 2 and 3, and a high pass-through in the case of Reform 1. For instance, inflation dropped from an annual rate of 6.2 percent during Reform 3 to 2.4 percent during Reform 2, to 1.9 percent during Reform 1. The unemployment rate was higher during Reform 2 than during Reform 1 , while the strictness of employment protection was higher during Reform 1 than during Reform 2.

If anything, labor market conditions would push towards a lower pass-through during Reform 1 and a higher pass-through during Reform 2, which is at odds with our finding of pass-through rates close to one for Reform 1 and close to zero for Reform 2. 
Table B3 - Expected Effects of Economic Conditions and Labor Market Regulations on Employers' Ability to Shift SSC Increases Induced by the Three Reforms

\begin{tabular}{|c|c|c|c|c|}
\hline & \multirow{2}{*}{$\begin{array}{l}\text { Possible effect } \\
\text { on pass-through } \\
\text { to workers }\end{array}$} & \multicolumn{3}{|c|}{ Value during } \\
\hline & & $\begin{array}{c}\text { Reform 1 } \\
(2000-2008)\end{array}$ & $\begin{array}{c}\text { Reform 2 } \\
(1989-1997)\end{array}$ & $\begin{array}{c}\text { Reform 3 } \\
(1982-1988)\end{array}$ \\
\hline \multicolumn{5}{|l|}{ Economic conditions } \\
\hline $\begin{array}{l}\text { Inflation } \\
\text { GDP growth } \\
\text { Unemployment rate among nonexecutives } \\
\text { Overall unemployment rate } \\
\text { Labor force participation rate } \\
\text { Share of full-time employment in total employment }\end{array}$ & $\begin{array}{l}\text { Positive } \\
\text { Unclear } \\
\text { Unclear* } \\
\text { Unclear* } \\
\text { Unclear* } \\
\text { Unclear }\end{array}$ & $\begin{array}{l}1.9 \% \\
1.7 \% \\
8.1 \% \\
8.3 \% \\
56.1 \% \\
83.1 \%\end{array}$ & $\begin{array}{l}2.4 \% \\
1.6 \% \\
9.3 \% \\
9.4 \% \\
55.8 \% \\
86.0 \%\end{array}$ & $\begin{array}{l}6.2 \% \\
2.3 \% \\
7.8 \% \\
8.3 \% \\
57.2 \% \\
89.3 \%\end{array}$ \\
\hline \multicolumn{5}{|l|}{ Labor market regulations } \\
\hline $\begin{array}{l}\text { Strictness of employment protection (OECD index) } \\
\text { Labor union density } \\
\text { Collective bargaining coverage (industry and firm level) } \\
\text { Ratio between national minimum wage and median wage }\end{array}$ & $\begin{array}{l}\text { Negative } \\
\text { Unclear* } \\
\text { Unclear* } \\
\text { Unclear }\end{array}$ & $\begin{array}{c}2.43 \\
8.0 \% \\
97.0 \% \\
0.64\end{array}$ & $\begin{array}{c}2.34 \\
9.3 \% \\
94.2 \% \\
0.59\end{array}$ & $\begin{array}{l}2.47^{a} \\
13.9 \% \\
87.8 \% \\
0.61\end{array}$ \\
\hline
\end{tabular}

Notes: This table provides the average of indicators of economic conditions and labor market conditions during the reforms studied in the paper, which could potentially affect the pass-through of employer SSC increases to workers. For each reform, averages are taken between the first year of implementation and the last year for which we estimate the pass-through.

* employer SSC increases to workers. For each reform, averages are taken between the first year of implementation and the last year for which we estimate the pass-through. * In the cases of individual-level or collective bargaining, theoretical models predict that SSC increases are more shifted to workers when they have stronger bargaining power (see Appendix A).
In that case, variables that affect positively workers' bargaining power (e.g., labor union density or the labor force participation rate) should lead to higher pass-through to workers, while variables that negatively affect workers' bargaining power (e.g., the unemployment rate) should mitigate the pass-through to workers. These predictions from static models may, however, appear at odds with the basic intuition that, in dynamic settings, employers have more leverage to shift SSC increases to workers when their bargaining power is more limited. As a consequence, we consider the effect on pass-through estimates of all variables affecting workers' bargaining power as unclear. The effect of collective bargaining coverage on pass-through depends on workers' bargaining power. As a consequence, the direction of the effect is also unclear.

${ }^{a}$ This average is computed over the period $1985-1988$ as no data are available for earlier years.

Sources: The measure of the strictness of employment protection is the OECD index for individual and collective dismissals (regular contracts). Statistics on trade union membership, collective bargaining coverage and the minimum wage also come from OECD statistics. All series were extracted on September 17,2019 from stats.oecd.org. These series are not available for all years, so that we often had to compute averages over a subset of years within each reform period. Unemployment and participation rates come from the French national statistical office (INSEE) series t301, t302 and t101. Inflation and GDP growth come from national statistics. 


\section{Perceptions of the SSC Reforms}

In this section we detail the information found in archives from press outlets and unions about the three reforms we study. We have in particular systematically searched archives from Le Monde, Les Echos and Libération newspapers, as well as the archives from the C.F.D.T., one of the main labor unions in France.

\section{C.1 Reform 1: Increase in Pension Contributions (1996)}

Press articles. Most press articles about this reform highlight the fact that it was signed by a majority of labor unions, with the notable exception of the Confédération Générale du Travail (C.G.T.), historically the union linked to the French Communist Party. The agreement was signed by Force Ouvrière (F.O.), the Confédération Française Démocratique du Travail (C.F.D.T.), the Confédération Générale des Cadres (C.G.C.), the Confédération Française des Travailleurs Chrétiens (C.F.T.C.), and the employer federation Conseil National du Patronat Français (C.N.P.F.). ${ }^{\text {A.12 }}$ The main message found in the press is that the agreement led to a decrease in to the rate of return of these schemes. For instance, an article from Les Échos stresses that "100 Francs of contribution are offering today (...) 8.94 Francs of pension, and the reform will lead to a reduction to 7.20 Francs of pension." A.13

Most newspaper articles suggest that the positive counterpart of the decrease in the returns to pension contribution was the planned increase in contributions for those earning more than the Social Security threshold. For instance, an article from Le Monde states that "the agreement also entails that wage earners whose wage is above the Social Security threshold would be able to constitute themselves a better pension: the contribution rate will be raised to 16 percent by 2005 for workers of existing firms, and as soon as 2000 for firms created after January 1, 1997." A.14 In another article in Les Échos, the increase in contribution is estimated to benefit 800,000 non executives paid above the Social Security threshold. ${ }^{\text {A.15 }}$

Archives from the C.F.D.T. union. We were granted access to the archives of the C.F.D.T. union. We have been able to consult all internal documents as well as the documents, leaflets or magazines addressed by the C.F.D.T. to its members.

In a document dedicated to pension benefits of union members, ${ }^{\text {A.16 }}$ the agreement of the complementary schemes AGIRC-ARRCO of April 25, 1996, is presented with the title "Improving Pension Rights". The text goes on describing the increase in SSC contributions:

\footnotetext{
A.12Focari, Christophe. "Tous d'accord sauf la CGT sur les retraites complémentaires," Libération, April 27, 1996.

A.13Pécresse, Jean-Francis. "Retraites complémentaires: négociations pour un accord à l'arraché," Les Échos, April 26, 1996.

A.14Bezat, Jean-Michel. "La baisse des retraites complémentaires est programmée," Le Monde, April 27, 1996.

A.15Pécresse Jean-Francis. "Réforme en profondeur du système de retraites complémentaires," Les Échos, April 26, 1996.

A.16 Bulletin du Retraité CFDT, No. 140, July August-September 1996.
} 
"From January 1, 2000, onwards for current firms and from January 1, 1997, onwards for new firms, the mandatory social security contribution rate will increase progressively to 16 percent instead of 6 percent on the fraction of the wage above the Social Security threshold. This measure will allow non executives to multiply by 2.66 the amount of pension benefits above the threshold. Firms have the possibility to apply this measure from now on."
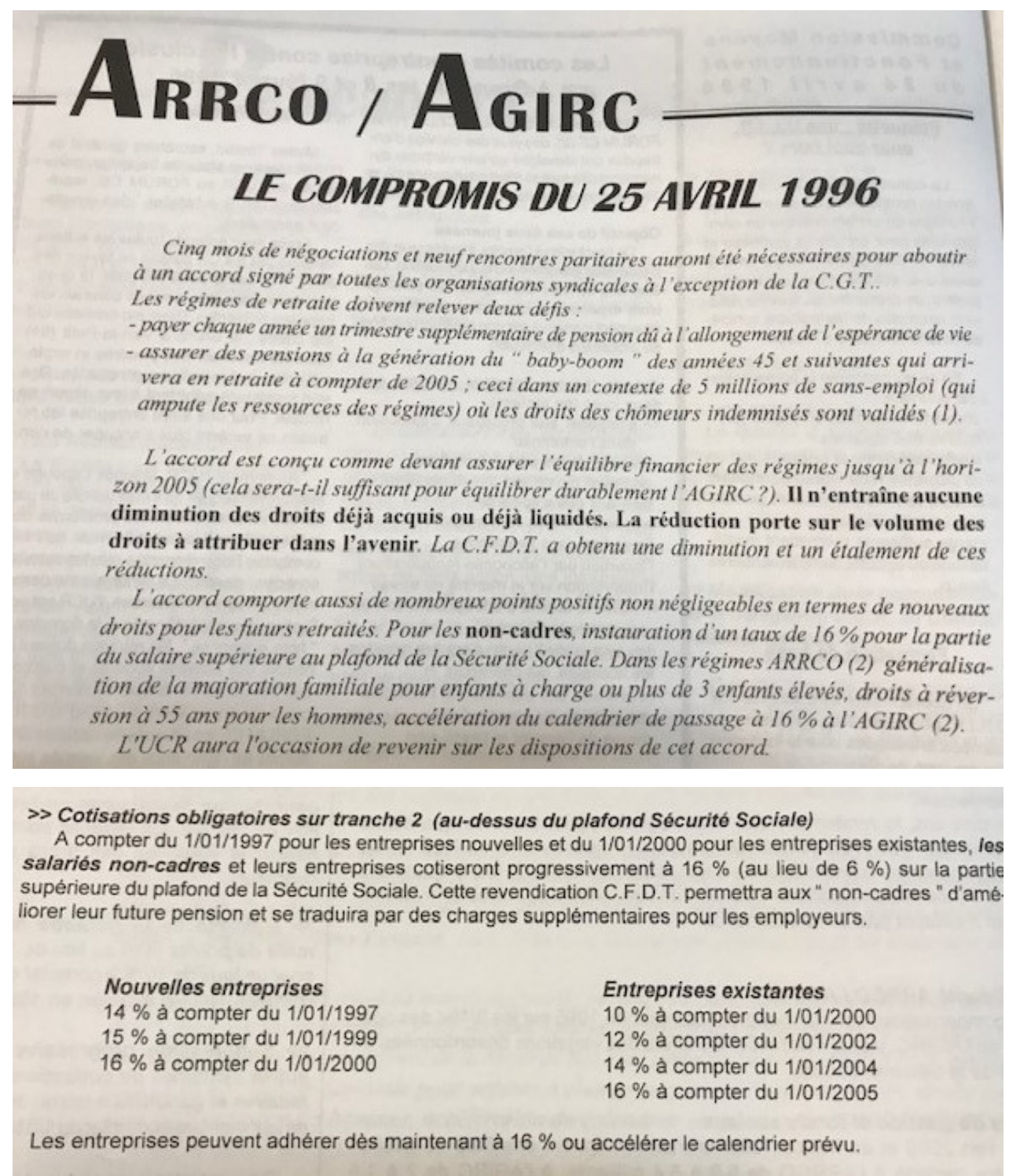

Figure C4 - The Reform Defended as a Good Compromise

Source: Le retraité militant CFDT, No. 96.06, June 1996, pp. 6-8.

In one of the union's magazines, Le retraité militant CFDT, also focusing on pension issues, the agreement is defended as a good compromise (see Figure C4): "The agreement is intended to ensure the financial balance of the schemes until the year 2005. It does not entail any reduction in pension rights already acquired or pension benefits already claimed. The reduction relates to the volume of pension rights to be allocated in the future. The 
C.F.D.T. obtained a reduction of these cuts in pension rights, and a slower phasing-in." The text goes on describing the positive aspects of this compromise, i.e., the increase in SSC rates above the threshold: "The agreement includes also numerous positive elements that are far from negligible in terms of additional pension rights for future retirees. For non executives, this includes the introduction of a rate of 16 percent for wages above the Social Security threshold." When describing the details of the measures, the article insists on the improvement in future pensions which is credited to the demands of the C.F.D.T. union:

\begin{abstract}
"From January 1, 1997, for new companies and from January 1, 2000, for existing companies, non-executive employees and their companies will gradually contribute 16 percent (instead of 6 percent) of the salary above the Social Security threshold. This demand from the C.F.D.T. will allow 'non executives' to improve their future pensions and will translate into increased pay compensations for employers."
\end{abstract}

\title{
C.2 Reform 2: Increase in Family Benefit Contributions (1989)
}

The announcement by the French Prime Minister Mr Michel Rocard in September 1988 to uncap family benefit contributions was part of a wider policy announcement to fight unemployment through the so-called "Plan Emploi". The public debate opposed employer organization and executives' unions, which criticized the reform, to other labor unions, which supported the principle of higher contributions for firms employing more highly paid workers. ${ }^{\text {A.17 }}$ We have found no press article discussing the possible incidence or impact on the wages of workers paid above the Social Security threshold, even if the debate among employee unions (executives vs. non executives) could suggest that it was feared it would impact the wages of those better paid workers.

\section{C.3 Reform 3: Increase in Health Care Contributions (1981).}

On November 12, 1981, the newspaper Le Monde reports on the debate among politicians following the announcement by the French government to increase health care contributions. $^{\text {A.18 }}$ A French MP from the Communist Party, Mr Bocquet, denounced the one-percent increase in employee Social Security contributions on all earnings but considered that the increase of employer SSCs was a step in the right direction: "Il faut faire payer les patrons!" (You have to make the bosses pay!). The center-right opposition, on the other hand, denounced SSC increases that targeted firms: "On ne peut faire mieux en matière de politique anti-emploi" (You can't do better in terms of anti-job policy) said for instance Mr Briane (MP for the U.D.F. center-right party). In another article, Le Monde mentions the negative reactions from most labor unions. A.19

\footnotetext{
A.17 "Incertitudes autour de l'effet sur l'emploi du déplafonnement des cotisations familiales," Le Monde, August 9, 1988.

A.18 "Solidarité nationale : M. Bocquet (P.C.) proteste contre l'augmentation des cotisations de la Sécurité sociale," Le Monde, December 11, 1981.

A.19 Dumont, Jean-Pierre. "Réactions hostiles du patronat et des syndicats. Les retombées amères de la solidarité," Le Monde, December 11, 1981.
} 
Most unions are reported being critical of the government plans, notably the increase in employee contribution on all earnings, and the employer organizations are also reported being very opposed to the increase in employer contributions. The article further points to the incoherence of uncapping employer contributions at a time of high unemployment, given the expected negative impacts on investment and employment decisions, according to the journalist.

A heated debate between the government and the employer organizations followed the announcement of the SSC increases. The minister in charge, Mrs Nicole Questiaux, is quoted in an article from Le Monde as declaring "The financial measures were chosen according to the objectives to fight unemployment. The decision to increase employers' contributions only above the Social Security threshold is explained by our desire to spare so-called labor-intensive companies." A.20 


\section{Data Sources}

This Appendix describes the earnings data that we use in the empirical analysis (Section D.1), the micro-simulation model on which we rely to compute Social Security contributions (Section D.2) and the data used in the meta-analysis (Section D.3.

\section{D.1 Earnings Data}

DADS panel data. Our primary source of data comes from the matched employeremployee DADS (Déclaration Annuelle de Données Sociales) Panel, which is constructed by the French Institut National de la Statistique et des Études Économiques (INSEE) from the compulsory declarations made annually by all employers for each of their employees. The DADS comes in two forms: (i) a panel based on a subsample of private sector employees from 1976 onwards and (ii) the comprehensive cross-section of all employees since 1993. Given that two of our earlier reforms of interest took place before 1993 (Reform 2 and Reform 3), we rely on the panel version of the DADS.

The DADS Panel consists of a 1/25th sample of private sector employees, born in October of even-numbered years, from 1976 onwards. In 2002, the sample size was doubled to represent $1 / 12$ th of all private sector workers. The data include roughly 1.1 million workers each year between 1976 and 2001, and 2.2 million workers from 2002 onwards. Some years of the original data sources are currently unavailable (1981, 1983, and 1990) and are therefore missing in the panel data.

Earnings definition. The DADS Panel provides only one measure of annual earnings that is consistent throughout the period: net taxable earnings, which are reported to tax authorities by employers (variable SN in the DADS Panel). Net taxable earnings are net of Social Security contributions, but not net of the non-income-tax-deductible component of flat-rate contributions, namely the Contribution sociale généralisée (CSG) and the Contribution au remboursement de la dette sociale (CRDS). Figure D5 shows the relationship between the different earnings concepts and how gross earnings and labor cost can be computed from net taxable earnings.

From 1993 onwards, additional earnings variables are available in the panel: the CSG tax base (variable SB) and net earnings (variable NETNET). The CSG tax base is a slightly larger base than gross earnings taxable for SSCs. It includes remunerations in the form of stock options, or profit-sharing plans, which are not included in the SSC tax base. Before 1993, INSEE provides an estimate of gross earnings based on the reported net taxable earnings, but gross earnings for SSC purposes are not available in the data released by INSEE. Net earnings correspond to net earnings effectively paid by firms to employees, i.e., after deduction of some specific employee contributions to restaurant vouchers or public transport passes, but before payment of the income tax.

As a result, we use the only raw information that is available through the period, i.e., net taxable earnings, and we rely on our microsimulation model to compute gross (posted) earnings, as well as labor cost including employer payroll taxes. 


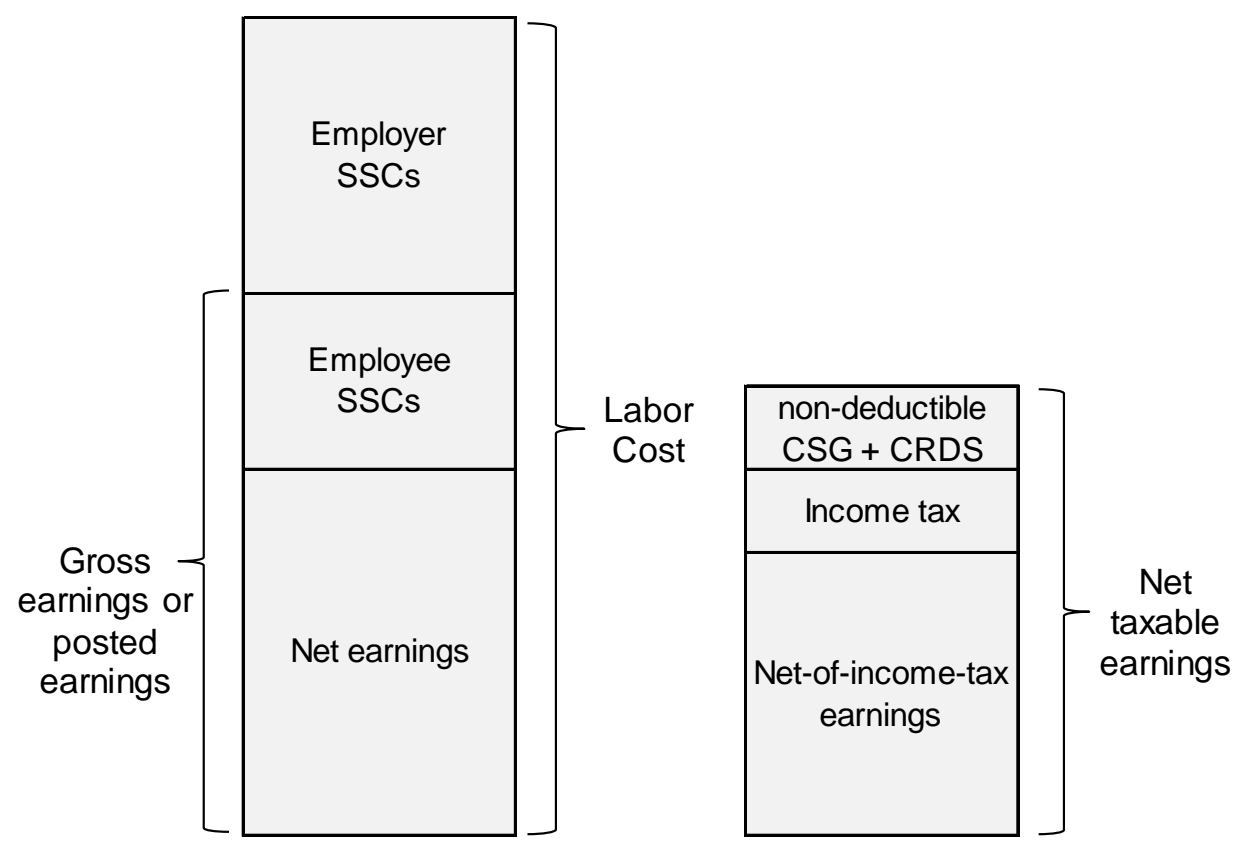

Figure D5 - Earnings Concepts in French Administrative Data

Notes: Gross earnings corresponds to posted earnings, the earnings reference mentioned in the labor contract. Labor cost is the total earnings paid by employers, i.e., gross earnings plus employer SSCs. Net earnings are earnings net of employer and employee SSCs, but not net of the progressive income tax, which is in France paid with a one-year delay. Net taxable earnings - the variable available in the DADS panel data - is the tax base for the progressive income tax. It is computed by adding to net earnings a fraction of the flat-rate contributions (CSG and CRDS) which is not deductible from the income tax base- by exception to the general rule that social contributions are in France deductible from the income tax base.

Multiple employers. The DADS data provide information on all job spells for each worker in the sample. For workers with multiple employers, we compute the sum of earnings across all employers, as the SSC rate is determined on the basis of total annual earnings.

\section{D.2 Micro-Simulation of SSCs}

TAXIPP model. Our study relies on the use of the TAXIPP model which is developed at the Institut des Politiques Publiques (IPP), and in particular on the Social Security contribution module. The model takes as input the SSC schedule, as collected in the IPP Tax and Benefit Tables, ${ }^{\text {A.21 }}$ and computes employee and employer SSCs, reductions in employer SSCs, flat-rate income tax (CSG and CRDS) as well as other payroll taxes. The model simulates the complexity of French SSCs in great detail, including local Social Security schemes such as the one in place in the Alsace-Moselle region.

Some simplifications have nevertheless been made: variations in the public transport payroll tax (Versement transport) across municipalities are not perfectly simulated but rather approximated by the size of the municipality where the firm is located; nor are the specific reductions in SSCs that are granted to firms operating in a small number of disadvantaged areas. ${ }^{\text {A.22 }}$

\footnotetext{
A.21 http://www.ipp.eu/en/tools/ipp-tax-and-benefit-tables/social-security-contributions/. A. 22 These approximations are relatively innocuous since they concern SSCs representing less than 0.5 percent of the labor cost.
} 
Identification of private sector firms. We identify private sector firms based on the variable ST (i.e., status), which classifies firms according to their public or private ownership. One issue comes from waves of privatization and nationalizations of several large firms in the 1980s. For instance, in 1986, the center-right government carried out large-scale privatization of major state-owned companies, which was partly reversed in 1988, before a further wave of privatization was undertaken in 1993. This means that some firms end up classified in the private sector while originally in the public sector (and vice versa). We restrict our sample to firms that are in the private sector throughout the period, thus excluding large utilities and some publicly-owned firms that were privatized during the period.

Identification of the applicable Social Security threshold. The Social Security threshold (SST) is defined for the pay period and the number of hours worked as specified in the employment contract. Given that we do not observe the number of hours worked before 1993, we are unable to compute the SST that applies to individuals working parttime before that date. We identify individuals working full-year based on the duration of the job spell (variable DP, i.e., durée de paie), and we identify full-time workers using the variable CE (i.e., condition d'emploi), which is available throughout the period. From 1993 onwards, we can use the effective number of hours worked (variable NBHEUR) to precisely determine the SST that applies to each worker, including those working part-time or less than a full year.

For individuals with multiple jobs, we sum up all the earnings and job spells, as Social Security contributions are computed based on the total remuneration of all jobs.

Firms created after 1997. For the implementation of Reform 1, the ARRCO agreement of April 1996 specified that firms created from 1997 onwards would be subject to the SSC rate increase much faster than existing firms, for which the rate increase was only gradually put in place. Table D4 shows the details of the phasing-in of the reform according to the date of creation of firms. Firms created after 1996 became subject to the maximum employer SSC rate of 12 percent as soon as 2000, whereas firms already existing before 1997 reached the maximum rate in 2005.

Table D4 - Marginal SSC Rates for the ARRCO Pension Scheme, 1999-2005

\begin{tabular}{|c|c|c|c|c|c|c|}
\hline \multirow[t]{3}{*}{ Date } & \multirow{2}{*}{\multicolumn{2}{|c|}{ Below the SST }} & \multicolumn{4}{|c|}{ Above the SST } \\
\hline & & & \multicolumn{2}{|c|}{ Firms created before 1997} & \multicolumn{2}{|c|}{ Firms created after 1997} \\
\hline & Employee & Employer & Employee & Employer & Employee & Employer \\
\hline January 1,2005 & $3.00 \%$ & $4.50 \%$ & $8.00 \%$ & $12.00 \%$ & $8.00 \%$ & $12.00 \%$ \\
\hline January 1, 2004 & $3.00 \%$ & $4.50 \%$ & $7.00 \%$ & $10.50 \%$ & $8.00 \%$ & $12.00 \%$ \\
\hline January 1, 2002 & $3.00 \%$ & $4.50 \%$ & $6.00 \%$ & $9.00 \%$ & $8.00 \%$ & $12.00 \%$ \\
\hline January 1, 2000 & $3.00 \%$ & $4.50 \%$ & $5.00 \%$ & $7.50 \%$ & $8.00 \%$ & $12.00 \%$ \\
\hline January 1, 1999 & $3.00 \%$ & $4.50 \%$ & $3.00 \%$ & $4.50 \%$ & $7.50 \%$ & $11.25 \%$ \\
\hline
\end{tabular}

Notes: Marginal Social Security contribution rates are here expressed as a percentage of gross earnings, as they are legislated. In the text of the ARRCO agreement of April 25, 1996, the rates are expressed before applying a coefficient (taux d'appel) of 125 percent, which has varied since the creation of the scheme but not during the recent period.

Sources: ARRCO Agreement of April 25, 1996, art. 26; Institut des Politiques Publiques (2018). 
The phasing-in of Reform 1 means that we need to identify the date of firm creation to precisely apply the correct schedule. We take advantage of another version of the DADS data, the DADS Postes, which is available since 1993 and covers the universe of all private sector employees and the firms in which they work. We construct a panel of firms using 1996-2008 data, which enables us to identify firms that were created from 1997 onwards. We then match this information with the DADS Panel data using each firm's unique identifier.

Identification of executives (cadres). The data do not provide information about the complementary pension scheme with which the wage earner is affiliated (either ARRCO, for non executives, or AGIRC, for executives). We proxy each worker's status using the information on the occupation declared by the employer. In most cases, the identification poses no problem as the occupation label mentions the title "executive" (cadre). The classification is more uncertain for certain occupation categories that could be classified or not within the executive group. To minimize classification errors, we exclude from the sample workers with such occupations. We also exclude apprentices and interns who are not subject to regular SSCs.

The 35-hour week reform. The data do not provide information on the actual date at which firms decided to switch to the 35-hour week in the early 2000s, which determines eligibility for specific SSCs reductions. We estimate this date based on each firm's reported working hours, by computing the share of the firm's employees who are declared as working 35 or 39 hours. We use the highest share to assign each firm to either of the weekly working hours regimes.

\section{D.3 Data Sources for the Meta-Analysis}

Table D5 presents the data that we use for the meta-regression analysis, whose results are reported in Table 5 in the main text. The control variables come from two main sources: (i) the World Bank national accounts data (for growth rate, inflation, unemployment rate) and (ii) the OECD database (for GDP growth, unemployment rate, inflation, strictness of employment protection legislation, and union density). For some countries, especially for the 1970s and 1980s, these data sources are complemented with data from INSEE (for France), the U.S. Union Membership and Coverage Database (for the U.S.), and the Argentinean Central bank (for Argentina). 
Table D5 - Meta-Analysis: Data Sources

\begin{tabular}{|c|c|c|c|c|c|c|c|c|c|c|c|c|c|}
\hline No. & Study & $\begin{array}{l}\text { Reform } \\
\text { years }\end{array}$ & $\begin{array}{l}\text { Data } \\
\text { years }\end{array}$ & $\begin{array}{l}\text { Period } \\
\text { dummy }\end{array}$ & Country & $\begin{array}{l}\text { Pass-through } \\
\text { estimate }\end{array}$ & $\begin{array}{l}\text { Tax-benefit } \\
\text { linkage }\end{array}$ & $\begin{array}{l}\text { Unit of } \\
\text { obs. }\end{array}$ & $\begin{array}{l}\text { GDP } \\
\text { growth }\end{array}$ & $\begin{array}{l}\text { Inflation } \\
\text { rate }\end{array}$ & $\begin{array}{l}\text { Unemployment } \\
\text { rate }\end{array}$ & $\begin{array}{l}\text { Strictness of } \\
\text { emp. protection }\end{array}$ & $\begin{array}{l}\text { Union } \\
\text { density }\end{array}$ \\
\hline 1 & Gruber (1994) & $1975-1979$ & $1974-1982$ & 1 & USA & 1.56 & 1 & 1 & 2.37 & 8.79 & 7.45 & $\mathrm{n} / \mathrm{a}$ & 22.80 \\
\hline 2 & Gruber (1997) & 1981 & $1979-1986$ & 1 & USA & 1.022 & 1 & 2 & 3.36 & 4.90 & 8.11 & 0.26 & 19.16 \\
\hline 3 & Gruber and Krueger (1991) & $1980 \mathrm{~s}$ & $1979-1988$ & 1 & USA & 0.865 & 1 & 1 & 3.06 & 5.63 & 7.50 & 0.26 & 19.08 \\
\hline 4 & Anderson and Meyer (1997) & 1978-1984 & $1978-1984$ & 1 & USA & 0.715 & 2 & 3 & 3.00 & 8.06 & 7.64 & $\mathrm{n} / \mathrm{a}$ & 21.73 \\
\hline 5 & Anderson and Meyer (2000) & 1985 & $1972-1997$ & 1 & USA & 1.427 & 2 & 3 & 3.23 & 3.41 & 6.16 & 0.26 & 16.04 \\
\hline 6 & Bozio et al. (2020) & 1989-1990 & $1985-1997$ & 1 & FRA & 0.100 & 0 & 1 & 1.94 & 2.33 & 9.10 & 2.34 & 9.98 \\
\hline 7 & Bozio et al. (2020) & $1982-1984$ & $1977-1988$ & 1 & FRA & 0.209 & 0 & 1 & 2.36 & 6.21 & 7.96 & 2.47 & 12.79 \\
\hline 8 & Adam et al. (2019) & $1982-2015$ & $1982-2015$ & 1 & GBR & -0.009 & 0 & 1 & 2.45 & 3.25 & 6.03 & 1.19 & 27.74 \\
\hline 9 & Saez et al. (2012) & 1992 & 2004-2009 & 2 & GRC & 0.295 & 0 & 1 & 2.51 & 5.71 & 10.08 & 2.80 & 24.77 \\
\hline 10 & Kugler and Kugler (2009) & 1993 & $1982-1996$ & 2 & $\mathrm{COL}$ & 0.2346 & 0 & 2 & 4.61 & 21.75 & 9.15 & $\mathrm{n} / \mathrm{a}$ & $\mathrm{n} / \mathrm{a}$ \\
\hline 11 & Cruces et al. (2010) & 1993 & 1995-2001 & 2 & ARG & 0.501 & 1 & 3 & 2.23 & 1.86 & 14.62 & $\mathrm{n} / \mathrm{a}$ & 35.20 \\
\hline 12 & Murphy (2007) & $1992-2002$ & $1992-2002$ & 2 & USA & 0.23 & 2 & 1 & 3.39 & 2.56 & 5.43 & 0.26 & 13.08 \\
\hline 13 & Baicker and Chandra (2006) & $1996-2002$ & $1996-2002$ & 2 & USA & 1.00 & 1 & 1 & 3.47 & 2.40 & 4.80 & 0.26 & 13.08 \\
\hline 14 & Baicker and Chandra (2006) & $1996-2002$ & $1996-2002$ & 2 & USA & -0.15 & 0 & 1 & 3.47 & 2.40 & 4.80 & 0.26 & 13.08 \\
\hline 15 & Komamura and Yamada (2004) & 2000 & $1997-2002$ & 3 & JPN & 1.2 & 1 & 2 & 1.10 & -0.78 & 5.04 & 1.70 & 20.80 \\
\hline 16 & Komamura and Yamada (2004) & 2000 & $1997-2002$ & 3 & JPN & 0.2 & 0 & 2 & 1.10 & -0.78 & 5.04 & 1.70 & 20.80 \\
\hline 17 & Bennmarker et al. (2009) & 2002 & $2001-2004$ & 3 & SWE & 0.23 & 0 & 2 & 2.92 & 1.49 & 5.76 & 2.61 & 77.10 \\
\hline 18 & Bozio et al. (2020) & $2000-2005$ & $1996-2008$ & 3 & FRA & 1.077 & 1 & 1 & 1.94 & 1.91 & 8.04 & 2.43 & 10.70 \\
\hline 19 & Korkeamäki and Uusitalo (2009) & $2003-2005$ & 1999-2004 & 3 & FIN & 0.49 & 0 & 2 & 3.00 & 0.53 & 8.92 & 2.17 & 72.35 \\
\hline 20 & Lehmann et al. (2013) & $2003-2005$ & 2003-2006 & 3 & FRA & 0.134 & 0 & 1 & 1.94 & 1.92 & 8.38 & 2.47 & 10.60 \\
\hline 21 & Saez et al. (2019) & 2007-2009 & $2002-2013$ & 3 & SWE & -0.085 & 0 & 1 & 1.24 & 1.45 & 7.60 & 2.61 & 68.34 \\
\hline
\end{tabular}

Notes: The time period is coded based on the date of the earliest reform being analyzed in the study, with 1: 1970s and 1980s, 2: 1990s, and 3: 2000s. The degree of tax-benefit linkage is coded as 0: none, 1: strong, and 3: uncertain. The unit of observation is coded as 1: worker, 2: firm, or 3: market level. All control variables are computed as means over the post-reform years considered in the analysis. The only exception concerns the variable "strictness of employment protection legislation", which is only available since 1985 . Hence for the period $1982-1988$ in France (estimate no. 7), we compute the mean value over the period 1985-1988; for the period 1981-1986 in the U.S., we compute the mean value over the period 1985-1986 (estimate no. 2), and for the period 1980-1988, we compute the mean over the period 1985-1988 (estimate no. 3).

Sources: The listed studies are described in Table 4. GDP growth rates come from the World Bank national accounts data and the OECD National Accounts data files (accessed on June 22, 2020, from data.worldbank.org). Unemployment rate comes from OECD database (OECD, 2020) (accessed on June 22, 2020 from data.oecd.org), except for France for the periods 1989-1997 and 1982-1988, for which we use the data from INSEE (2016), and for Argentina and Columbia, for which we use data from the World bank retrieved from the International Labour Organization, ILOSTAT database. Inflation rates come from the World Bank national accounts data and the OECD National Accounts data files, except for Argentina, for which we use data from the Banco Central de la Republica Argentina (accessed on June 22, 2020, from www.bcra.gob.ar). The indicator for strictness of employment protection legislation comes from OECD data and is available from 1985. Specifically, we use version 1 of the OECD's "Strictness of employment protection - individual dismissals (regular contracts)" data series. Labor union density comes from OECD data except for the U.S., for which we use data from the Union Membership and Coverage Database (Hirsch and Macpherson, 2003), for France, for which union density comes from OECD data except for the U.S., for which we use data from the Union Membership and Coverage Database (Hirsch and Macpherson, 2003), for France, for which Table 1). 


\section{E Pass-Through Estimates}

Table E6 - Pass-Through of Employer SSCs to Workers: Complete Results

\begin{tabular}{|c|c|c|c|c|}
\hline \multirow{2}{*}{$\begin{array}{l}\text { Reform: } \\
\text { Reference year }\left(t_{0}\right) \text { : } \\
\text { Dependent variable: }\end{array}$} & \multicolumn{2}{|c|}{$\begin{array}{c}\text { Reform } 1 \\
\text { Increase in pension } \\
\text { SSCs above the SST } \\
(1999)\end{array}$} & \multirow{2}{*}{$\begin{array}{c}\text { Reform } 2 \\
\text { Uncapping of } \\
\text { Family SSCs } \\
(1988) \\
\log (\text { earnings }) \\
(3)\end{array}$} & \multirow{2}{*}{$\begin{array}{c}\text { Reform } 3 \\
\text { Uncapping of } \\
\text { Health Care SSCs } \\
(1980) \\
\log (\text { earnings }) \\
(4)\end{array}$} \\
\hline & $\begin{array}{c}\log (\text { hourly wage }) \\
(1)\end{array}$ & $\begin{array}{c}\log (\text { earnings }) \\
(2)\end{array}$ & & \\
\hline \multicolumn{5}{|c|}{ Panel A. Baseline specification } \\
\hline$t_{0}+1$ & $\begin{array}{c}-0.283 \\
(0.233)\end{array}$ & $\begin{array}{c}-0.258 \\
(0.203)\end{array}$ & $\begin{array}{c}0.186 \\
(0.304)\end{array}$ & $\begin{array}{l}\mathrm{n} / \mathrm{a} \\
\mathrm{n} / \mathrm{a}\end{array}$ \\
\hline$t_{0}+2$ & $\begin{array}{c}0.104 \\
(0.233)\end{array}$ & $\begin{array}{c}0.192 \\
(0.211)\end{array}$ & $\begin{array}{l}\mathrm{n} / \mathrm{a} \\
\mathrm{n} / \mathrm{a}\end{array}$ & $\begin{array}{c}0.066 \\
(0.131)\end{array}$ \\
\hline$t_{0}+3$ & $\begin{array}{c}0.331^{*} \\
(0.190)\end{array}$ & $\begin{array}{c}0.179 \\
(0.173)\end{array}$ & $\begin{array}{r}-0.020 \\
(0.177)\end{array}$ & $\begin{array}{l}\mathrm{n} / \mathrm{a} \\
\mathrm{n} / \mathrm{a}\end{array}$ \\
\hline$t_{0}+4$ & $\begin{array}{l}0.625^{* * *} \\
(0.241)\end{array}$ & $\begin{array}{c}0.485 \\
(0.228)\end{array}$ & $\begin{array}{c}-0.178 \\
(0.180)\end{array}$ & $\begin{array}{l}0.419^{* * *} \\
(0.123)\end{array}$ \\
\hline$t_{0}+5$ & $\begin{array}{l}1.037^{* * *} \\
(0.281)\end{array}$ & $\begin{array}{l}0.704^{* *} \\
(0.263)\end{array}$ & $\begin{array}{c}-0.325 \\
(0.220)\end{array}$ & $\begin{array}{l}0.294^{* *} \\
(0.128)\end{array}$ \\
\hline$t_{0}+6$ & $\begin{array}{l}1.071^{* * *} \\
(0.271)\end{array}$ & $\begin{array}{l}0.683^{* * *} \\
(0.258)\end{array}$ & $\begin{array}{c}0.049 \\
(0.246)\end{array}$ & $\begin{array}{l}0.356^{* * *} \\
(0.137)\end{array}$ \\
\hline$t_{0}+7$ & $\begin{array}{l}1.021^{* * *} \\
(0.279)\end{array}$ & $\begin{array}{l}0.758^{* * *} \\
(0.269)\end{array}$ & $\begin{array}{c}-0.042 \\
(0.170)\end{array}$ & $\begin{array}{l}0.422^{* * *} \\
(0.150)\end{array}$ \\
\hline$t_{0}+8$ & $\begin{array}{l}0.934^{* * *} \\
(0.303)\end{array}$ & $\begin{array}{l}0.812^{* * *} \\
(0.293)\end{array}$ & $\begin{array}{c}0.186 \\
(0.166)\end{array}$ & $\begin{array}{l}0.384^{* *} \\
(0.172)\end{array}$ \\
\hline$t_{0}+9$ & $\begin{array}{l}0.906^{* * *} \\
(0.327)\end{array}$ & $\begin{array}{l}0.969^{* * *} \\
(0.324)\end{array}$ & $\begin{array}{c}0.215 \\
(0.170)\end{array}$ & $\begin{array}{l}\mathrm{n} / \mathrm{a} \\
\mathrm{n} / \mathrm{a}\end{array}$ \\
\hline $\mathrm{N}$ & 490,537 & 496,030 & 594,549 & 642,084 \\
\hline \multicolumn{5}{|c|}{ Panel B. Controlling for worker-specific trends } \\
\hline$t_{0}+1$ & $\begin{array}{c}-0.049 \\
(0.238)\end{array}$ & $\begin{array}{c}-0.041 \\
(0.207)\end{array}$ & $\begin{array}{c}0.176 \\
(0.299)\end{array}$ & $\begin{array}{l}\mathrm{n} / \mathrm{a} \\
\mathrm{n} / \mathrm{a}\end{array}$ \\
\hline$t_{0}+2$ & $\begin{array}{c}0.388 \\
(0.242)\end{array}$ & $\begin{array}{c}0.412^{*} \\
(0.213)\end{array}$ & $\begin{array}{l}\mathrm{n} / \mathrm{a} \\
\mathrm{n} / \mathrm{a}\end{array}$ & $\begin{array}{c}0.092 \\
(0.119)\end{array}$ \\
\hline$t_{0}+3$ & $\begin{array}{l}0.512^{* *} \\
(0.218)\end{array}$ & $\begin{array}{l}0.419^{* *} \\
(0.191)\end{array}$ & $\begin{array}{c}-0.027 \\
(0.190)\end{array}$ & $\begin{array}{l}\mathrm{n} / \mathrm{a} \\
\mathrm{n} / \mathrm{a}\end{array}$ \\
\hline$t_{0}+4$ & $\begin{array}{l}0.743^{* * *} \\
(0.260)\end{array}$ & $\begin{array}{l}0.665^{* * *} \\
(0.234)\end{array}$ & $\begin{array}{r}-0.050 \\
(0.203)\end{array}$ & $\begin{array}{l}0.281^{* *} \\
(0.114)\end{array}$ \\
\hline$t_{0}+5$ & $\begin{array}{l}1.053^{* * *} \\
(0.294)\end{array}$ & $\begin{array}{l}0.888^{* * *} \\
(0.265)\end{array}$ & $\begin{array}{r}-0.139 \\
(0.216)\end{array}$ & $\begin{array}{c}0.185 \\
(0.116)\end{array}$ \\
\hline$t_{0}+6$ & $\begin{array}{l}1.075^{* * *} \\
(0.294)\end{array}$ & $\begin{array}{l}0.899^{* * *} \\
(0.266)\end{array}$ & $\begin{array}{c}0.010 \\
(0.228)\end{array}$ & $\begin{array}{r}0.228^{*} \\
(0.121)\end{array}$ \\
\hline$t_{0}+7$ & $\begin{array}{l}1.113^{* * *} \\
(0.306)\end{array}$ & $\begin{array}{l}1.052^{* * *} \\
(0.279)\end{array}$ & $\begin{array}{c}0.027 \\
(0.217)\end{array}$ & $\begin{array}{l}0.261^{* *} \\
(0.126)\end{array}$ \\
\hline$t_{0}+8$ & $\begin{array}{l}1.077^{* * *} \\
(0.318)\end{array}$ & $\begin{array}{l}1.112^{* * *} \\
(0.291)\end{array}$ & $\begin{array}{c}0.100 \\
(0.224)\end{array}$ & $\begin{array}{c}0.209 \\
(0.133)\end{array}$ \\
\hline$t_{0}+9$ & $\begin{array}{l}1.064^{* * *} \\
(0.335)\end{array}$ & $\begin{array}{l}1.157^{* * *} \\
(0.308)\end{array}$ & $\begin{array}{c}0.061 \\
(0.229)\end{array}$ & $\begin{array}{l}\mathrm{n} / \mathrm{a} \\
\mathrm{n} / \mathrm{a}\end{array}$ \\
\hline $\mathrm{N}$ & 490,537 & 496,030 & 594,549 & 642,084 \\
\hline
\end{tabular}

Notes: See notes of Table 3 in the main text. ${ }^{* * *} \mathrm{p}<0.01,{ }^{* *} \mathrm{p}<0.05,{ }^{*} \mathrm{p}<0.1$.

Sources: DADS Panel 2010; TAXIPP 0.4. 


\section{F Heterogeneity Analysis}

We investigate the heterogeneity of wage responses to the three SSC reforms across worker and firm characteristics. Specifically, we analyze the differences in pass-through rates along four dimensions: by sector, by firm size, by gender, and by age of the workers. Table F7 reports the results obtained when controlling for worker-specific trends (Equation 7 in the main text). The baseline estimates using the full sample can be found in Table 3 .

The main objective of this heterogeneity analysis is to investigate if the marked differences in pass-through across the three reforms are driven by specific subsamples or, instead, if they hold uniformly across groups of workers and firms.

Panel A in Table F7 presents the estimates contrasting the estimated pass-through for two sub-samples of workers based on the firm's sector in the pre-reform year. We group under the label "Industry" all firms in the manufacturing and primary sector (extraction and agriculture), while we group under the label "Services" all firms in the service and retail sectors. For Reform 1, we find very similar results to our baseline estimates in both sub-samples, with estimates of the pass-through rate close to 1 (albeit being less precisely estimated). For Reforms 2 and 3, the estimated pass-through rates are close to zero for the Industry and around 0.5 for Services. For Reform 2, we find that the pass-through rate is significantly higher for Services than for the Industry. In both sectors, the pass-through estimates for Reform 2 and Reform 3 are smaller than the corresponding estimates for Reform 1. The differences across reforms are, however, not always statistically significant due to lack of statistical power ( $p$-values not reported).

Panel B compares the estimated pass-through rate for workers in large vs. small firms in the pre-reform year. We define large (small) firms as firms whose number of employees is larger (smaller) than the median. The two sub-samples are constructed separately for the treatment and control groups. For all reforms, we find a larger pass-through rate for large firms than for small firms, the difference being statistically significant only for Reform 1 when $\log$ (earnings) is used as the dependent variable. For both small and large firms, the pass-through estimates for Reform 2 and Reform 3 are smaller than the corresponding estimates for Reform 1. The differences between Reform 1 and Reform 2 or Reform 3 are, however, only statistically significant for large firms.

Panel C compares the pass-through rates for male and female workers. There is limited heterogeneity according to workers' gender. In the case of Reform 1 (Reform 2), we find pass-through estimates that are close to and not significantly different from 1 (from 0 ) for both male and female workers. For Reform 3, we find a significant pass-through rate of 0.42 for males while the pass-through rate estimate for females is slightly negative and not significantly different from 0 . The differences between pass-through estimates for Reform 1 , on the one hand, and Reform 2 or Reform 3, on the other hand, are large and significantly different from 0 in most cases.

Panel D compares older workers to younger ones. We define older workers as those whose age is above the median (respectively below the median for the young). The two sub-samples are constructed separately for the treatment and control groups. The results for Reform 1 and Reform 2 suggest that the pass-through rate was larger for younger workers than for older ones, but the estimates are very imprecise and the differences 
are statistically significant only for Reform 2. By contrast, we find a significantly larger pass-through rate for older workers than for younger ones in the case of Reform 3. This difference is driven by the large and somewhat puzzling estimated pass-through rate of 0.75 for older workers in Reform 3. Among all estimates reported for Reform 2 and Reform 3, this is the only one to be larger than the corresponding estimates for Reform 1. For younger workers, we find marked and statistically significant differences in pass-through rates between Reform 1 and Reform 2 or Reform 3.

Overall, we do not detect significant heterogeneity across most subsamples, even though we lack the statistical power to reach definitive conclusions. If anything, pass-through rates tend to be larger among large firms and younger workers (except for Reform 3). More importantly, the results show that differences in pass-through rates between Reform 1, on the one hand, and Reform 2 and Reform 3, on the other hand, are observed in almost all subsamples. 
Table F7 - Estimates of the Pass-Through of Employer SSCs to Workers: Heterogeneity Analysis (Controlling for Worker-Specific Trends)

\begin{tabular}{|c|c|c|c|c|}
\hline \multirow{2}{*}{$\begin{array}{l}\text { Reform: } \\
\text { Reference year }\left(t_{0}\right) \text { : } \\
\text { Dependent variable: }\end{array}$} & \multicolumn{2}{|c|}{$\begin{array}{c}\text { Reform 1: } \\
\text { Increase in pension } \\
\text { SSCs above the SST } \\
(1999)\end{array}$} & \multirow{2}{*}{$\begin{array}{c}\text { Reform 2: } \\
\text { Uncapping of } \\
\text { Family SSCs } \\
(1988) \\
\text { Log(earnings }) \\
(3)\end{array}$} & \multirow{2}{*}{$\begin{array}{c}\text { Reform 3: } \\
\text { Uncapping of } \\
\text { Health Care SSCs } \\
(1980) \\
\text { Log(earnings) } \\
(4)\end{array}$} \\
\hline & $\log ($ hourly wage $)$ & $\begin{array}{c}\log (\text { earnings }) \\
(2)\end{array}$ & & \\
\hline \multicolumn{5}{|c|}{ Panel A. Industry vs. services } \\
\hline Industry $\left(t_{0}+8\right)$ & $\begin{array}{l}1.110^{* * *} \\
(0.465)\end{array}$ & $\begin{array}{l}0.872^{* * *} \\
(0.396)\end{array}$ & $\begin{array}{c}-0.264 \\
(0.295)\end{array}$ & $\begin{array}{c}0.114 \\
(0.166)\end{array}$ \\
\hline $\mathrm{N}$ & 243,132 & 245,126 & 367,924 & 421,135 \\
\hline Services $\left(t_{0}+8\right)$ & $\begin{array}{l}0.919^{* *} \\
(0.434)\end{array}$ & $\begin{array}{l}1.340^{* * *} \\
(0.425)\end{array}$ & $\begin{array}{c}0.660^{*} \\
(0.342)\end{array}$ & $\begin{array}{c}0.380^{*} \\
(0.222)\end{array}$ \\
\hline $\mathrm{N}$ & 247,405 & 250,904 & 226,628 & 220,949 \\
\hline$t$-test of difference ( $p$-value) & 0.764 & 0.421 & 0.045 & 0.340 \\
\hline \multicolumn{5}{|c|}{ Panel B. Large firms vs. small firms } \\
\hline Large firms $\left(t_{0}+8\right)$ & $\begin{array}{l}1.356^{* * *} \\
(0.433)\end{array}$ & $\begin{array}{l}1.696^{* * *} \\
(0.416)\end{array}$ & $\begin{array}{c}0.362 \\
(0.283)\end{array}$ & $\begin{array}{c}0.378 \\
(0.197)\end{array}$ \\
\hline $\mathrm{N}$ & 243,241 & 246,721 & 295,123 & 319,045 \\
\hline Small firms $\left(t_{0}+8\right)$ & $\begin{array}{c}0.722 \\
(0.467)\end{array}$ & $\begin{array}{c}0.459 \\
(0.399)\end{array}$ & $\begin{array}{r}-0.253 \\
(0.357)\end{array}$ & $\begin{array}{c}0.038 \\
(0.178)\end{array}$ \\
\hline $\mathrm{N}$ & 247,296 & 249,309 & 299,429 & 323,039 \\
\hline$t$-test of difference ( $p$-value) & 0.320 & 0.032 & 0.178 & 0.200 \\
\hline \multicolumn{5}{|c|}{ Panel C. Male vs. female workers } \\
\hline Male workers $\left(t_{0}+8\right)$ & $\begin{array}{l}1.010^{* * *} \\
(0.379)\end{array}$ & $\begin{array}{l}1.081^{* * *} \\
(0.336)\end{array}$ & $\begin{array}{c}0.102 \\
(0.253)\end{array}$ & $\begin{array}{l}0.420^{* * *} \\
(0.148)\end{array}$ \\
\hline $\mathrm{N}$ & 368,141 & 372,340 & 458,061 & 508,586 \\
\hline Female workers $\left(t_{0}+8\right)$ & $\begin{array}{l}1.306^{* *} \\
(0.593)\end{array}$ & $\begin{array}{l}1.443^{* *} \\
(0.588)\end{array}$ & $\begin{array}{c}0.110 \\
(0.481)\end{array}$ & $\begin{array}{r}-0.175 \\
(0.285)\end{array}$ \\
\hline $\mathrm{N}$ & 122,396 & 123,690 & 136,491 & 133,498 \\
\hline$t$-test of difference ( $p$-value) & 0.689 & 0.591 & 0.988 & 0.066 \\
\hline \multicolumn{5}{|c|}{ Panel D. Older vs. younger workers } \\
\hline Older workers $\left(t_{0}+8\right)$ & $\begin{array}{c}0.646 \\
(0.491)\end{array}$ & $\begin{array}{c}0.669 \\
(0.440)\end{array}$ & $\begin{array}{c}-0.517 \\
(0.406)\end{array}$ & $\begin{array}{l}0.748^{* * *} \\
(0.203)\end{array}$ \\
\hline $\mathrm{N}$ & 224,472 & 226,338 & 253,287 & 319,880 \\
\hline Younger workers $\left(t_{0}+8\right)$ & $\begin{array}{l}1.324^{* * *} \\
(0.416)\end{array}$ & $\begin{array}{l}1.377^{* * *} \\
(0.386)\end{array}$ & $\begin{array}{r}0.481^{*} \\
(0.267)\end{array}$ & $\begin{array}{c}-0.207 \\
(0.176)\end{array}$ \\
\hline $\mathrm{N}$ & 266,065 & 269,692 & 341,265 & 322,204 \\
\hline$t$-test of difference ( $p$-value) & 0.288 & 0.225 & 0.032 & 0.000 \\
\hline
\end{tabular}

Notes: The different columns correspond to different SSC reforms: the increase in pension SSCs between 2000 and 2005 (columns 1 and 2); the uncapping of family SSCs in 1989 and 1990 (column 3); and the uncapping of health care SSCs in 1981 and 1983 (column 4). Estimates are obtained from a difference-in-difference specification that compares workers whose earnings in the pre-reform year were in the range of 1 to 1.4 times the SST (treatment group) with workers whose earnings in the pre-reform year were in the range of 0.9 to 1 times the SST (control group). All specifications control for worker-specific trends. Standard errors clustered at the individual level are shown in parentheses. ${ }^{* * *} \mathrm{p}<0.01,{ }^{* *} \mathrm{p}<0.05$, * $\mathrm{p}<0.1$.

Sources: DADS Panel 2010; TAXIPP 0.4. 


\section{G Robustness Checks}

This appendix presents the results of various tests carried out to assess the robustness of the baseline estimates reported in the main text. We test the sensitivity of our results to using alternative definitions of the treatment and control groups (Section G.1) and to relaxing some of our sample restrictions, e.g., by including executives in the analysis of Reforms 2 and 3, or by including individuals working part-time or part of the year in the analysis of Reform 1 (Section G.2). We then present additional results for Reform 1 using total earnings (instead of hourly wage), which is the outcome variable that we use for the two earlier reforms (Section G.3). Finally, we analyze a placebo reform that is set in a period during which no SSC reform was implemented (Section G.4).

\section{G.1 Definition of Treatment and Control Groups}

We test the sensitivity of our results to the definitions of the treatment and control groups by systematically varying the upper and lower earnings thresholds that determine whether workers are assigned to either group in the reference year $\left(t_{0}\right)$.

Estimates for the shifting parameter at $t_{0}+8$ are shown in Figure G6 when we do not include worker-specific trends, and in Figure G7 when we control for trends. We show estimates for various choices of the treatment group's upper earnings threshold (figures to the left) and of the control group's lower earnings threshold (figures to the right).

The pass-through estimates are reasonably similar although, as expected, standard errors become larger when we reduce the size of the treatment group or the control group, i.e., when we shrink the window towards the SST. Panel (a) presents the estimates for Reform 1. The results confirm full pass-through to wages, as the estimates are not significantly different from 1 in almost all variants. Panel (b) shows the results for Reform 2. The point estimates, which are between 0 and 0.4 , are always significantly different from 1 and are seldom significantly different from zero except when the lower earnings threshold of the control group is moved further away from the Social-Security threshold. The estimates for Reform 3 appear more sensitive to the definitions of treatment and control groups (Panel c) when controlling for worker-specific trends. For instance, we find that setting the upper threshold of the treatment group very close to the SST (1.2 times the SST) leads to a relatively imprecisely estimated pass-through rate of 0.7 , compared to estimates closer to $0.2-0.5$ in other cases. Aside from this exception, estimates of the pass-through rate for Reform 3 are always significantly different from 1.

\section{G.2 Sensitivity to Relaxing Sample Restrictions}

Table G8 reports the results from several robustness checks that we carry out to evaluate the sensitivity of our baseline estimates (shown in Panel A) to relaxing the sample restrictions. Recall that our estimates of the pass-through rate of employer SSCs to wages are based on a sample that excludes executive workers (since they were not affected by Reform 1) and is restricted to individuals working full-time during the entire year.

In Panel B, we test the sensitivity of our results for Reforms 2 and 3 to including 
executive workers in the sample, as these workers were also affected by the two reforms. The results are not significantly different from the baseline estimates reported in Panel A.A.23

In Panel C, we test the robustness of our estimates for Reform 1 to including individuals who worked only part of the year (non-full-year), as the data allow us to accurately compute their SSCs from 1993 onwards. The estimates are virtually unchanged and are not significantly different from the baseline estimates.

In Panel D, we extend the sample to include part-time workers. Again, the results are very similar to the baseline estimates.

\section{G.3 Earnings Responses vs. Wage Responses (Reform 1)}

For Reform 1, we can estimate the impact of increased employer SSCs on both (hourly) wages and earnings, whereas we do not observe the number of hours worked for the earlier reforms (Reforms 2 and 3). The figures shown in the main text for Reform 1 are related to the wage response, i.e., the proper incidence response. For completeness, we present here similar figures for the earnings response.

Figure G8 parallels Figure 3 in the main text and shows the earnings response to Reform 1 by comparing the evolution of gross (or posted) earnings and the evolution of labor cost between the treatment and control groups. Figure G9 presents the reduced-form estimates (Panel a) and the estimated pass-through rate (Panel b), and can be compared to Figure 6. As is clear from these figures and the regression results reported in Table 3, the pass-through estimates based on earnings are extremely close to those based on hourly wages.

\section{G.4 Placebo Reform}

We perform a placebo test to check whether underlying inequality trends during our period of interest could disqualify the common trend assumption. To conduct this placebo analysis, we focus on periods during which no SSC reform took place. Visual inspection of Figure 1 in the main text reveals that the only reform-free period of sufficient time length is between 1992 and 1999, i.e., the time interval between the end of Reform 2 and the start of Reform 1. We set the placebo reform to take place in 1996 and define our control and treatment groups using 1995 as the placebo reference year.

Graphical evidence is presented in Figure G10. Panels (a) and (b) show the evolution in levels of posted earnings/gross earnings and labor cost around the placebo reform year. These two graphs are constructed in a similar way as those presented in the main text (Figures 3 to 5). There is no evidence of differential earnings trends between the treatment and control groups. Moreover, the reduced-form estimates shown in panel (c) point to zero effects on gross earnings and labor cost.

\footnotetext{
A.23 Note that the share of executives in the labor market was relatively low during this period (less than
} 10 percent). 
(a) Reform 1: Increase in Pension SSCs

Control group's lower wage threshold

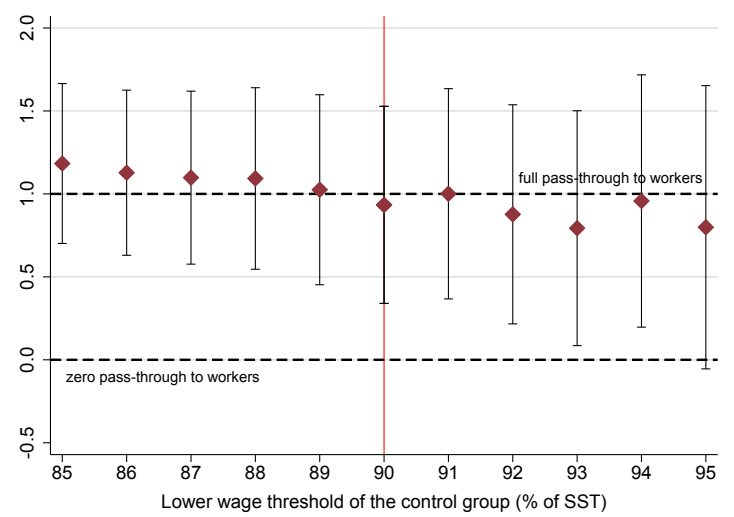

Treatment group's upper wage threshold

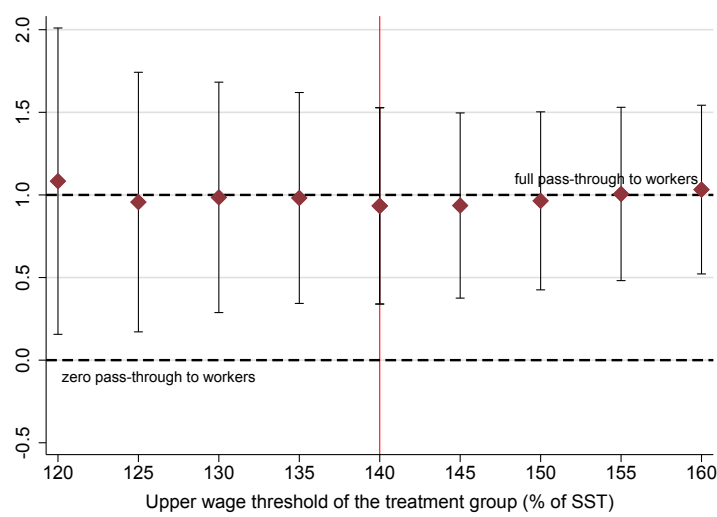

(b) Reform 2: Uncapping of Family SSCs

Control group's lower earnings threshold

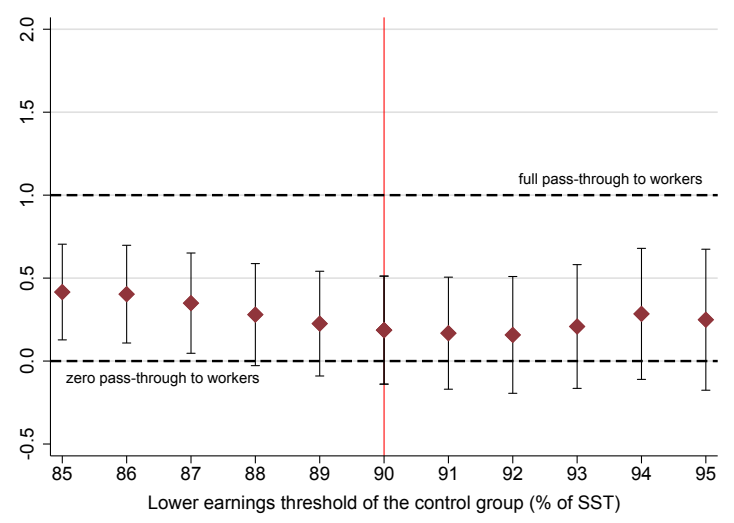

Treatment group's upper earnings threshold

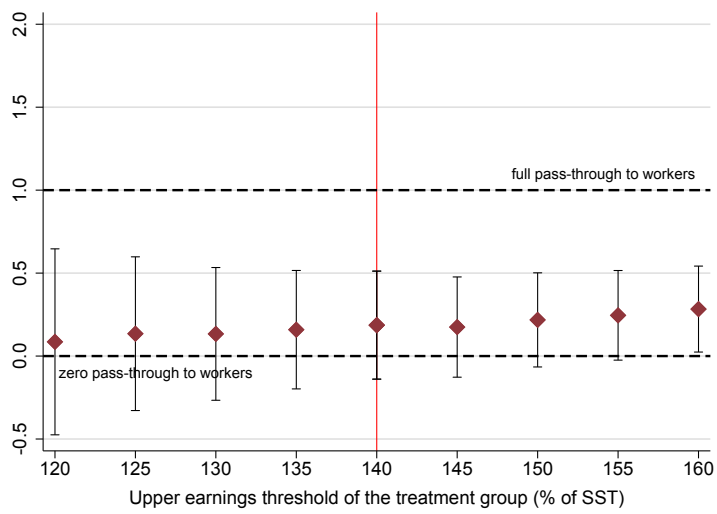

(c) Reform 3: Uncapping of Health Care SSCs

Control group's lower earnings threshold

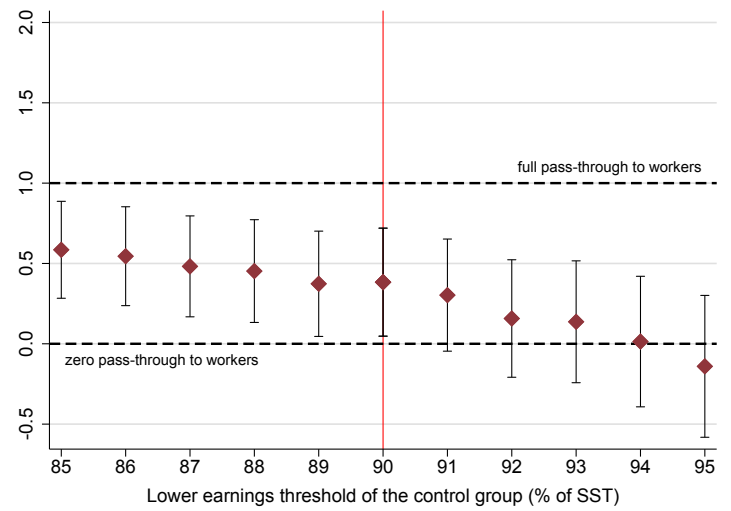

Treatment group's upper earnings threshold

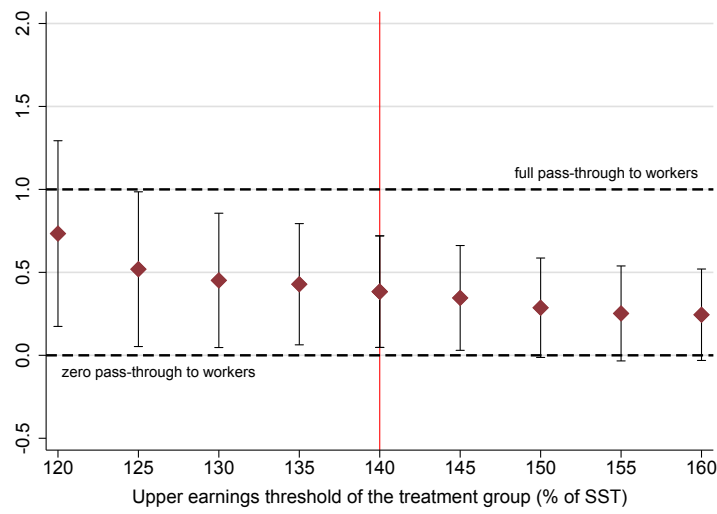

Figure G6 - Estimated Pass-Through to Workers: Sensitivity to Varying the Lower and Upper Earnings Thresholds of the Control and Treatment Groups (not Controlling for Worker-Specific Trends)

Notes: The pass-through estimates shown in this figure are evaluated at $t_{0}+8$, where $t_{0}$ denotes the last pre-reform year, and are based on a specification that does not include worker-specific linear time trends. The left panels show the estimates obtained for various choices of the control group's lower earnings threshold (expressed in percentage of the Social Security threshold or SST) while keeping fixed the upper threshold of the treatment group (1.4 times the SST). The right panels show the estimates when varying the treatment group's upper earnings threshold (expressed in percentage of the Social Security threshold) while keeping fixed the lower threshold of the control group (0.9 times the SST). The vertical solid lines show the thresholds that are used in the baseline specification. The markers represent the estimated pass-through of employer SSCs to workers. The vertical T-bars show the 95 percent confidence intervals around the point estimates, with standard errors clustered at the individual level. 
(a) Reform 1: Increase in Pension SSCs

Control group's lower wage threshold

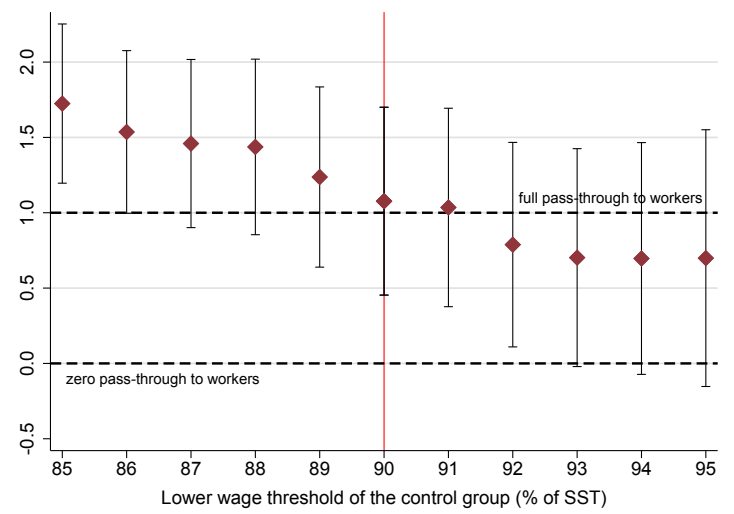

Treatment group's upper wage threshold

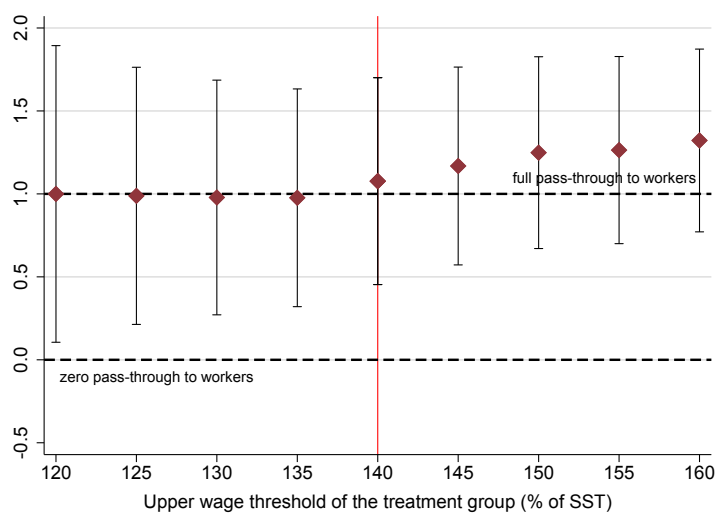

(b) Reform 2: Uncapping of Family SSCs

Control group's lower earnings threshold

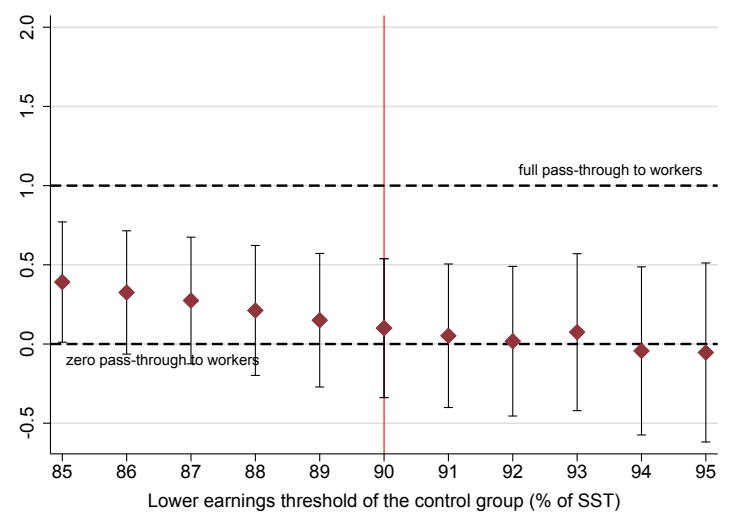

Treatment group's upper earnings threshold

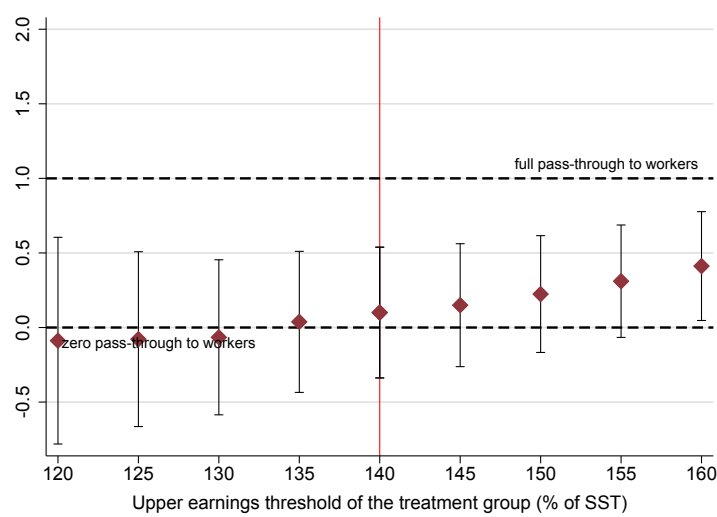

(c) Reform 3: Uncapping of Health Care SSCs

Control group's lower earnings threshold

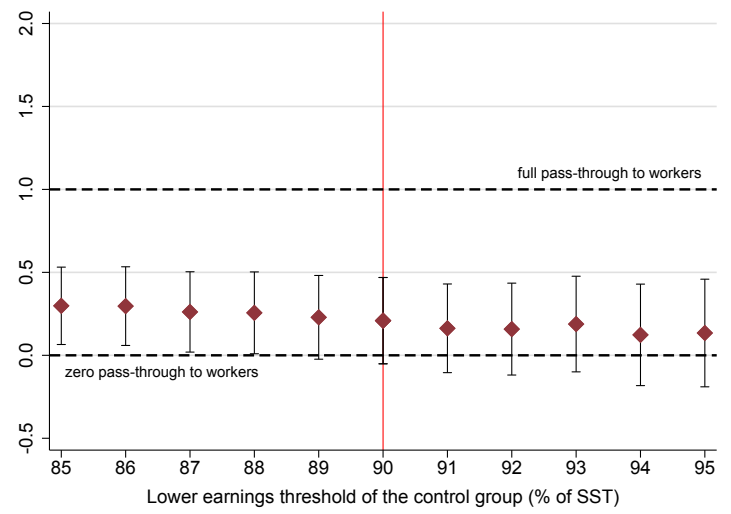

Treatment group's upper earnings threshold

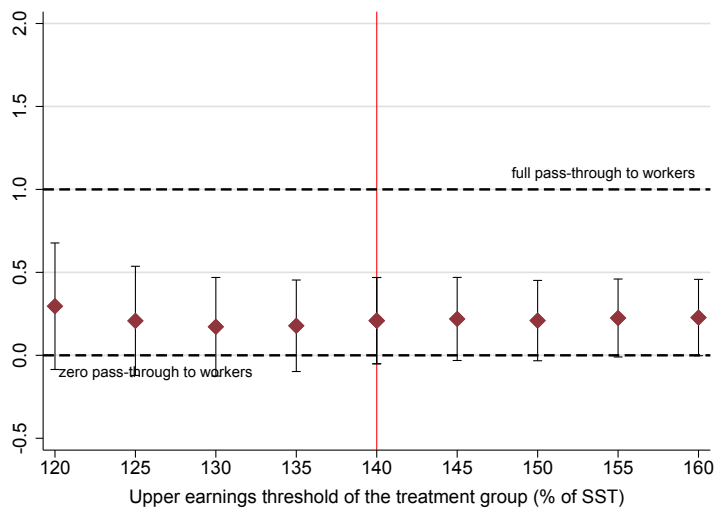

Figure G7 - Estimated Pass-Through to Workers: Sensitivity to Varying the Lower and Upper Earnings Thresholds of the Control and Treatment Groups (Controlling for Worker-Specific Trends)

Notes: The pass-through estimates shown in this figure are evaluated at $t_{0}+8$, where $t_{0}$ denotes the last pre-reform year, and are based on a specification that controls for worker-specific linear time trends. The left panels show the estimates obtained for various choices of the control group's lower earnings threshold (expressed in percentage of the Social Security threshold or SST) while keeping fixed the upper threshold of the treatment group (1.4 times the SST). The right panels show the estimates when varying the treatment group's upper earnings threshold (expressed in percentage of the Social Security threshold) while keeping fixed the lower threshold of the control group (0.9 times the SST). The vertical solid lines show the thresholds that are used in the baseline specification. The markers represent the estimated pass-through of employer SSCs to workers. The vertical T-bars show the 95 percent confidence intervals around the point estimates, with standard errors clustered at the individual level. 
Table G8 - Estimates of the Pass-Through of Employer SSCs to Workers: Sensitivity to Alternative Sample Definitions (Controlling for Worker-Specific Trends)

\begin{tabular}{|c|c|c|c|c|}
\hline $\begin{array}{l}\text { Reform: } \\
\text { Reference year }\left(t_{0}\right) \text { : }\end{array}$ & $\begin{array}{r}\text { Refo } \\
\text { Increase } \\
\text { SSCs abo } \\
(1\end{array}$ & $\begin{array}{l}\text { 1: } \\
\text { thension } \\
\text { SST }\end{array}$ & $\begin{array}{c}\text { Reform 2: } \\
\text { Uncapping of } \\
\text { Family SSCs } \\
\quad(1988)\end{array}$ & $\begin{array}{c}\text { Reform 3: } \\
\text { Uncapping of } \\
\text { Health Care SSCs } \\
(1980) \\
\end{array}$ \\
\hline Dependent variable: & $\begin{array}{c}\log (\text { hourly wage }) \\
(1)\end{array}$ & $\begin{array}{c}\log (\text { earnings }) \\
(2)\end{array}$ & $\begin{array}{c}\log (\text { earnings }) \\
(3)\end{array}$ & $\begin{array}{c}\log (\text { earnings }) \\
(4)\end{array}$ \\
\hline
\end{tabular}

Panel A. Baseline estimates (excluding executives, restricted to full-time, full-year workers)

$\begin{array}{ccccc}t_{0}+8 & 1.077^{* * *} & 1.112^{* * *} & 0.100 & 0.209 \\ & (0.318) & (0.291) & (0.224) & (0.133) \\ \mathrm{N} & 490,537 & 496,030 & 594,549 & 642,084\end{array}$

Panel B. Including executive workers

$t_{0}+8$

0.112

0.096

$\mathrm{N}$

$\mathrm{N}$

646,029

657,734

Panel C. Including individuals working less than full year
$t_{0}+8$
$1.076^{* * *}$
$1.103^{* * *}$
(0.316)
(0.289)
$\mathrm{N}$
517,286
523,276

Panel D. Including part-time workers
$t_{0}+8$
$1.072^{* * *}$
$1.101^{* * *}$
(0.290)
$\mathrm{N}$
523,317
529,363

Notes: The different columns correspond to different SSC reforms: the increase in pension SSCs between 2000 and 2005 (columns 1 and 2); the uncapping of family SSCs in 1989 and 1990 (column 3); and the uncapping of health care SSCs in 1981 and 1983 (column 4). Estimates are obtained from a difference-in-difference specification that compares workers whose earnings in the pre-reform year were in the range of 1 to 1.4 times the SST (treatment group) with workers whose earnings in the pre-reform year were in the range of 0.9 to 1 times the SST (control group). All specifications control for worker-specific linear time trends. Standard errors clustered at the individual level are shown in parentheses. ${ }^{* * *} \mathrm{p}<0.01$, ${ }^{* *} \mathrm{p}<0.05,{ }^{*} \mathrm{p}<0.1$.

Sources: DADS Panel 2010; TAXIPP 0.4. 
(a) Posted/Gross Earnings $(w h)$

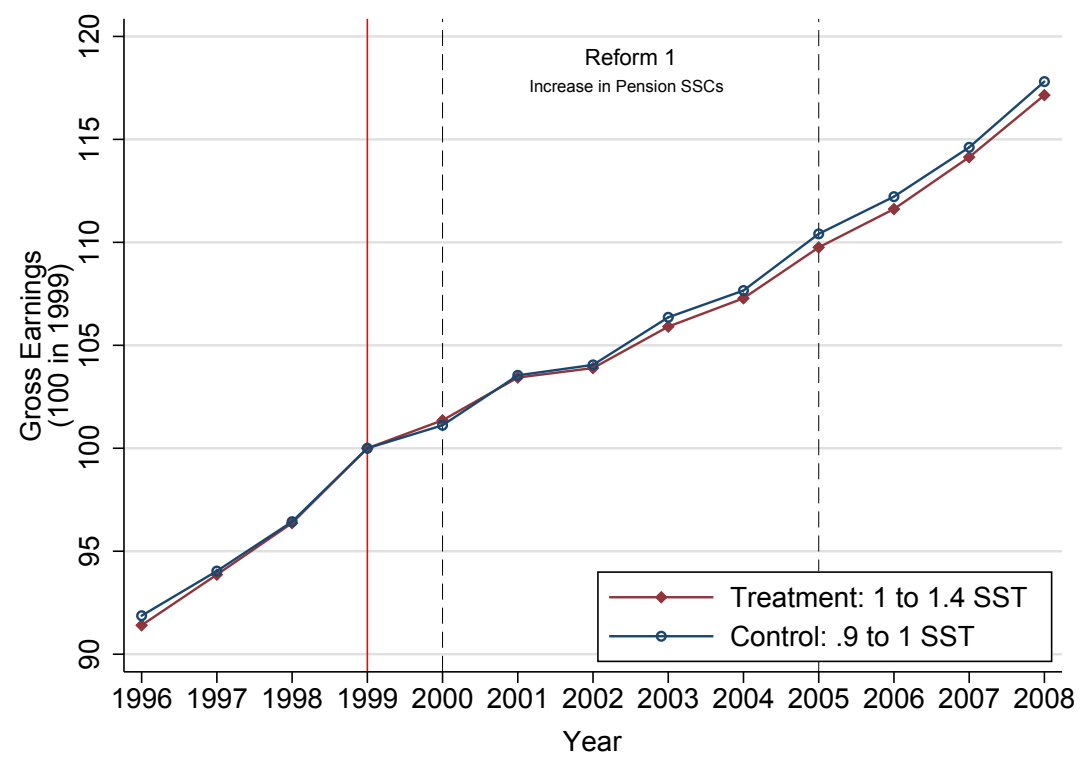

(b) Labor Cost $(z h)$

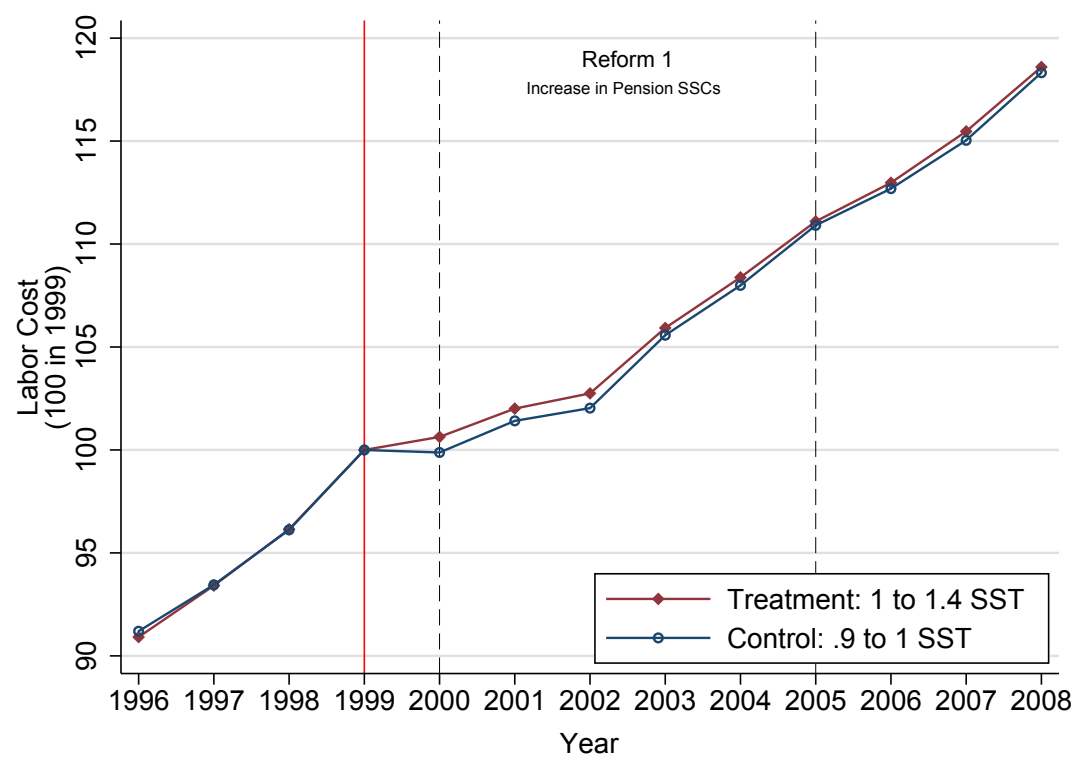

Figure G8 - Earnings Responses to the Increase in Pension SSCs (Reform 1)

Notes: The figure shows the evolution of average real gross earnings (Panel a) and average real labor cost (Panel b) between 1996 and 2008 for two groups of workers that were affected differently by the increase in the pension SSCs for non executives between 2000 and 2005. The figure is based on an unbalanced panel of workers who are observed in the last pre-reform year (denoted by a vertical solid line) and at least another year. The vertical dashed lines denote the reform years (start and end). Earnings levels are normalized to 100 for both groups in the reference year (1999). The treatment group includes workers whose gross earnings in 1999 were 1 to 1.4 times the SST that year. These workers experienced an increase in their average SSC rate due to the reform. The control group includes workers whose gross earnings in 1999 were 0.9 to 1 times the SST that year. These workers did not experience a change in their average SSC rate due to the reform.

Sources: DADS Panel 2010; TAXIPP 0.4. 
(a) Log Difference in Gross Earnings and Labor Cost

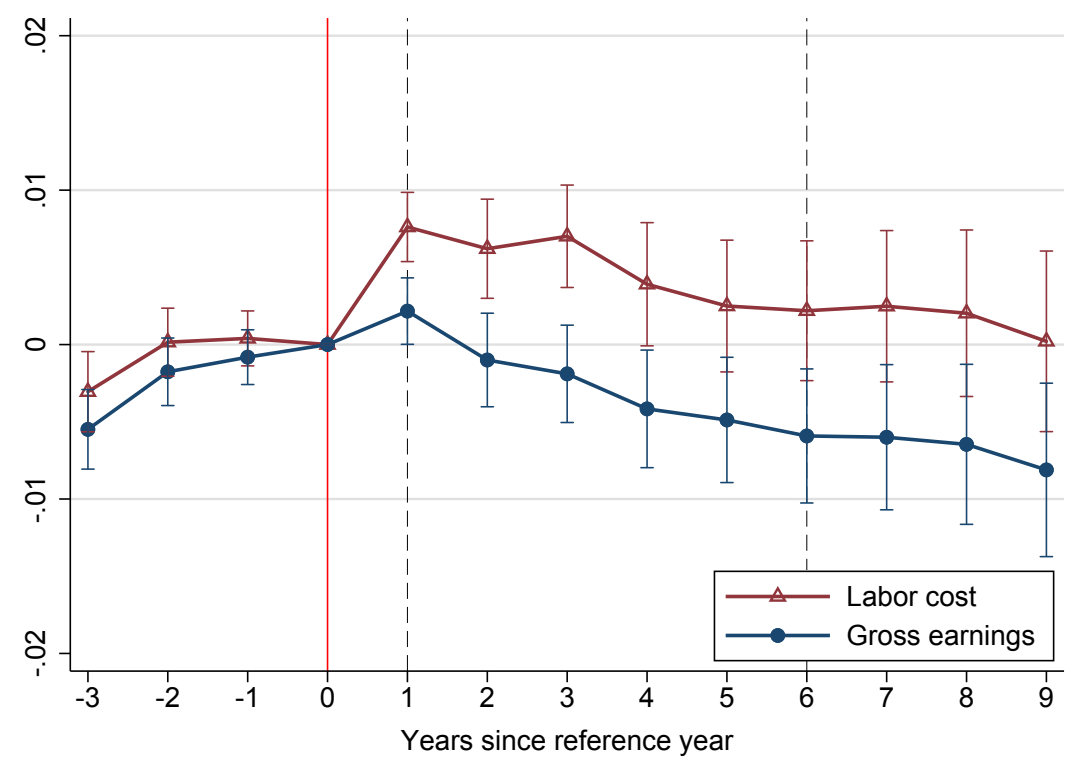

(b) Pass-Through to Workers (2SLS)

Baseline specification

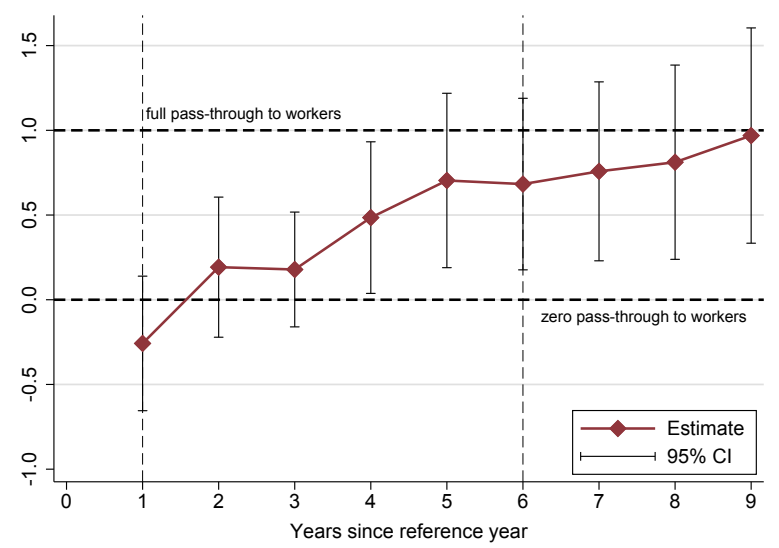

Controlling for worker-specific trends

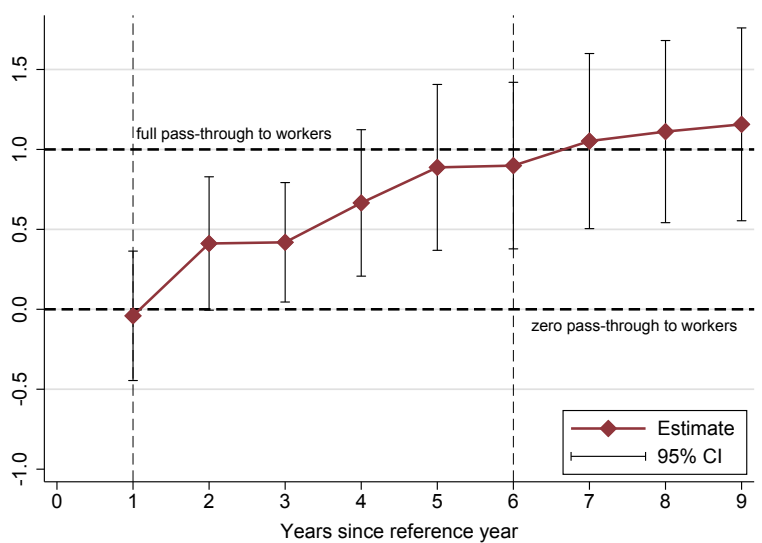

Figure G9 - Reform 1: Estimated Pass-Through to Workers (Earnings)

Notes: Panel (a) shows the estimated log differences between the average real gross earnings (circle markers) and the average real labor cost (triangle markers) of two groups of workers that were affected differently by the increase in the pension SSCs for non executives between 2000 and 2005. The vertical dashed lines denote the reform years (start and end). The difference-in-differences estimation is performed on an unbalanced panel of workers who are observed in the last pre-reform year and at least another year. The treatment group includes workers whose gross earnings in the last pre-reform year (1999) were 1 to 1.4 times the SST that year. These workers experienced an increase in their average SSC rate due to the reform. The control group includes workers whose gross earnings in 1999 were 0.9 to 1 times the SST that year. These workers did not experience a change in their average SSC rate due to the reform. The markers represent the parameter estimates on the interaction between the treatment group and year dummies, which is normalized to zero in the reference year (1999). The vertical T-bars show the 95 percent confidence intervals around the point estimates, with standard errors clustered at the individual level. Panel (b) shows the estimated pass-through rate of employer SSCs to the wage of treated workers relative to control workers over a period up to 8 years after the reform. The vertical dashed lines denote the reform years (start and end). The estimated pass-through to workers of the increase in employer SSCs is obtained from a 2SLS regression of $\log$ (gross earnings) on $\log (1+\mathrm{SSC}$ rate), where $\log (1+\mathrm{SSC}$ rate) is instrumented by the interaction between the treatment group and year dummies. The estimation is performed separately for each of the post-reform years based on Equation (6) in the main text. The pass-through estimates reported in the left panel are obtained from a specification that does not control for worker-specific trends in addition to worker and year fixed effects. The pass-through estimates reported in the right panel obtained from an augmented specification that controls for worker-specific trends in addition to worker and year fixed effects. The diamond markers represent the estimated pass-through rate while the vertical T-bars denote the 95 percent confidence intervals around the point estimates, with standard errors clustered at the individual level. The full set of estimates can be found in Appendix Table E6.

Sources: DADS Panel 2010; TAXIPP 0.4 
(a) Gross Earnings

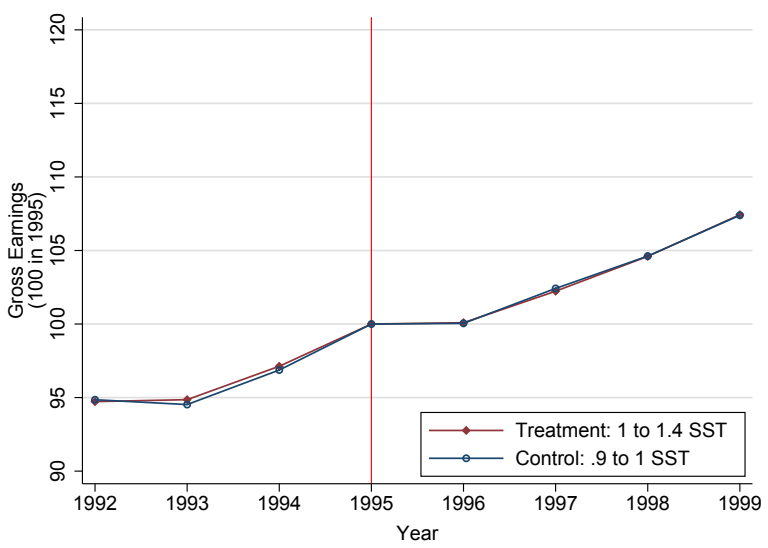

(b) Labor Cost

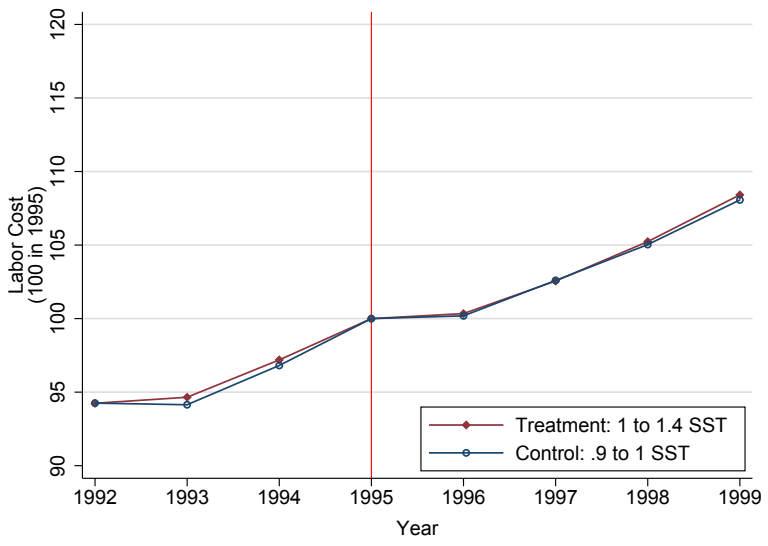

(c) Log Difference in Gross Wage and Hourly Labor Cost

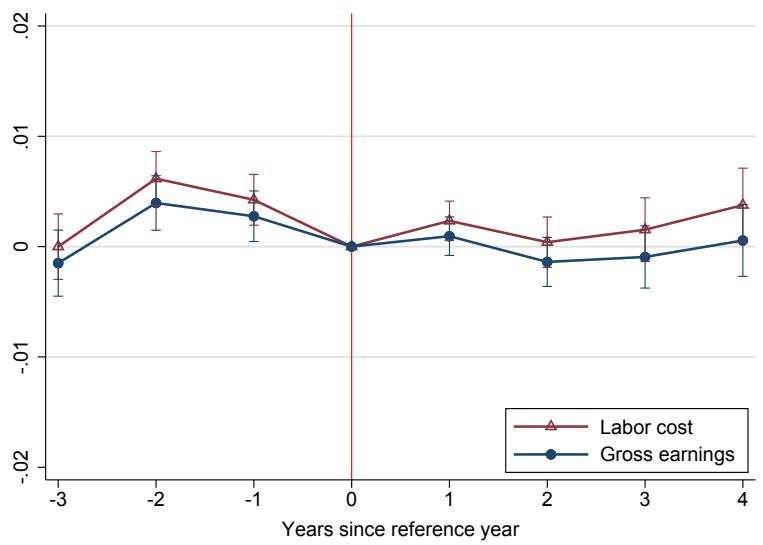

\section{Figure G10 - Placebo Reform (1996): Graphical Evidence on Earnings Responses}

Notes: The top panels of the figure show the evolution of average real gross earnings (Panel a) and of average real labor cost (Panel b) between 1992 and 1999 for two groups of workers around a placebo reform which is set to take place in 1996. The difference-in-differences estimation is performed on an unbalanced panel of workers who are observed in the last pre-reform year (denoted by a vertical solid line) and at least another year. Earnings levels are normalized to 100 for both groups in the placebo reference year (1995). The treatment group includes workers whose gross earnings in 1995 were 1 to 1.4 times the SST that year. The control group includes individuals whose gross earnings in 1995 were 0.9 to 1 times the SST that year. Panel (c) shows the estimated log differences between the average real gross earnings (circle markers) and the average real labor cost (triangle markers) of the two groups of workers. The markers represent the parameter estimates on the interaction between the treatment group and year dummies, which is normalized to zero in the placebo reference year (1995). The vertical T-bars show the 95 percent confidence intervals around the point estimates, with standard errors clustered at the individual level.

Sources: DADS Panel 2010; TAXIPP 0.4. 


\section{Appendix References}

Atkinson, Anthony B., "On the Measurement of Inequality," Journal of Economic Theory, 1970, 2, 244-263.

Feldstein, Martin S., "Tax Incidence in a Growing Economy with Variable Factor Supply," The Quarterly Journal of Economics, 1974, 88 (4), 551-573.

_ and Jeffrey B. Liebman, "Social Security," in Alan J. Auerbach and Martin S. Feldstein, eds., Handbook of Public Economics, Vol. 4, Elsevier, 2002, pp. 2245-2324.

González, Cecilia Senén, Bárbara Medwid, and David Trajtemberg, "Union Membership in Argentina. A Theoretical and Methodological Debate," Manuscript presented at the 15th IIRA World congress, 2009.

Gruber, Jon and Emmanuel Saez, "The Elasticity of Taxable Income: Evidence and Implications," Journal of Public Economics, 2002, 84 (1), 1-32.

Gruber, Jonathan, "The Incidence of Payroll Taxation: Evidence from Chile," Journal of Labor Economics, 1997, 15 (3), S72-101.

Hirsch, Barry T. and David A. Macpherson, "Union Membership and Coverage Database from the Current Population Survey: Note," Industrial and Labor Relations Review, 2003, 56 (2), 349-54.

INSEE, "Activité, emploi et chômage en 2015 et en séries longues," INSEE Résultat, 2016, (183).

Institut des Politiques Publiques, IPP Tax and Benefit Tables, 2018. Url: www.ipp.eu/en/tools/ipp-tax-and-benefit-tables.

Kleven, Henrik Jacobsen and Esben Anton Schultz, "Estimating Taxable Income Responses Using Danish Tax Reforms," American Economic Journal: Economic Policy, November 2014, 6 (4), 271-301.

Kotlikoff, Laurence J. and Lawrence H. Summers, "Tax Incidence," in Alan J. Auerbach and Martin S. Feldstein, eds., Handbook of Public Economics, Vol. 2, Elsevier, 1987, pp. 1043-1092.

Lindbeck, Assar and Mats Persson, "The Gains from Pension Reform," Journal of Economic Literature, 2003, 41 (1), 74-112.

McDonald, Ian M. and Robert M. Solow, "Wage Bargaining and Employment," The American Economic Review, 1981, 71 (5), 896-908.

Musgrave, Richard A., "The Role of Social Insurance in an Overall Programme for Social Welfare," in William Bowen, Frederick Harbison, Richard Lester, and Herman Somers, eds., The Princeton Symposium on The American System of Social Insurance, McGraw-Hill, 1968, pp. 23-40.

OECD, Unemployment rate (indicator) 2020. doi: 10.1787/997c8750-en.

Rogerson, Richard, Robert Shimer, and Randall Wright, "Search-Theoretic Models of the Labor Market-A Survey," Journal of Economic Literature, 2005, 43 (4), 959-988.

Saez, Emmanuel, Benjamin Schoefer, and David Seim, "Payroll Taxes, Firm Behavior, and Rent Sharing: Evidence from a Young Workers' Tax Cut in Sweden," The American Economic Review, 2019, 109 (5), 1717-63. 
_ , Joel Slemrod, and Seth H. Giertz, "The Elasticity of Taxable Income with Respect to Marginal Tax Rates: A Critical Review," Journal of Economic Literature, 2012, 50 (1), 3-50.

Samuelson, Paul A., "An Exact Consumption-Loan Model of Interest with or without the Social Contrivance of Money," Journal of Political Economy, 1958, 66. 